\title{
TESTING AND ANALYSIS OF CAP CONCRETE STRESS AND STRAIN DUE TO SHRINKAGE, CREEP, AND EXPANSION - FINAL REPORT
}

Hector N. Guerrero

Michael L. Restivo

August 2011

Savannah River National Laboratory Savannah River Nuclear Solutions Aiken, SC 29808

Prepared for the U.S. Department of Energy under contract number DE-AC09-08SR22470.

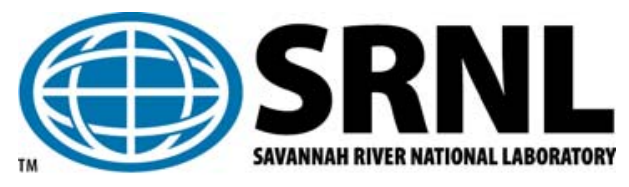




\section{DISCLAIMER}

This work was prepared under an agreement with and funded by the U.S. Government. Neither the U.S. Government or its employees, nor any of its contractors, subcontractors or their employees, makes any express or implied:

1. warranty or assumes any legal liability for the accuracy, completeness, or for the use or results of such use of any information, product, or process disclosed; or

2. representation that such use or results of such use would not infringe privately owned rights; or

3. endorsement or recommendation of any specifically identified commercial product, process, or service.

Any views and opinions of authors expressed in this work do not necessarily state or reflect those of the United States Government, or its contractors, or subcontractors.

Printed in the United States of America

Prepared for

U.S. Department of Energy 
SRNL-STI-2010-00771

Revision 0

INTENTIONALLY LEFT BLANK 
SRNL-STI-2010-00771

Revision 0

\section{REVIEWS AND APPROVALS}

\section{AUTHORS:}

H. N. Guerrero, Engineering Development Laboratory

Date

M. L. Restivo, Engineering Development Laboratory

Date

TECHNICAL REVIEW:

C. A. Langton, Engineering Process Development

Date

APPROVAL:

B. J. Giddings, Manager

Date

Engineering Development Laboratory

A. B. Barnes, Manager

Date

Engineering Process Development

S.L. Marra, Manager

Date

Environmental \& Chemical Process Technology Research Programs

M. Serrato

Date

SRNL Reactor D\&D project manager

J. K. Blankenship,

Date SDD Engineering 


\section{PREFACE OR ACKNOWLEDGEMENTS}

This work is part of a larger effort in the decommissioning of P- and R- Reactors under the auspices of the American Recovery and Reinvestment Act of 2009. We are indebted to the technical leadership of Christine Langton, as well as her encouragement and advice in researching the very large field of cement and concrete. We thank William Mhyre for his help in securing and mixing materials for the Cap Concrete slab specimens. We are also thankful to Vernon Bush for his expertise and help in setting up the instrumentation and data acquisition for the tests, to Jerry Corbett for designing the molds for the specimens, and to George Taylor for his help in setting up the environmental chambers. 


\section{EXECUTIVE SUMMARY}

In-situ decommissioning of SRS P and R Reactors will entail filling the reactor vessels with a special concrete and entombing the reactors with protective cover layers of Ordinary Portland Cement (OPC) concrete, called "Cap Concrete". It is known that concrete experiences shrinkage strains during drying with the potential for tensile stresses to develop. A risk thus exists for cracking, allowing ingress of water into the reactor vessels with implications for possible transport of radioactive contamination to the environment. The extent of shrinkage for the Cap Concrete and the potential for surface cracking needed to be assessed, and means for mitigating the resulting stresses needed to be evaluated

An experimental program and accompanying analytical study was thus initiated to investigate the phenomena of drying, shrinkage, creep and use of admixtures that affect the performance of the Cap Concrete during the early periods of curing and drying. The experimental program utilized four slab specimens measuring $229 \mathrm{~mm}$ x $229 \mathrm{~mm}$ x $305 \mathrm{~mm}$ each. The concrete mixture had a water-to-cement ratio of $0.64,46.4 \mathrm{wt} \%$ coarse aggregate, $29.2 \mathrm{wt} \%$ fine aggregate, $3 \mathrm{wt} \%$ fly ash, Conex, an expansive admixture, and other admixtures. Slab specimens were installed into two environmental chambers (ECs) at controlled temperatures of $23^{\circ} \mathrm{C}$, and $40 \%$ and $80 \%$ relative humidity $(\mathrm{RH})$, respectively for 50 days and at ambient field conditions for another 34 days.

Observations on the measured strains were as follows: The specimens kept at $40 \% \mathrm{RH}$ initially had increasing negative strains indicating preponderance of shrinkage stresses. After 500 hrs, increasing expansive effects of $\mathrm{CaO}$ hydration started to appear in the interior of the specimen, which initially had zero strain and was still moist. When the test was terminated after 84 days, maximum strains of $716 \mu \varepsilon$ were reached at this location and were still rising. At levels closer to the top surface, initially negative strains started to increase and became positive at the end of the test. Drier layers closest to the surface retained negative strains, reaching -336 $\mu \varepsilon$. For the specimens kept at $80 \% \mathrm{RH}$, increasing positive strains started immediately after molding and reached $775 \mu \varepsilon$ in the center at the end of testing. The rate of strain increase appeared to correspond to the humidity level.

Predictive methods for shrinkage and creep strains based on code type calculations and physicsbased methods were used to model the experimental setup and results were compared to the experimental data. First, a 2-dimensional finite element diffusion model was used to obtain an experimentally determined expression for moisture diffusion constant in the slab specimens. This model was then used to predict the propagation of moisture profile in other geometries. In a second finite element stress/strain model, the predicted humidity results from the diffusion model were used to calculate capillary stresses responsible for shrinkage by means of the Kevin-Laplace equation. This required knowledge of the development of the early age modulus of elasticity with time. The close correspondence between the degree of hydration (measured by adiabatic calorimetry) and modulus of elasticity was used to obtain this relation. The effect of creep was modeled by using the Bazant-Baweja B3 model for creep compliance, which is based on solidification theory. Prediction of rate of increase of the expansive strains due to the hydration of the $\mathrm{CaO}$ component of Conex to $\mathrm{Ca}(\mathrm{OH})_{2}$ could not be obtained due to lack of data on the reaction rate of $\mathrm{CaO}$ under liquid or water vapor curing vs. relative humidity. However, the effect of the final maximum expansion of $\mathrm{Ca}(\mathrm{OH})_{2}$, as obtained from these tests and vendor data, combined with shrinkage was assessed by the model, as discussed below. 
The experimental data from Slab Specimens 3 and 4 (subjected to $40 \% \mathrm{RH}$ ) were used to validate the predictive methods for combined shrinkage and creep. The results of calculations simulating the test specimens at $40 \% \mathrm{RH}$ showed good agreement with the strain data for the surface layers. The calculations showed that while the relaxation effect of creep was significant, tensile stresses at the surface of the specimen would exceed the tensile strength of the concrete (3.38 MPa).

Analysis of the full scale Cap Concrete placement showed that under full restraint, combined shrinkage, creep, and fully developed expansive strains of $1000 \mu \varepsilon$ due to the shrinkage compensating admixture (from this work and vendor data), leads to compressive stresses of- 2.8 $\mathrm{x} 10^{6} \mathrm{~Pa}$ at the surface and maximum stresses up to $-11.4 \times 10^{6} \mathrm{~Pa}$ in the interior. The effect of creep is to reduce the maximum stress by $37 \%$. The above testing and analysis validate the use of the shrinkage compensating admixture, Conex, to eliminate the possibility of micro-cracks developing on the surface of the Cap concrete during and after curing. 


\section{TABLE OF CONTENTS}

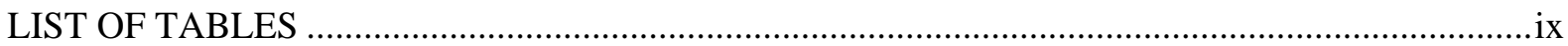

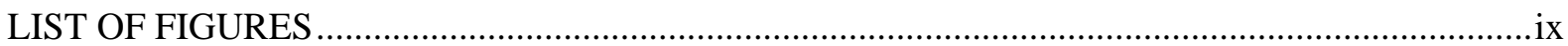

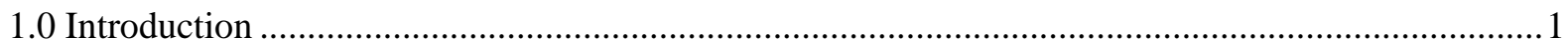

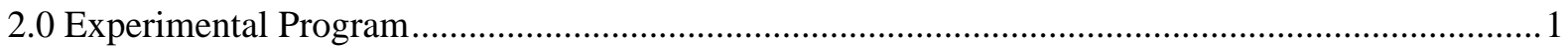

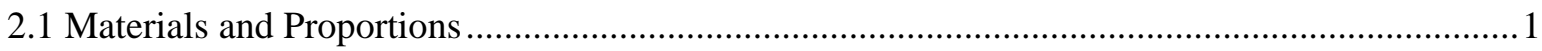

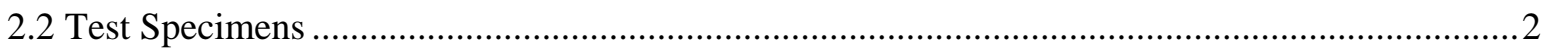

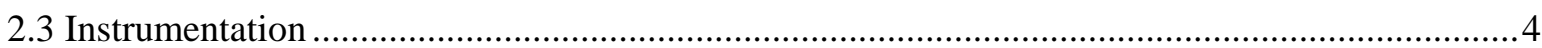

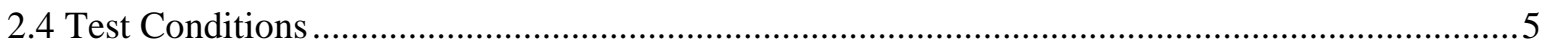

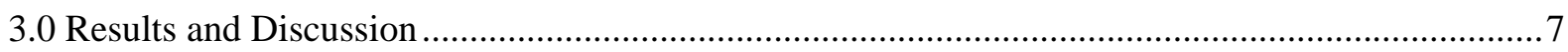

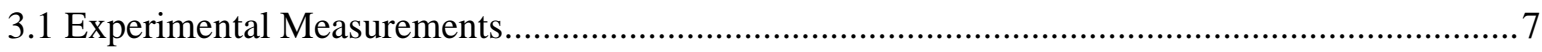

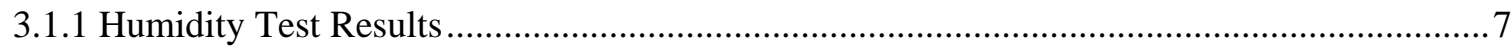

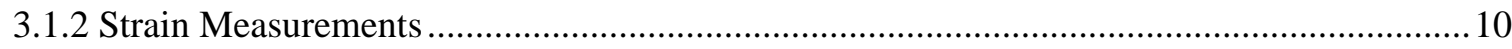

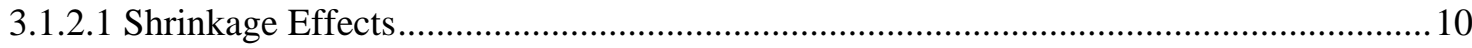

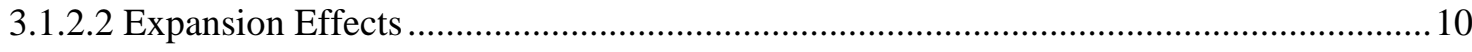

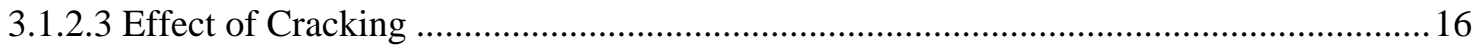

3.2 Analysis of Shrinkage, Creep and Expansive Strains and Stress Development in Slab Specimens

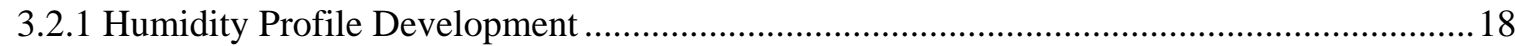

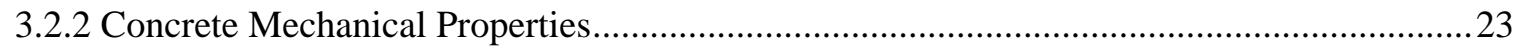

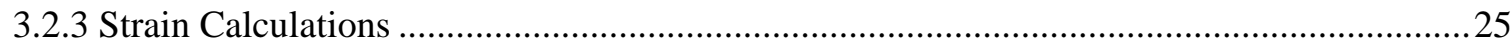

3.2.3.1 Estimation of Time Varying Free Shrinkage Strain ......................................................25

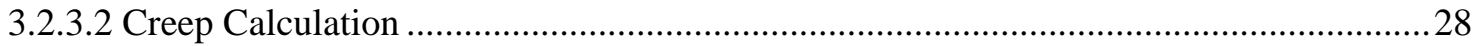

3.2.3.3 Analysis of Restrained Shrinkage Strains in Slab Specimens .......................................30

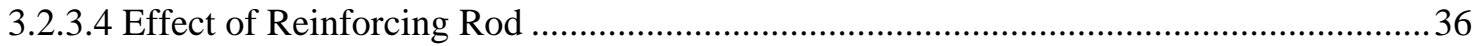

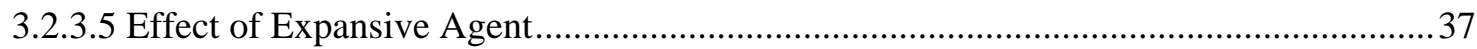

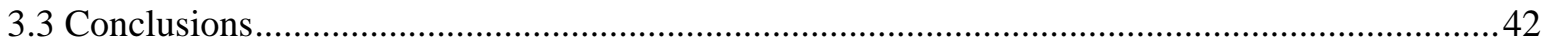

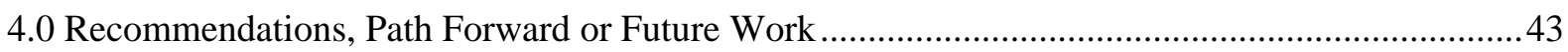

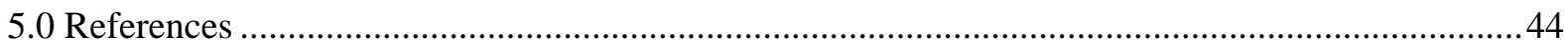

Appendix A Calculation of Cap Concrete Compressive Strength Development with Age ................. 45

Appendix B Calculation of Creep Strain for Slab Specimens....................................50 


\section{LIST OF TABLES}

Table 2-1. Cap Concrete Mixture Proportions 2

\section{LIST OF FIGURES}

Figure 2-1. Assembly Drawings of Cap Concrete Test Specimen Mold and Instrumentation. 3

Figure 2-2 Picture of Specimen Molds with and without Restraining Bars and Instrumentation ..........4

Figure 2-3 Concrete Slab Specimen Instrument Locations ............................................................... 5

Figure 2-4 Poured Cap Concrete Test Specimens Installed in Environmental Chamber .......................5

Figure 2-5 Air and Slab Specimen Temperatures in Environmental Chambers 1 and 2..................... 6

Figure 2-6 Relative Humidity in Environmental Chambers 1 and 2 during the Testing...................... 7

Figure 3-1 Relative Humidity Histories inside Slab 1 for First 1200 hrs ...........................................8

Figure 3-2 Relative Humidity Histories inside Slab 2 for First 1200 hrs ..........................................8

Figure 3-3 Relative Humidity Histories inside Slab 3 for First 1200 hrs ...........................................

Figure 3-4 Relative Humidity Histories inside Slab 3 for First 1200 hrs ...........................................9

Figure 3-5 Strain Histories in Slab Specimen 1 for First 1200 hrs.................................................11

Figure 3-6 Strain Histories in Slab Specimen 2 for First 1200 hrs.................................................11

Figure 3-7 Strain Histories in Slab Specimen 3 for First 1200 hrs..................................................12

Figure 3-8 Strain Histories in Slab Specimen 4 for First 1200 hrs.................................................. 12

Figure 3-9 Strain History of Center Restraining Bars for Slab Specimens 2 and 4 ........................... 13

Figure 3-10 Strain Histories in the Experimental Work of Kim and Lee [2] ..................................13

Figure 3-11 Extended Strain Time Histories after Slab Specimens Removal from the Environmental

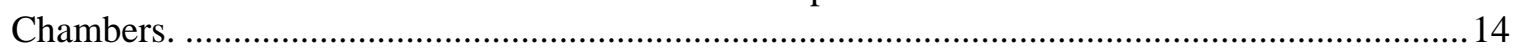

Figure 3-12 Development of Expansive Strains in Concrete Due to Shrinkage Compensating Admixture (Collepardi [7]) .................................................................................................. 15

Figure 3-13 Moisture Capacity as a Function of Relative Humidity................................................17

Figure 3-14 Experimental vs. Predicted Relative Humidity Values (by CEB-FIB Model) in Slab Specimen at $80 \%$ Ambient RH ................................................................................ 21

Figure 3-15 Experimental vs. Predicted Relative Humidity Values (by CEB-FIB Model ) in Slab

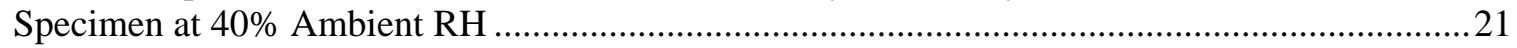


Figure 3-16 Experimental vs. Predicted Relative Humidity Values (this work) in Slab Specimen .....22

Figure 3-17 Experimental Relative Humidities in Slab Specimen vs. Predicted Values (This Work) at 40\% Ambient RH....

Figure 3-18 Heat of Hydration for the Cap Concrete vs. Cumulative Heat 24

Figure 3-19 Development of Concrete Modulus of Elasticity with Age..... 25

Figure 3-20 Calculation of Time Varying Shrinkage Strain by Capillary Stress Model vs. BazantBaweja B3 Model... 26

Figure 3-21 Illustration of Creep Integration for Time Varying Stress 29

Figure 3-22 Creep Compliance Curves for Various Loading Times 30

Figure 3-23 Deformed Grid of Slab Specimen Model Under Combined Shrinkage and Creep ...........32

Figure 3-24 Axial Strain Contour Map for Slab Specimen Model at $1200 \mathrm{hrs}$ 32

Figure 3-25 Predicted Axial Strain Distribution at Slab Specimen Center Plane at 1200 hrs...... 33

Figure 3-26 Predicted vs. Experimental Strain Time History for Slab Specimens 3 and 4.................33

Figure 3-27 Stress Contour Map for Slab Specimen Model at 1200 hrs..........................................34

Figure 3-28 Calculated Axial Stresses at Center Plane for Slab Specimen Model at 1200 hrs............35

Figure 3-29 Deformed Grid for Slab Specimen Model with Rebar 36

Figure 3-30 Calculated Axial Stresses in Slab Specimen 3 without Rebar and Slab Specimen 4 without Rebar

Figure 3-31 Predicted Relative Humidity Time Histories for Full Scale Slab . 39

Figure 3-32 Deformed Grid for Full Scale Cap Concrete Model with Shrinkage Compensating Admixture 39

Figure 3-33 Contour Map of Axial Strains for Full Scale Cap Concrete Model with Shrinkage Compensating Admixture

Figure 3-34 Axial Strains in the Center Plane of Full Scale Concrete Model with Shrinkage Compensating Admixture

Figure 3-35 Contour Map of Axial Stress for Full Scale Cap Concrete Model with Shrinkage Compensating Admixture

Figure 3-36 Predicted Axial Stresses in Center Plane of Full Scale Cap Concrete Model with Shrinkage Compensating Admixture 


\section{LIST OF ABBREVIATIONS}

$\begin{array}{ll}\text { AEA } & \text { Air-entraining Admixture } \\ \text { ASTM } & \text { American Society for Testing Materials } \\ \text { EC } & \text { Environmental Chamber } \\ \text { OPC } & \text { Ordinary Portland Cement } \\ \text { RH } & \text { Relative Humidity } \\ \text { RTV } & \text { Room Temperature Vulcanizing } \\ \text { SRNL } & \text { Savannah River National Laboratory }\end{array}$




\subsection{Introduction}

In-situ decommissioning of Reactors P- and R- at the Savannah River Site will require filling the reactor vessels with a special concrete based on materials such as magnesium phosphate, calcium aluminate or silica fume.. Then the reactor vessels will be overlain with an $8 \mathrm{ft}$. thick layer of Ordinary Portland Cement (OPC) steel reinforced concrete, called the "Cap Concrete". The integrity of this protective layer must be assured to last for a sufficiently long period of time to avoid ingress of water into the reactor vessel and possible movement of radioactive contamination into the environment. During drying of this Cap Concrete however, shrinkage strains are set up in the concrete as a result of diffusion and evaporation of water from the top surface. This shrinkage varies with depth in the poured slab due to a non-uniform moisture distribution. This differential shrinkage results in restraint of the upper layers with larger shrinkage by lower layers with lesser displacements. Tensile stresses can develop at the surface from the strain gradients in the bulk slab, which can lead to surface cracking. Further, a mechanism called creep occurs during the curing period or early age produces strains under the action of restraining forces [1].

To investigate the potential for surface cracking, an experimental and analytical program was started under TTQAP SRNL-RP-2009-01184 [2]. Slab sections made of Cap Concrete mixture were instrumented with embedded strain gages and relative humidity sensors and tested under controlled environmental conditions of $23^{\circ} \mathrm{C}$ and relative humidities (RH) of $40 \%$ and $80 \%$ over a period of 50 days. Calculation methods were also developed for predictions of stress development in the full-scale concrete placement over the reactor vessels. These methods were evaluated by simulating conditions for the test specimens and the calculation results compared to the experimental data. A closely similar test with strain gages was performed by Kim and Lee [3] for a concrete mixture that did not employ humidity sensors and the admixtures used in this program. Yuan and Wan [1] tried to predict the shrinkage strains and stresses in the Kim and Lee experiment, but did not include a creep analysis. Grasley and Lange [4] conducted full restraint load tests on a concrete prism instrumented with humidity sensors over a 7 day curing period. The hypothetical case of full-scale placement of the Cap Concrete was also analyzed using the developed analytical methods. The calculation performed in this report is for scoping purposes only.

\subsection{Experimental Program}

\subsection{Materials and Proportions}

The materials and mix proportions of the Cap Concrete are given in Table 2-1. It is to be noted that the w/c (water to cement) ratio is 0.638 . Conex is a shrinkage compensating admixture, while Darex II AEA is an air entrainment admixture. 
SRNL-STI-2010-00771

Revision 0

Table 2-1. Cap Concrete Mixture Proportions

\begin{tabular}{|c|c|}
\hline Material & Lbs/cubic yd \\
\hline Portland Cement (ASTM Type I) & 470 \\
\hline Fly ash & 120 \\
\hline Fine aggregate & 1165 \\
\hline Coarse aggregate & 1850 \\
\hline Water & 300 \\
\hline Krystal Interval Membrane & 11 \\
\hline Conex & 50 \\
\hline Darex II AEA & 11 \\
\hline Superplast 1000 & 11 \\
\hline
\end{tabular}

\subsection{Test Specimens}

The concrete mixture was poured into four Lexan molds, measuring $228.6 \mathrm{~mm}$ x $228.6 \mathrm{~mm}$ x $300 \mathrm{~mm}$ (9” x 11.8” x 9"). Figure 2-1 is an assembly drawing of the mold with instrumentation installed, and Figure 2-2 shows pictures of two types of molds with simulated placement of the strain gages and relative humidity sensors. Figure 2-3 gives the locations of the sensors. One type of mold had a simulated rebar or restraining rod with instrumentation and the other type had only instrumentation but not the simulated rebar. The test specimen was based loosely on the one used in ASTM C878/C 878M-09, "Standard Method for Restrained Expansion of Shrinkage-Compensating Concrete" [5]. The standard specimen measures $76.2 \mathrm{~mm}$ x $26.2 \mathrm{~mm}$ x $254 \mathrm{~mm}$ (3” x 3"x 10”), with a 10-24 all-thread restraining rod and is intended for dimensional measurement of the concrete expansion. For our test, measurement of the relative humidity and strains were also required. Consequently, the test specimen was made larger than the standard specimen to allow placement of the sensors, as in the work of Kim and Lee [2] where the specimen measured $152.4 \mathrm{~mm}$ x $152.4 \mathrm{~mm}$ x 305 $\mathrm{mm}$ (6” x 12"x 12”). In this study, the restraining rod was a $12.7 \mathrm{~mm}$ (1/2-inch) stainless steel rod with half of its length stepped down to $9.5 \mathrm{~mm}$ (3/8”) diameter at several places to simulate protrusions on the surface of rebars and ensure no slip between the concrete and the restraining rod. The area ratio between the rod and the concrete was 0.002 , similar to that in ASTM C878M-09. The ends of the rod were screwed into two end plates to distribute the tensile or compressive load from the rod evenly across the cross-sectional area of the concrete specimen. The end plates were made of $12.7 \mathrm{~mm}$ thick steel plates perforated with $50.8 \mathrm{~mm}$ dia. holes to lock them into the concrete even while the concrete shrunk.

The molds were open at the top and were not removed for the duration of the test. Thus, moisture evaporation occurred only from the top surface of the specimen. The top was sealed with plastic sheathing for about 6 hrs while preparations were made for installation into the environmental chambers. After the concrete hardened for a few days, the exposed seam between the concrete and the Lexan side walls were sealed with RTV sealant to prevent escape of moisture from a possible crack opening between the grout and the walls. Figure 2-4 shows a picture of finished grout specimens inside an environmental chamber. 


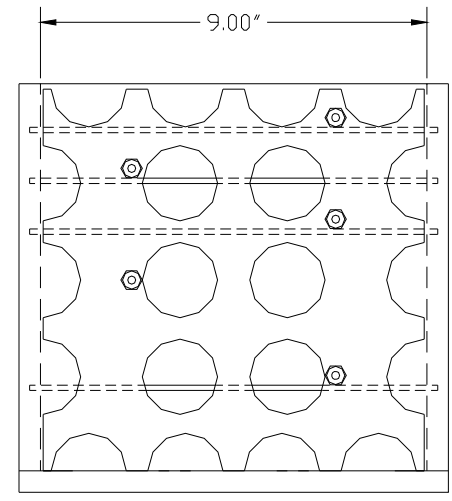

END
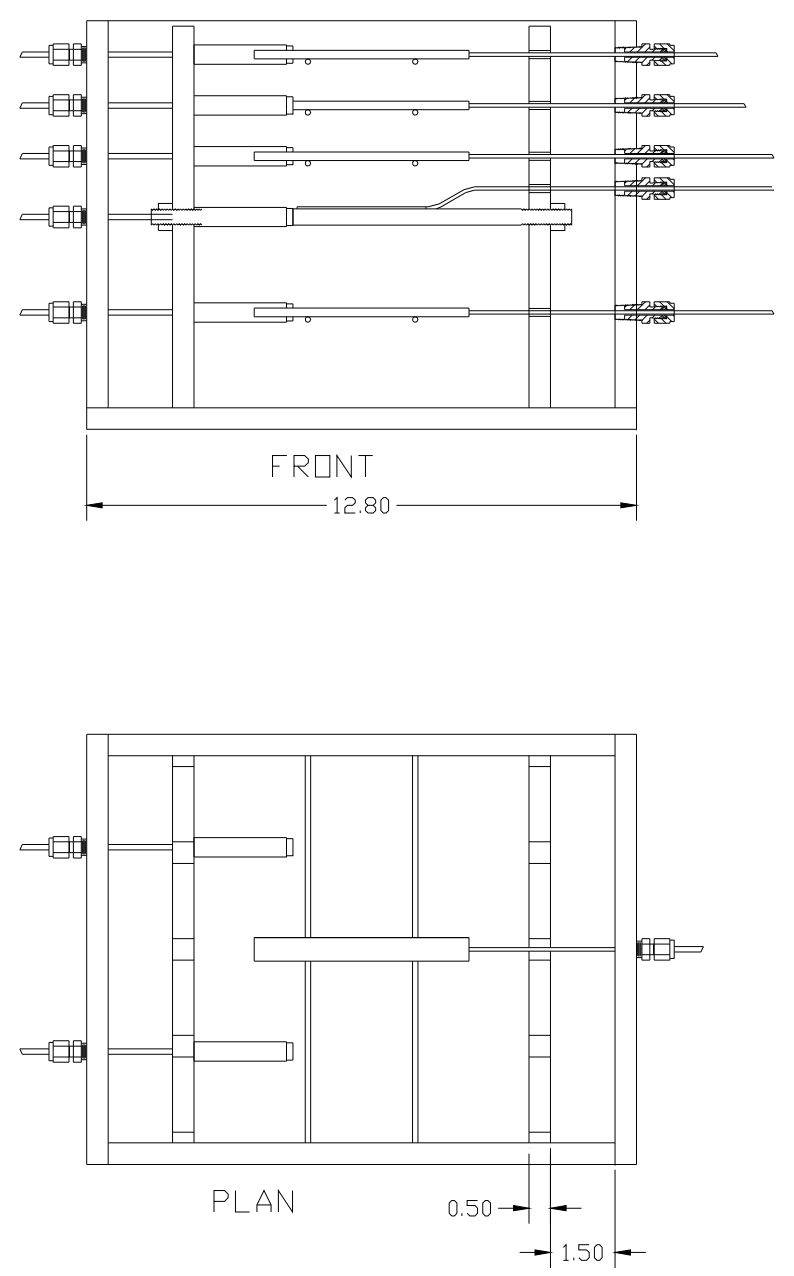

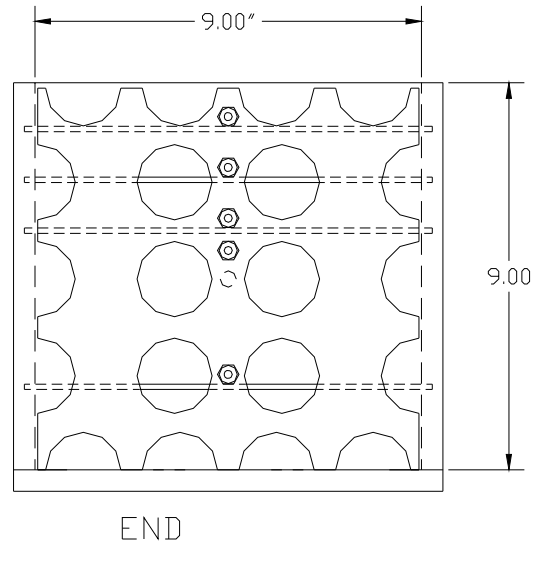

EN

Figure 2-1. Assembly Drawings of Cap Concrete Test Specimen Mold and Instrumentation. 


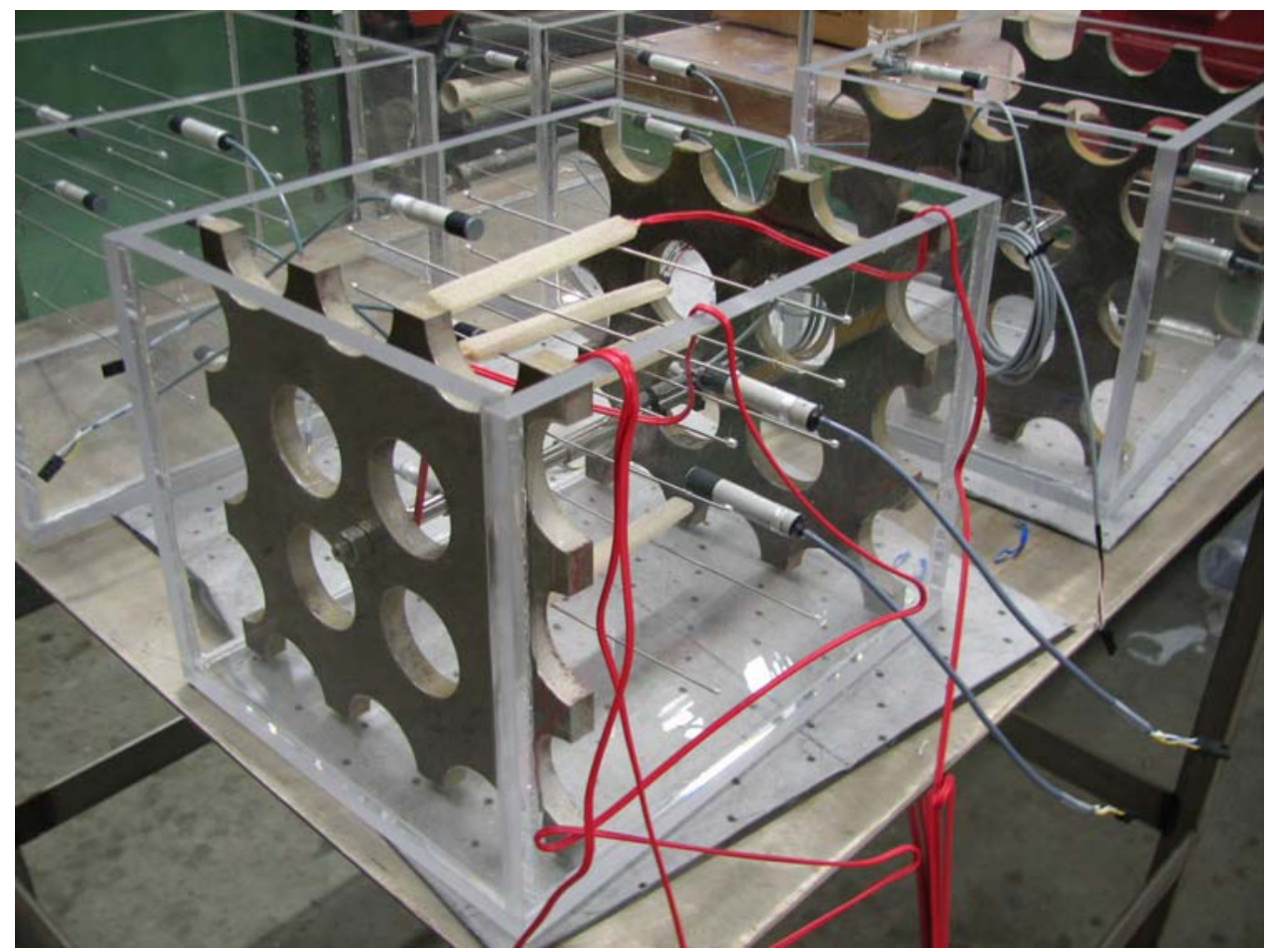

Figure 2-2 Picture of Specimen Molds with and without Restraining Bars and Instrumentation

\subsection{Instrumentation}

The strain gages were special concrete embeddable strain gages made by Tokyo Sokki Kenkyujo Co, Model PM-60-2L. Five of these strain gages were installed in two molds without the restraining rod at elevations shown in Figure 2-3. Two other molds with restraining rods had 4 concrete strain gages at the same elevations as in Figure 1, except at mid elevation. However, it had a fifth weldable strain gage (Kyowa KCW-5-120-G1011) attached to the middle of the restraining rod. A National Instruments SCXI-1521B Quarter Bridge Strain Gage Input Module was used to complete the strain gage bridge connection to the Data Acquisition System using Labview software.

Humirel HM1500LF relative humidity sensors were inserted through the walls of the molds and were embedded in the grout. Goretex sheet material, which allowed vapor to go through but not liquid, was used to protect the sensitive sensor components. The humidity sensors were calibrated by placing them inside various individual enclosed chambers above saturated salt solutions. At a given temperature, the atmosphere above a saturated salt solution is always at a given relative humidity. The three salts used and their corresponding fixed relative humidity values at $25^{\circ} \mathrm{C}$ are: $\mathrm{LiCl}_{2}(11.3 \%), \mathrm{MgCl}_{2}$ (32.8\%), and $\mathrm{NaCl}(75.3 \%)$ [6]. The calibration data of the sensors followed closely the manufacturer's calibration equation, with a quoted accuracy of $+/-3 \% \mathrm{RH}$ from $10-95 \%$ $\mathrm{RH}$.

Thermocouples were also installed 1 inch and 4.5 inches from the top surface of the grout specimen. Instrument nomenclature and positions are shown in Figure 2-3. 


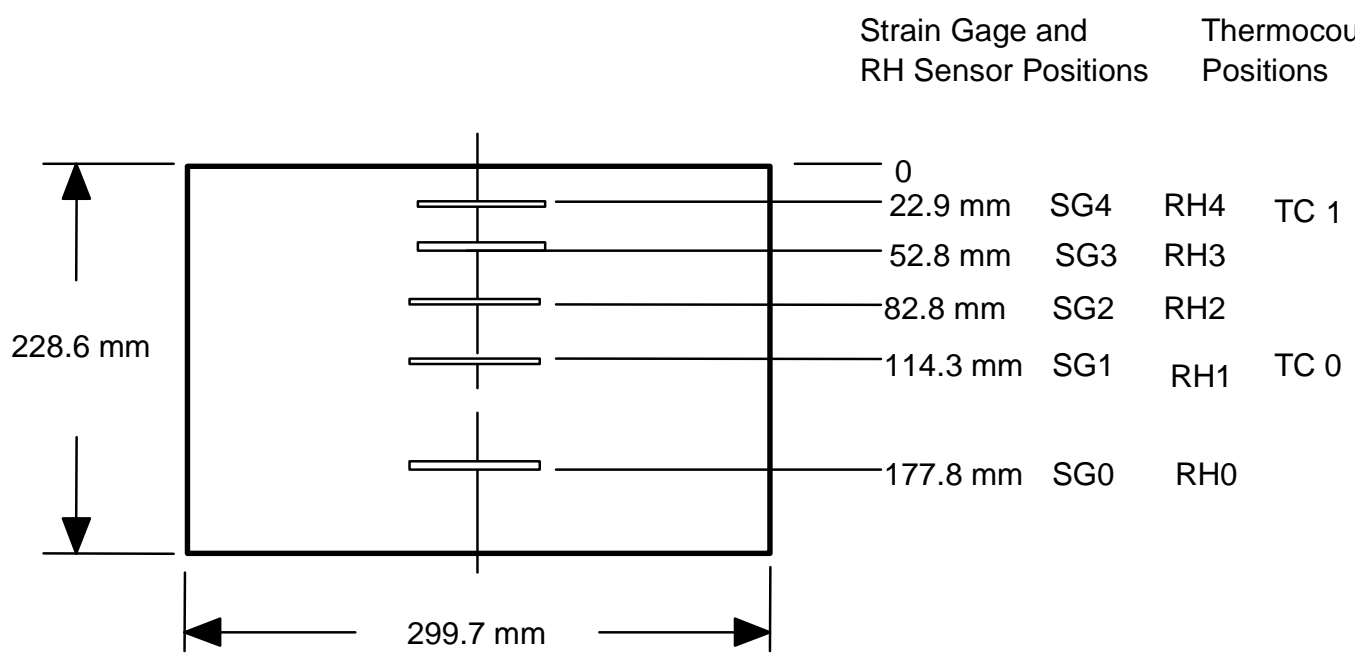

Figure 2-3 Grout Slab Specimen Instrument Locations

\subsection{Test Conditions}

Of the four identical test specimens cast with the same capping concrete mixture, two, Slab Specimens 1 and 2, were installed inside Environmental Chamber 1 and tested at the same test conditions of $23+/-1^{\circ} \mathrm{C}$ and $80 \% \mathrm{RH}$. The other two specimens, Slab Specimens 3 and 4 , were installed inside Environmental Chamber 2, and tested at $23+/-1^{\circ} \mathrm{C}$ and $40 \% \mathrm{RH}$. Slab Specimens 1 and 3 did not have a rebar, while Slab Specimens 2 and 4 did. Figure 2-4 is a photograph of Slab Specimens 3 and 4 in Environmental Chamber 2.

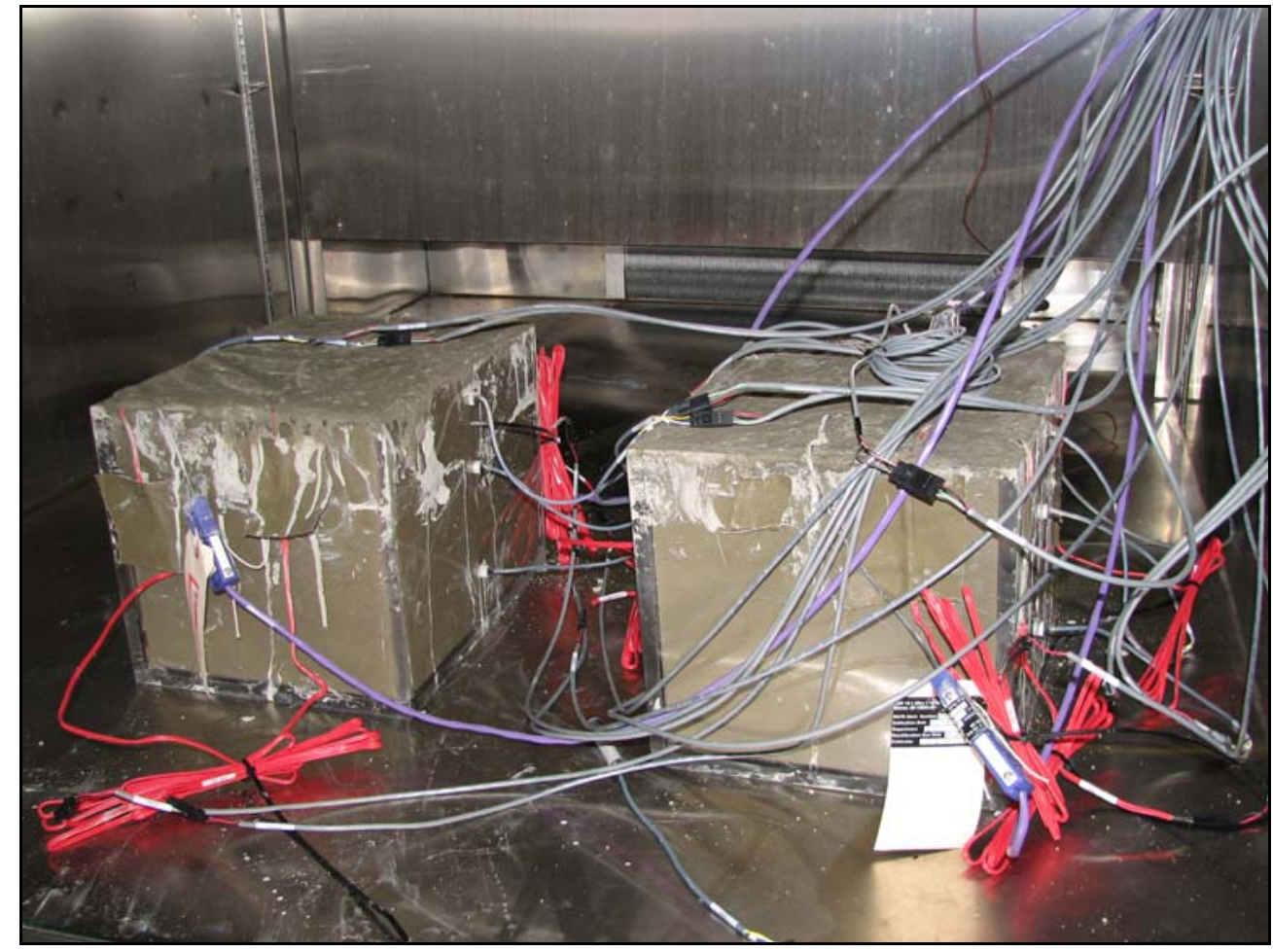

Figure 2-4 Poured Cap Concrete Test Specimens Installed in Environmental Chamber 
The environmental chamber test was conducted over a period of 50 days. Figure 2-5 shows the air temperatures in the respective environmental chambers, with some variability due to the cycling of the building temperature. The slab temperatures are also given in the figure, where $T_{0}$ refers to the temperature in the middle of the slab and $T_{1}$ refers to the temperature 1inch below the top surface of the slab. The concrete specimen temperatures declined about $1^{\circ} \mathrm{C}$ over a duration of $100 \mathrm{hrs}$ after insertion into the chamber and remained relatively flat during the test period. There was a slight $0.3^{\circ} \mathrm{C}$ decrease in Slabs 2 and 3 temperatures after the $677 \mathrm{hr}$ mark coincident with a minor $\mathrm{RH}$ control problem in EC 2. A much larger temperature spike was observed in EC 1 at the $1040 \mathrm{hr}$ mark with major loss of temperature and relative humidity control after that time due to equipment failure.

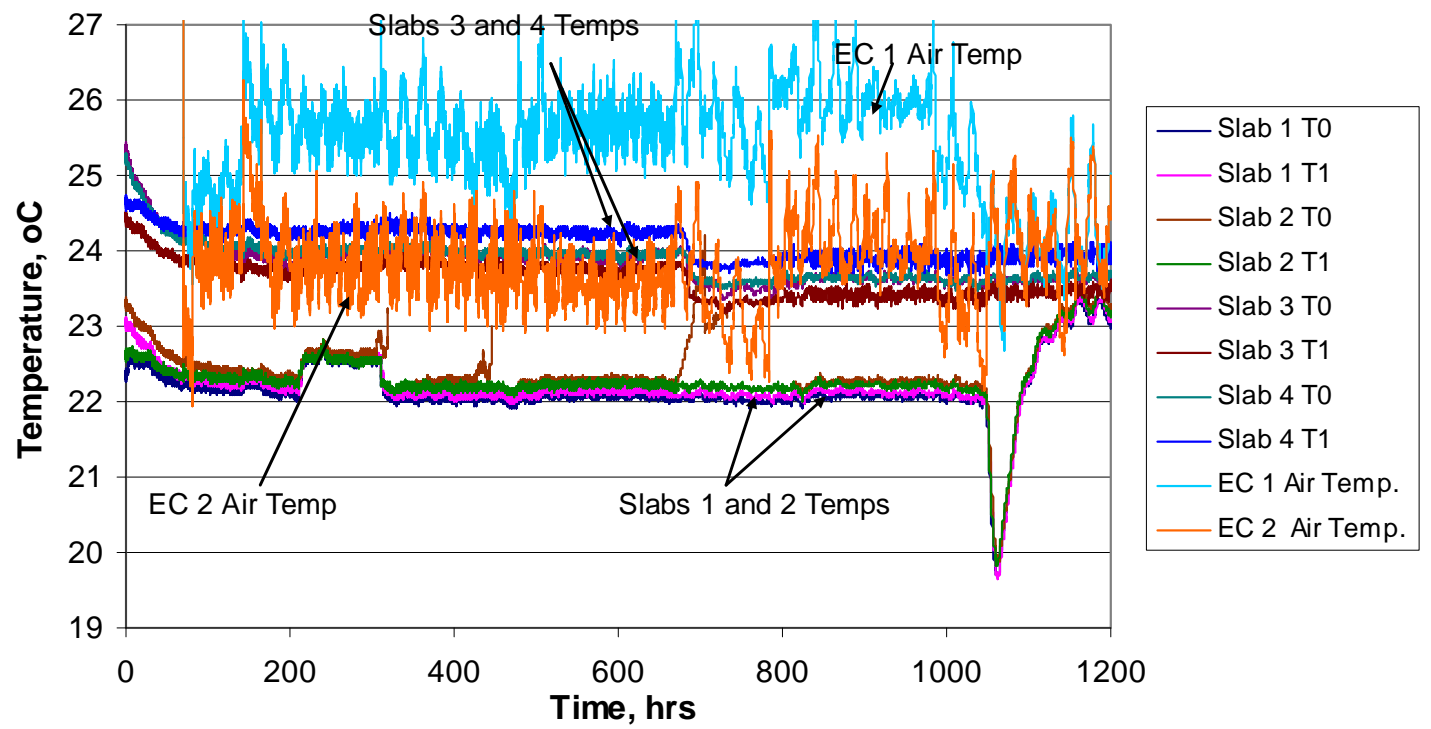

Figure 2-5 Air and Slab Specimen Temperatures in Environmental Chambers 1 and 2

The recorded values of relative humidity in EC 1 and EC 2, using Humirel humidity sensors are given in Figure 2-6, with a tight error band of less than $+/-1 \%$ for EC1 and $+/-2 \%$ for EC2. The relative humidity in both chambers was relatively constant except for EC 1, when a loss of control was experienced, and the RH increased to $100 \%$ at 1045 hrs. The relativity humidity control for EC2 also had an increased error band of $+/-5 \%$ after 700 hrs 


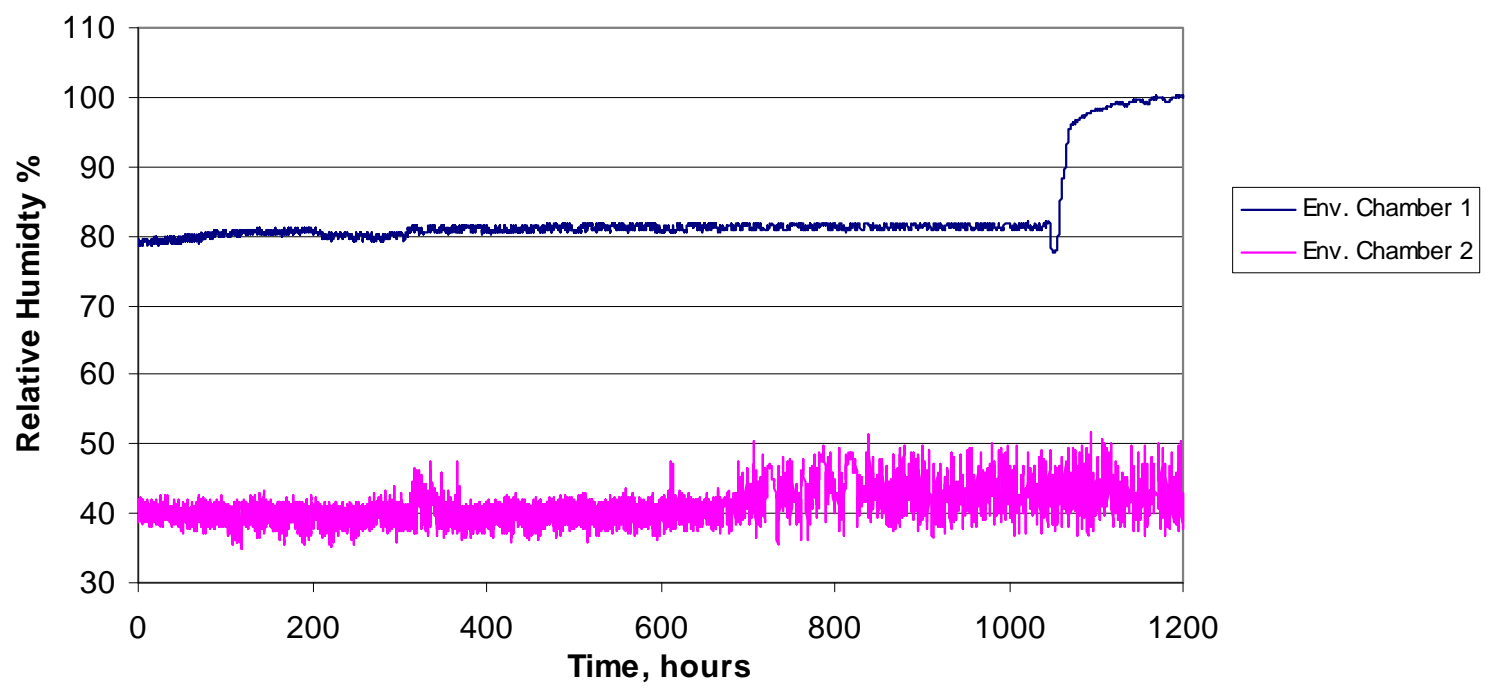

Figure 2-6 Relative Humidity in Environmental Chambers 1 and 2 during the Testing

\subsection{Results and Discussion}

\subsection{Experimental Measurements}

\subsubsection{Humidity Test Results}

Relative humidity measurements for Slabs 1and 2 for the first 1040 hrs, when the ambient temperature and relative humidity conditions in Environmental Chamber 1 were well controlled at $23^{\circ} \mathrm{C}$ and $80 \% \mathrm{RH}$, are given in Figures 3-1 and 3-2, respectively. The relative humidity values for both slab specimens were similar and did not go below $90 \%$. The time histories of the relative humidities in Slabs 3 and 4 for the first 1200 hrs and ambient conditions of $23^{\circ} \mathrm{C}$ and $40 \% \mathrm{RH}$ are given in Figures 3-3 and 3-4, respectively. 


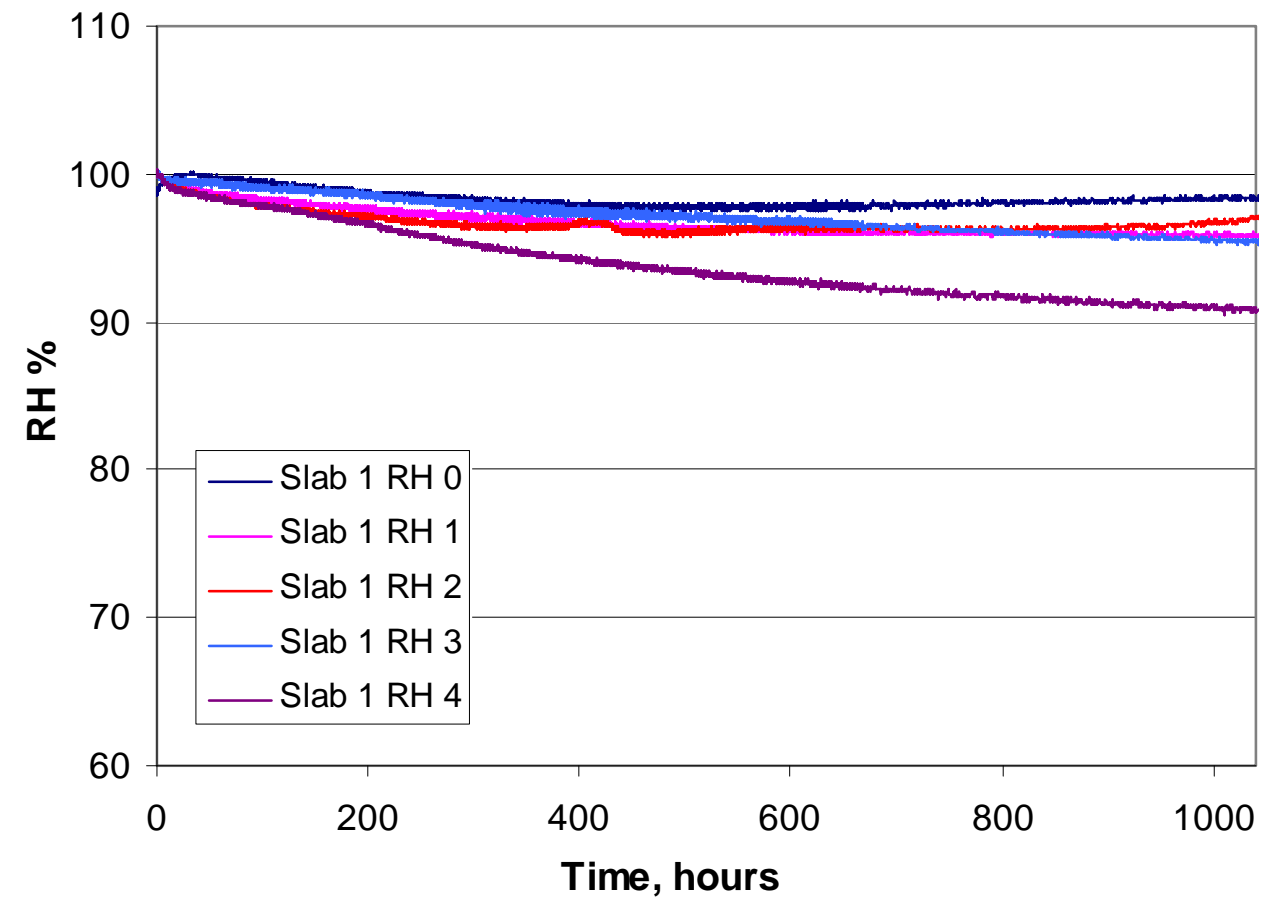

Figure 3-1 Relative Humidity Histories inside Slab 1 for First 1040 hrs

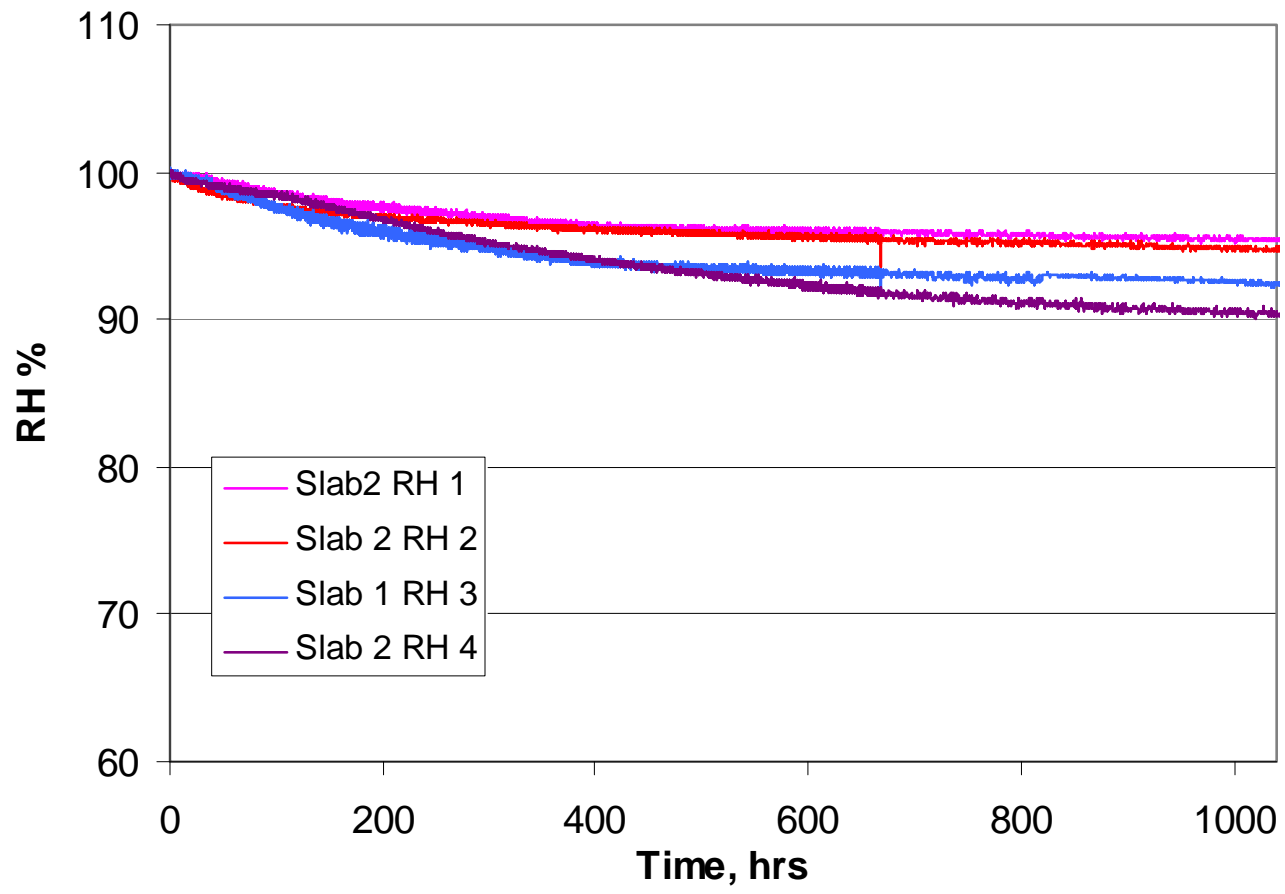

Figure 3-2 Relative Humidity Histories inside Slab 2 for First 1040 hrs 


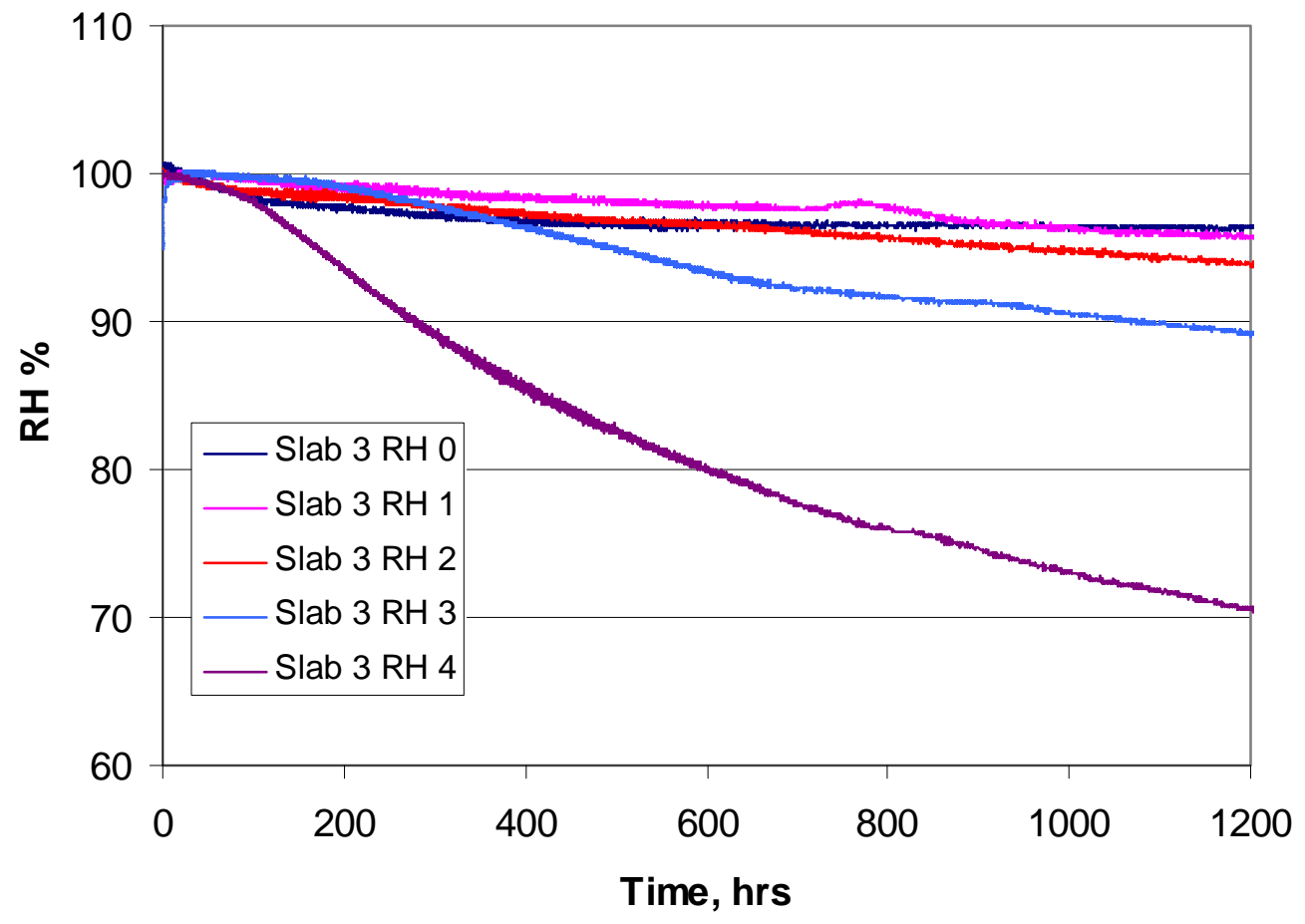

Figure 3-3 Relative Humidity Histories inside Slab 3 for First 1200 hrs

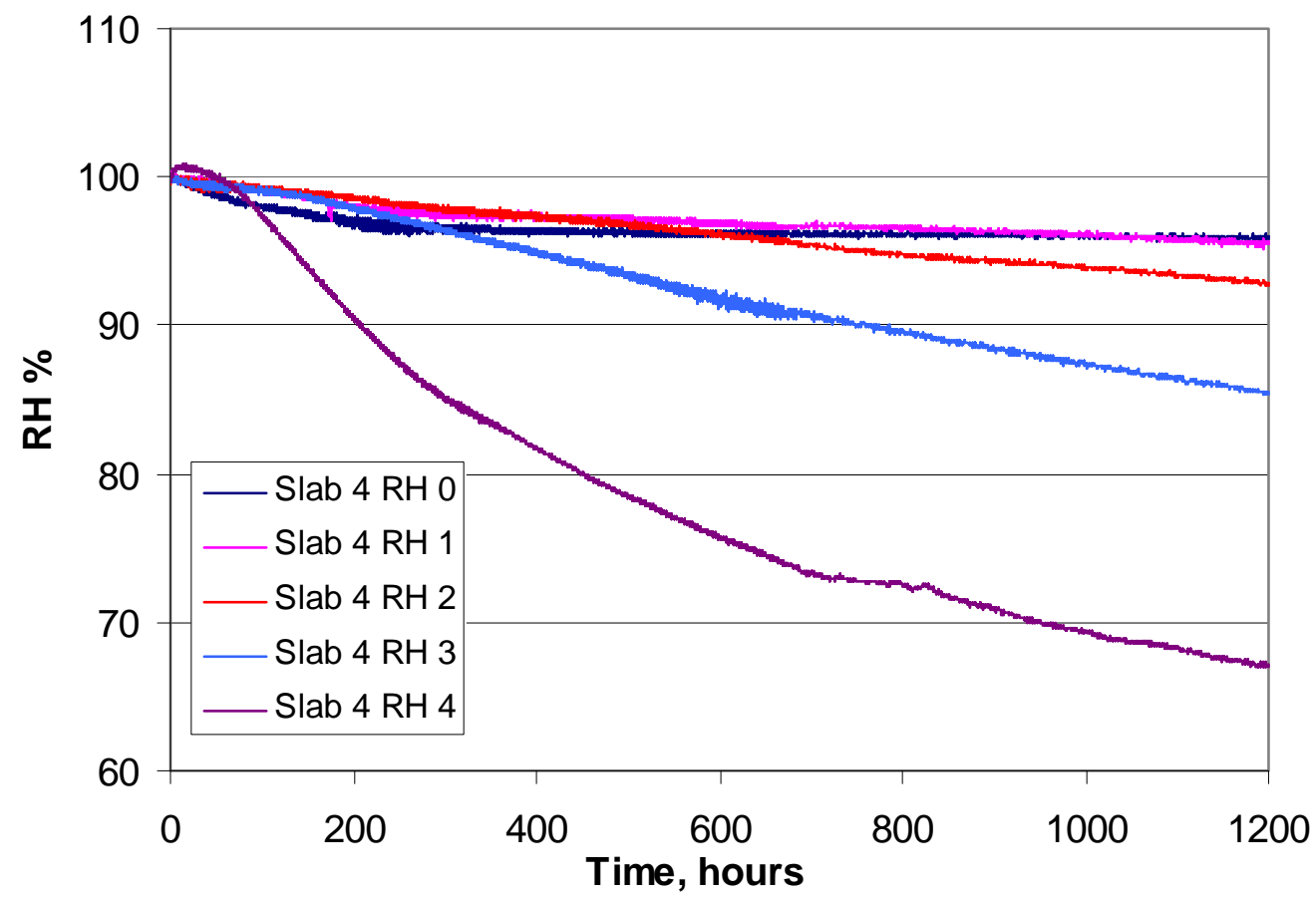

Figure 3-4 Relative Humidity Histories inside Slab 3 for First 1200 hrs 


\subsubsection{Strain Measurements}

The strain data as a function of time for Slab Specimens 1, 2, 3 and 4 are given in Figures 3-5 to 3-8, respectively. The data from the strain gages attached to the restraining bars in Slabs 2 and 4 are given in Figures 3-9.

\subsubsection{Shrinkage Effects}

In the present work, the development of strains at various depths were in some respects similar to those found in the work of Kim and Lee, who used a similar test setup without a restraining rod, but in other respects were significantly different than the Kim and Lee results. For Slab Specimens 3 and 4, where the ambient relative humidity was set at $40 \%$, negative strains were recorded for the first $500 \mathrm{hrs}$ (Figures 3-7 and 3-8), as expected for drying and shrinking concrete. The highest negative strains were close to the top surface, e.g, S3S4, where the humidity was 67-70\%. In contrast deep within the test specimen (e.g, S3S0) where the humidity was still close to $100 \%$, the strain was almost zero. The strain gradient corresponded to a humidity profile which decreased from the interior towards the open top surface (Figure 3-1 to 3-4). This strain behavior is quite similar to the experimental results of Kim and Lee (Figure 3-10).

\subsubsection{Expansion Effects}

A different strain behavior was observed for Slab Specimens 1 and 2, however. These test specimens were exposed to an ambient relative humidity of $80 \%$. The strains were all positive and increasing with time, with the highest positive strain exhibited by the strain gages in the interior of the test specimen (See Figures 3-5 and 3-6). The small dip and rapid strain increase after 1044 hrs correspond to temperature variations of the slabs due to the Environmental Chamber 1 control problems. The continuation of the test for Slab Specimens 3 and 4 (after 500 hrs) showed a similar response (Figures 3-7 and 3-8). For S3SG0 (strain gage farthest from the surface), the strain was close to zero for the first 500 hrs but then started to increase in the positive direction. Other interior strains also started to increase after 700 hrs. Summary plots of the strain histories of all 4 slab specimens that extended beyond the period of controlled humidity up to 84 days are given in Figure 3-10a through 3-10d. These plots show the positive strains continued to grow and had not leveled out at the end of the test.

Instrumentation and data acquisition system checks were performed to insure confidence in the data. Drift tests, gain calibration tests and uncertainty analysis could not explain the positive strains. Drift tests on free strain gages immersed in water were also performed. The acrylic material of the strain gages absorbed water which resulted in increased strains. However, the bulk modulus of the acrylic was a factor of 10 lower than the grout so that the strain gages embedded in cured grout should respond only to the grout expansion or contraction.

The positive strain measurements were therefore attributed to the effects of the shrinkage compensating admixture Conex. Conex is based mainly on $\mathrm{CaO}$ and produces a calcium hydroxide platelet crystal system based on calcium aluminate/calcium hydroxide, according to the manufacturer. The reaction between $\mathrm{CaO}$ and water to produce $\mathrm{Ca}(\mathrm{OH})_{2}$ results in a volume increase by a factor of 1.96 relative to $\mathrm{CaO}$. The hydroxide crystals fill the concrete pores and, depending on concentration, exert compressive stress on the concrete skeleton. 


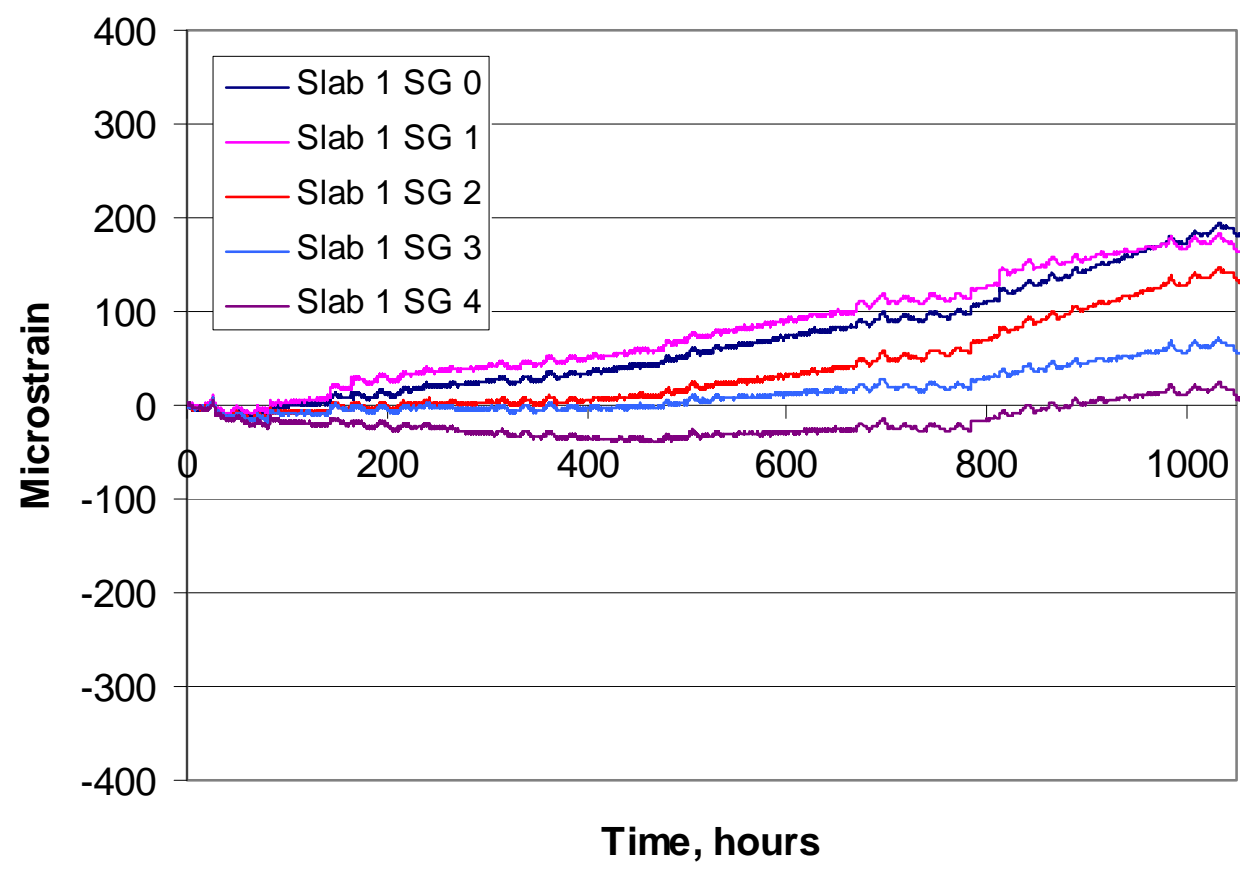

Figure 3-5 Strain Histories in Slab Specimen 1 for First 1200 hrs

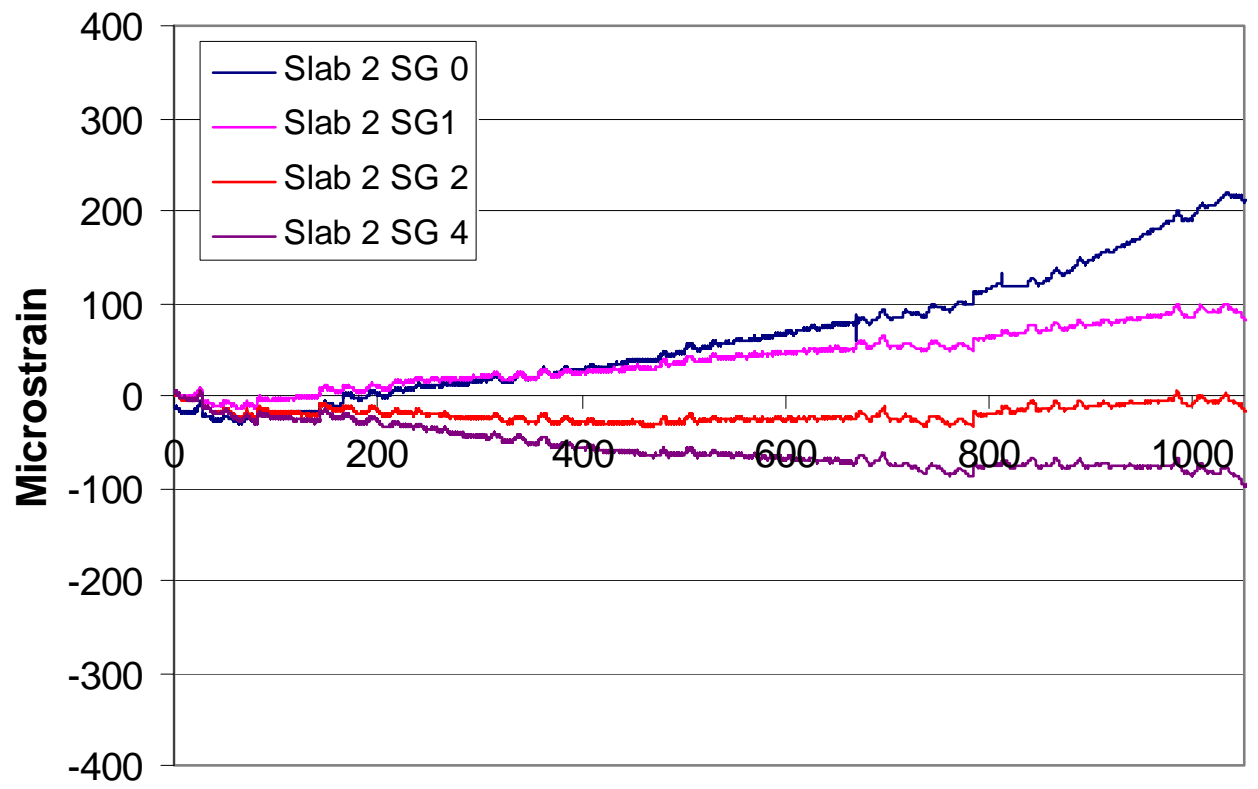

Time, hours

Figure 3-6 Strain Histories in Slab Specimen 2 for First 1200 hrs 


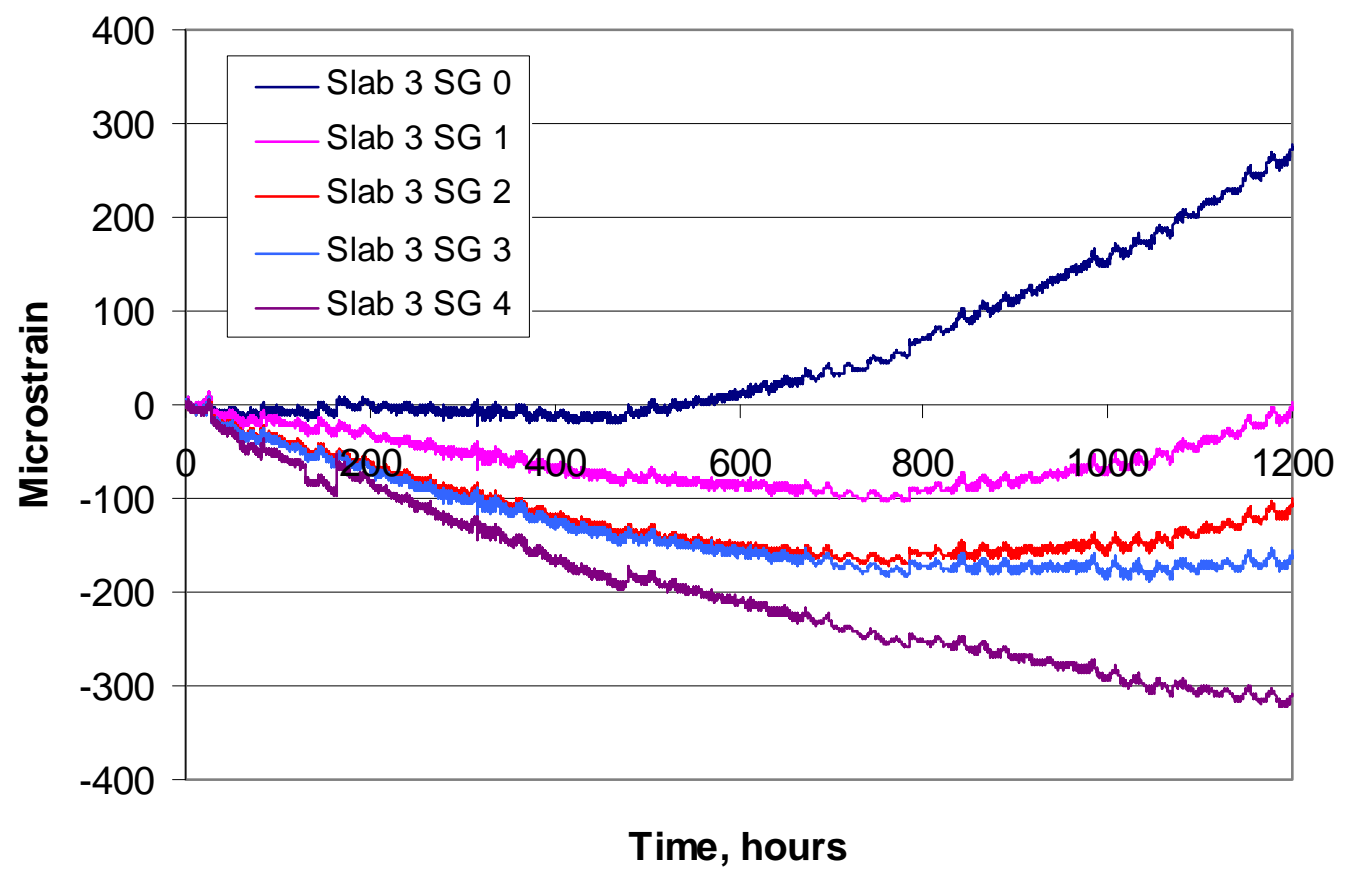

Figure 3-7 Strain Histories in Slab Specimen 3 for First 1200 hrs

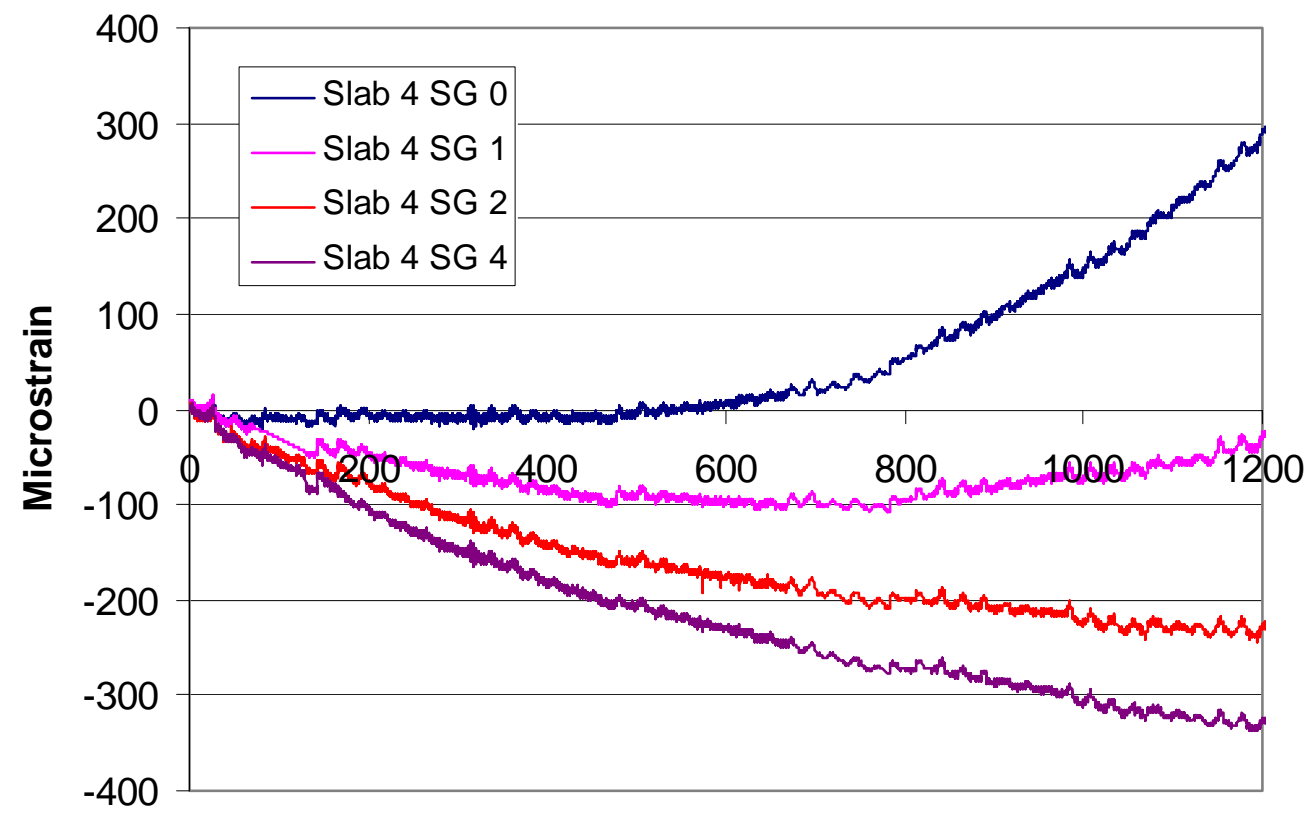

Time, hours

Figure 3-8 Strain Histories in Slab Specimen 4 for First 1200 hrs 


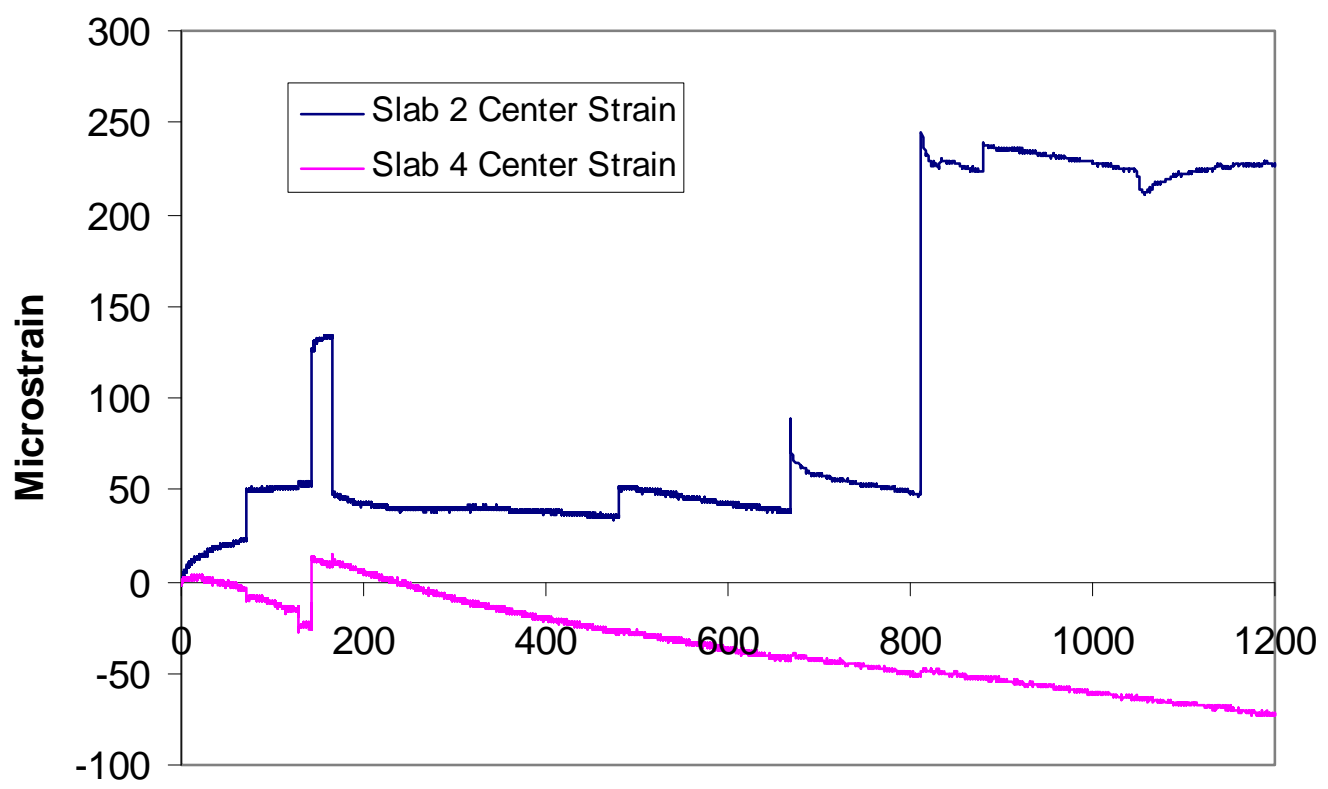

Time, hrs

Figure 3-9 Strain Histories of Center Restraining Bars for Slab Specimens 2 and 4

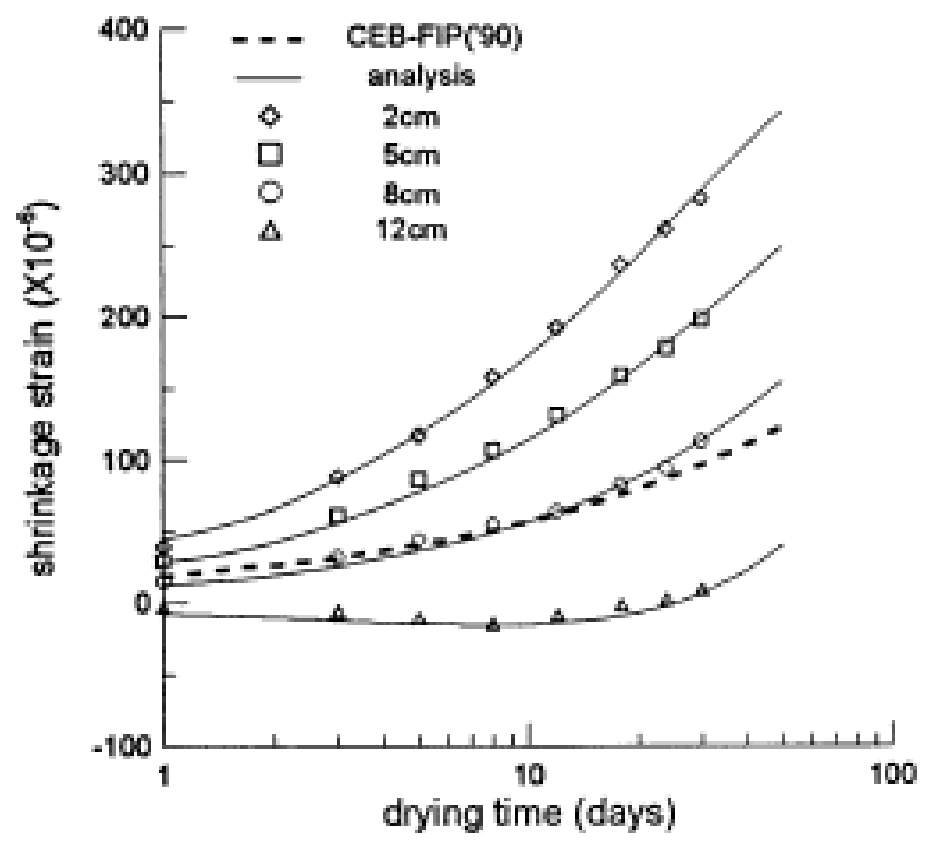

(a) $\operatorname{Mix} I(w / c=0.65)$

Figure 3-10 Strain Histories in the Experimental Work of Kim and Lee [3] 
(a) Slab Specimen 1

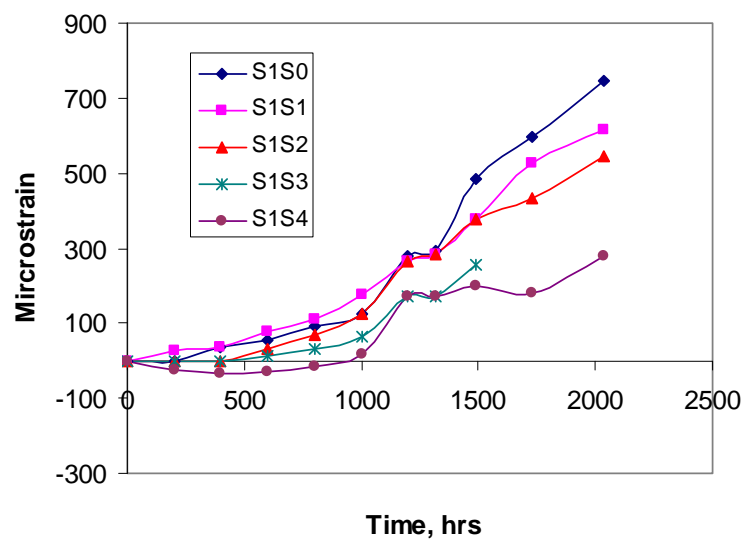

(c) Slab Specimen 3

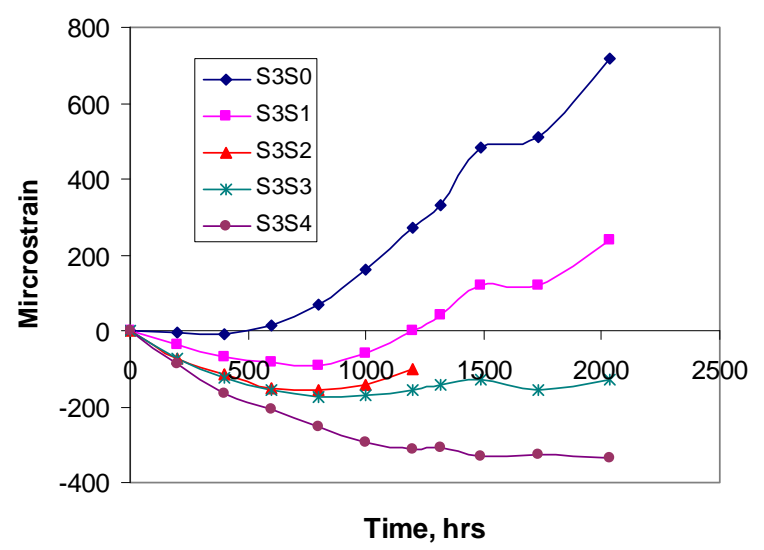

(b) Slab Specimen 2

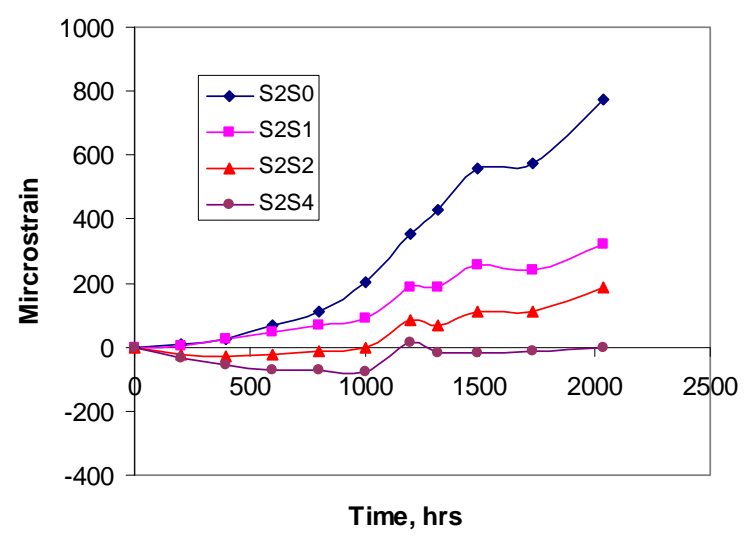

(d) Slab Specimen 4

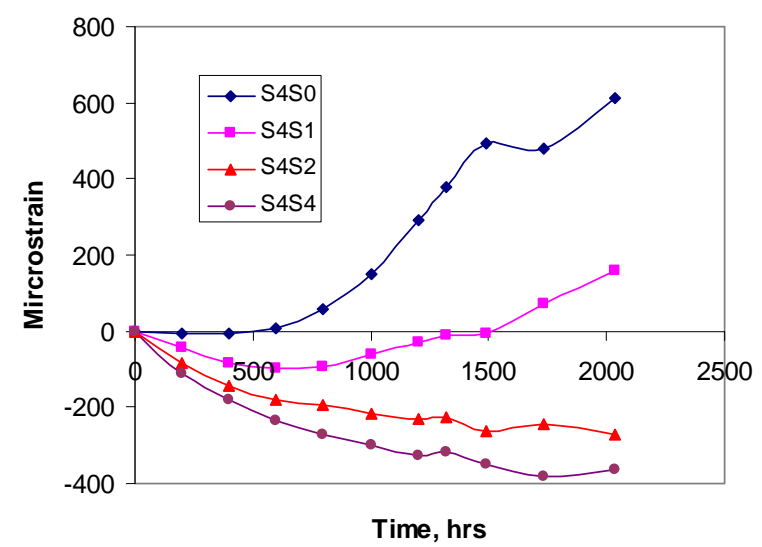

Figure 3-11 Extended Strain Time Histories after Slab Specimens Removal from the Environmental Chambers.

(Note: After 1200 hrs, ambient conditions were $25^{\circ} \mathrm{C}$, 65-80\% RH.) 
J. Abbuhl and J. Langham of Euclid Chemical Company [7] provided values of 0.04$0.06 \%$ expansion for a typical Conex dosage of $6 \%$ by weight in a concrete mixture similar to the Cap Concrete, but with a w/c ratio of 0.55 (vs. 0.65 for the Cap Concrete) and 7 day wet curing. They estimate a $0.1 \%$ expansion for a $10 \%$ dosage of Conex, as for the Cap Concrete. Collepardi [8] measured expansion strains in concrete specimen with w/c of $0.65, \mathrm{CaO}$ admixture $10 \mathrm{wt} \%$ of the cement component, as shown in Figure 3-12, which are closely similar to those in the Cap Concrete mixture. Here, maximum positive strains of $700 \mu \varepsilon$ (Curve A) were reached after underwater curing for 3 days and $450 \mu \varepsilon$ (Curve B) for curing with plastic sheathing. After exposure to air at $65 \% \mathrm{RH}$, the expansion effect was close to disappearing after 30 days. In the current test, maximum positive strains up to $775 \mu \varepsilon$ were reached after slow reaction of the $\mathrm{CaO}$ with residual water from the mixture, and were still rising at the termination of the test at 84 days.

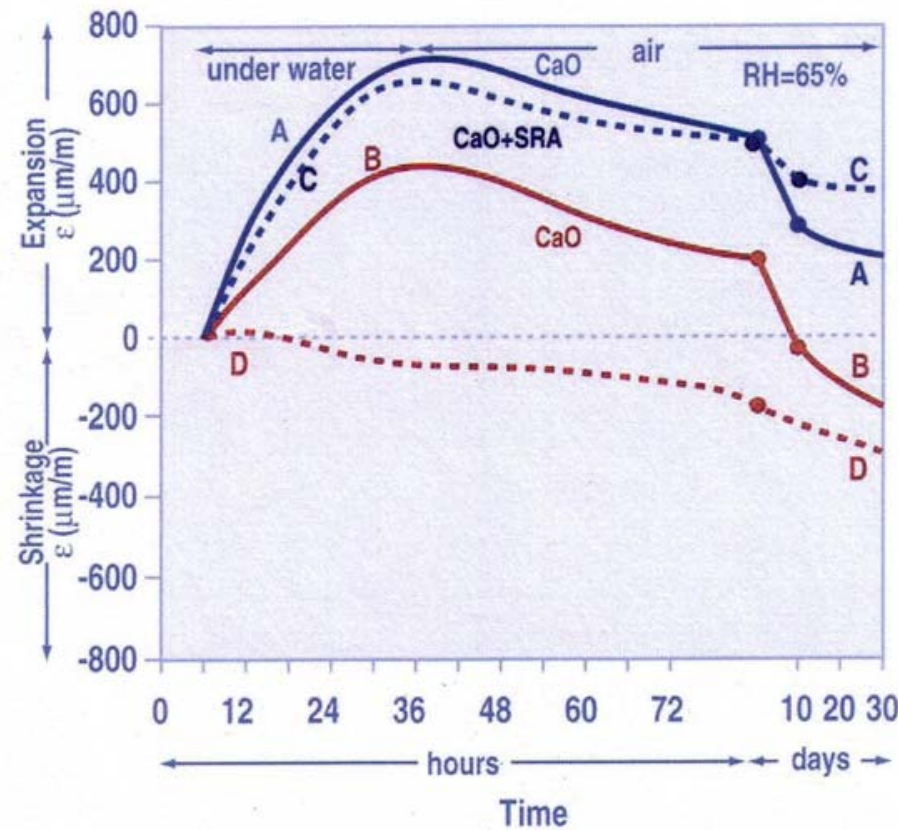

Figure 3-12 Development of Expansive Strains in Concrete Due to Shrinkage Compensating Admixture (Collepardi [8])

Our tests did not involve any wet curing. However, all sides of the specimens were sealed by the mold except for the top surface, which was sealed with plastic sheathing for at least 6 hrs prior to being subjected to the environmental chamber air atmosphere. Consequently, the inner regions remained moist. For Slab Specimens 1 and 2, subjected to $80 \%$ ambient relative humidity, internal relative humidity varied between $98 \%$ to $90 \%$ within the first 50 days of the test. In contrast to wet curing, where full $\mathrm{CaO}$ hydration is complete within 3 days, the test results indicate that the transformation of the lime component $(\mathrm{CaO})$ of the admixture to calcium hydroxide extended to and beyond the 84 days of the test. Positive strains started to grow immediately after the specimens were installed in the environmental chamber (Figures 3-5 and 3-6). The expansion rates measured by the embedded strain gages increased with depth, with a maximum strain of $750 \mu \varepsilon$ at $177 \mathrm{~mm}$ from the surface (S1S0) at the end of extended curing period of 84 days (Figure 3-11). The top layer $22.8 \mathrm{~mm}$ from the surface, as indicated by S1S4 (Slab specimen 1, Strain gage 4), 
exhibited an initial small shrinkage, then had a small positive strain towards the end of the test period. This suggests that the moisture content at each location has a strong influence on the hydration rate of $\mathrm{CaO}$. This delayed hydration effect is even more pronounced with Slab Specimens 3 and 4 subjected to $40 \%$ relative humidity air. The strain at $177 \mathrm{~mm}$ from the surface initially remained at zero for 20 days but eventually increased to $716 \mu \varepsilon$ at the end of 84 days. The surface layer at $22.8 \mathrm{~mm}$ experienced constant shrinkage up to $-336 \mu \varepsilon$ that never reversed direction. Intermediate layers showed an initial shrinking and then expansion.

The above expansion behavior in the experiment can be explained by the difference in hydration rate of $\mathrm{CaO}$ in liquid water and water vapor. Ramachandran, et al [9], showed a doubling of the hydration time, in a relative water vapor pressure of 0.5 , compared to liquid water. This may be due to diminished mobility of Ca ions in water vapor compared to liquid water [10]. Figure 3-13 [11] shows that for a $\mathrm{w} / \mathrm{c}=0.6$, the moisture capacity, $d w / d h$, at a relative humidity of 0.4 is $(0.2 / 1.4=1 / 7)$ of that at $100 \%$ relative humidity. Thus, the hydration time of $\mathrm{CaO}$ cured in air, as is the case of the present tests, may be an order of magnitude longer than if wet cured for at least 3 days, which is the standard practice. If wet curing is used, shrinkage would not be evident as the expansive effect of Conex would simultaneously develop.

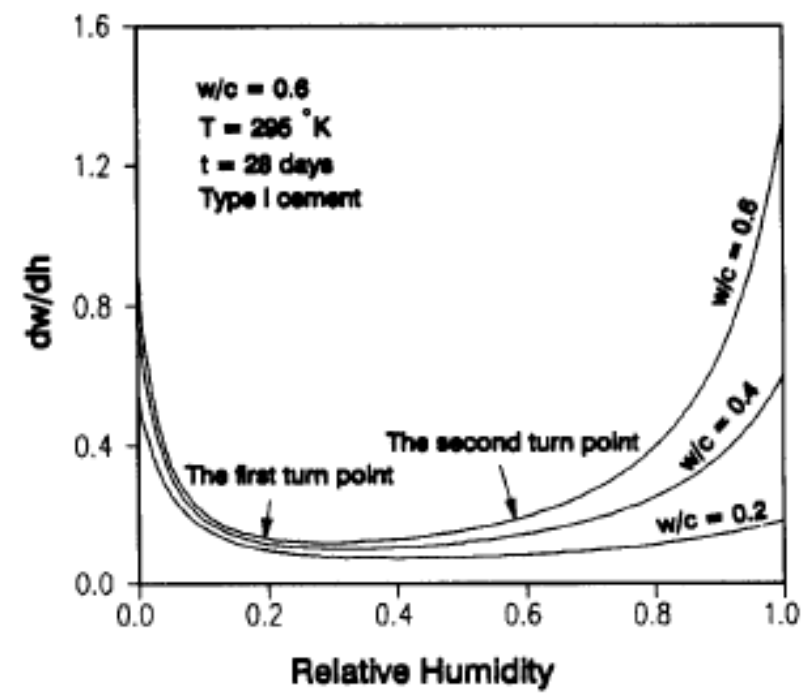

Figure 3-13 Moisture Capacity as a Function of Relative Humidity [11]

\subsubsection{Effect of Cracking}

Evidence of micro-cracking due to tensile stresses can be seen during the early period of the strain histories of S3S4 and S4S4 located near the top surfaces of Slab Specimens 3 and 4 (Figures 3-7 and 3-8) as well as in the center strain gages applied to the rebars of Slabs 2 and 4 (Figure 3-9). These are observed as step increases in strain and can be interpreted as relaxations of stress due to creep or cracking. These cracks can be attributed to tensile stresses imposed by expansive strains produced by shrinkage compensating admixture that are restrained by the rebar. The expansive strains are in the interior of the slab surrounding the rebar and deeper into the sealed exterior, where the high moisture content was conducive to conversion of the $\mathrm{CaO}$ to 
$\mathrm{Ca}(\mathrm{OH})_{2}$. Near the surface of the slab, compressive strains are recorded by strain gages embedded in the grout due to drying. Since the rebars are supported on $1 / 2$-inch perforated plates that extend from top to bottom of the slabs, these plates transmit the average stress from the grout to the rebar. As the high expansive strains in the grout below the rebar grow, the rebar slips from the local grout surrounding the rebar, which is at a lower strain. Thus, periodic positive jumps in the rebar strain gage are recorded, such as in Figure 3-9, Center Strain of Slab 2, which was cured at 80\% RH. For Slab 1, cured at $40 \% \mathrm{RH}$, a greater proportion of the slab was in compression than in expansion. 


\subsection{Analysis of Shrinkage, Creep and Expansive Strains and Stress Development in Slab} Specimens

This section provides analytical methods to predict the development of strains and stresses due to shrinkage, creep and expansive effects of admixtures during the early age of the Cap Concrete installation over the P- and R-reactors. The purpose of this section is to evaluate and validate these methods by comparison with the data on the Cap Concrete slab specimens. The problem is analyzed by considering the following aspects:

a. Grout shrinkage during curing

In a poured slab, diffusion and evaporation from the top surface, together with autogenous drying or self-dessication lead to uneven moisture distribution, where the humidity is high in the interior, decreasing towards the surface. Capillary pressure is responsible for setting up shrinkage strains. The upper portions having larger shrinkage strains are restrained by lower layers with smaller shrinkage.

\section{b. $\underline{\text { Creep }}$}

Creep refers to the increase in strain under a sustained load. Even without an external load, curing cementitious materials undergo creep due to the action of inherent restraining forces such as an immovable under-layment, reinforcing bars and differential shrinkage. This reduces the actual shrinkage strains and relaxes the restraining forces.

\section{c. Methods to reduce shrinkage}

A standard method to reduce grout shrinkage is to install reinforcing steel rods (rebar) which increases effective concrete modulus of elasticity in the surrounding concrete section. A supplementary technique is to include an admixture, such as Conex, which is designed to expand against restraint and thereby reduce shrinkage and its effects.

The following subsections discuss analytical methods for predicting the humidity profile, grout mechanical properties, free shrinkage strains, creep, effect of restraints and expansive agent on the final shrinkage strains and stresses.

\subsubsection{Humidity Profile Development}

An analytical model to predict potential cracking of the Cap Concrete during its drying period has to account for the effects of hydration, moisture transport and environmental influences. Drying shrinkage is induced by the removal of water from the pore structure of the grout by evaporation and diffusion. Negative capillary pressure is linked to the development of curved capillary menisci in the partially saturated pore system. Capillary stresses are then initiated in the solid microstructure by this reduction in pore fluid pressure to satisfy force equilibrium, applying a compression on the solid microstructure and leading to bulk shrinkage.

Capillary pressure can be obtained from the Kelvin-Laplace equation [4],

$$
p_{c}=\frac{-\ln (h) R T}{v_{m}}=\frac{2 \gamma}{r}
$$

where: $\mathrm{p}_{\mathrm{c}}$ is the capillary pressure, 
$\mathrm{h}$ is the internal relative humidity

$\mathrm{R}$ is the universal gas constant

$\mathrm{T}$ is the temperature, $\mathrm{K}$

$\mathrm{v}_{\mathrm{m}}$ is the molar volume of water

$\gamma$ is surface tension of water

$r$ is the average radius of the fluid meniscus in the pores of the medium

Prior to using Eq. 1, a means of predicting the internal relative humidity distribution is required. This is obtained from the diffusion equation, which can be written to give the relative humidity explicitly as,

$$
\frac{\partial h}{\partial t}=\operatorname{div}\left(D_{h} \operatorname{grad}(h)\right)
$$

where $D_{h}$ is the moisture diffusion coefficient, defined as the ratio between permeability k and moisture capacity, $\partial w / \partial h$, i.e., $D_{h}=k /(\partial w / \partial h)$.

An expression for $D_{h}$ is given in the CEB-FIB model code [1] as a function of relative humidity,

$$
D_{h}=D_{1}\left(\alpha+\frac{1-\alpha}{1+\left[(1-h) /\left(\left(1-h_{c}\right)\right]^{n}\right.}\right)
$$

Estimates for the various terms are given in [2] as follows: $\alpha=0.05, h_{c}=0.80, n=15$.

and

$$
D_{1}=\frac{D_{1,0}}{f_{c k} / f_{c k 0}}
$$

where $D_{I}=3.6 \times 10^{-6} \mathrm{~m}^{2} / \mathrm{h}, f_{c k o}=10 \mathrm{MPa}, f_{c k}=f_{c m}-8 \mathrm{MPa}$, and

$f_{c m}$ is the mean compressive strength.

Using expressions (3) and (4) with the values given above, the differential equation (2) was solved for the slab specimen in two-dimensional geometry with a general purpose finite element program. The boundary conditions were for the gradient of the humidity at the sides and bottom surfaces, respectively, to be zero,

$$
\frac{\partial h}{\partial x}=\frac{\partial h}{\partial y}=0
$$

and $\mathrm{h}=0.4$ or 0.8 at the top surface.

Figures 3-14 and 3-15 give the predicted values of humidity as functions of time at the strain gage positions as shown in Figure 2-3 for ambient relative humidity of $80 \%$ and $40 \%$, respectively. The comparisons in Figures 3-14 and 3-15 do not give close agreement between the model and the specimen behavior. This may be due to the specific grout mixture used in the present test as compared to the average behavior of a large number of data sets used to derive Equation (3), as well as the non-wet curing schedule of the present test.

When we used the form of the correlating equation suggested by Xi et al [11], 


$$
D_{h}=\alpha_{h}+\beta_{h}\left[1-2 \exp \left(-10^{\gamma(h-1)}\right)\right]
$$

with the following parameters, $\alpha_{\mathrm{h}}=0.006, \beta_{\mathrm{h}}=0.03$ and $\gamma=2.5$, we obtained very close agreement for the case of $40 \% \mathrm{RH}$ (Figure 3-17) and fair agreement to within $5 \% \mathrm{RH}$ at $80 \%$ RH (Figure 3-16). The prediction of relative humidity by the CEB-FIB model (Eq. 4) gives good agreement at high relative humidity, but poor results at low humidity may be due to the fact that it is based on data for standard practice which utilize wet curing and thus a narrow range of normally high humidity conditions. The Xi method allows for constant low diffusivity at low humidity and rapid rise of diffusivity at high humidity. This close agreement over a wide range of humidity is necessary to be able to use the humidity model in detailed and localized stress calculations. 


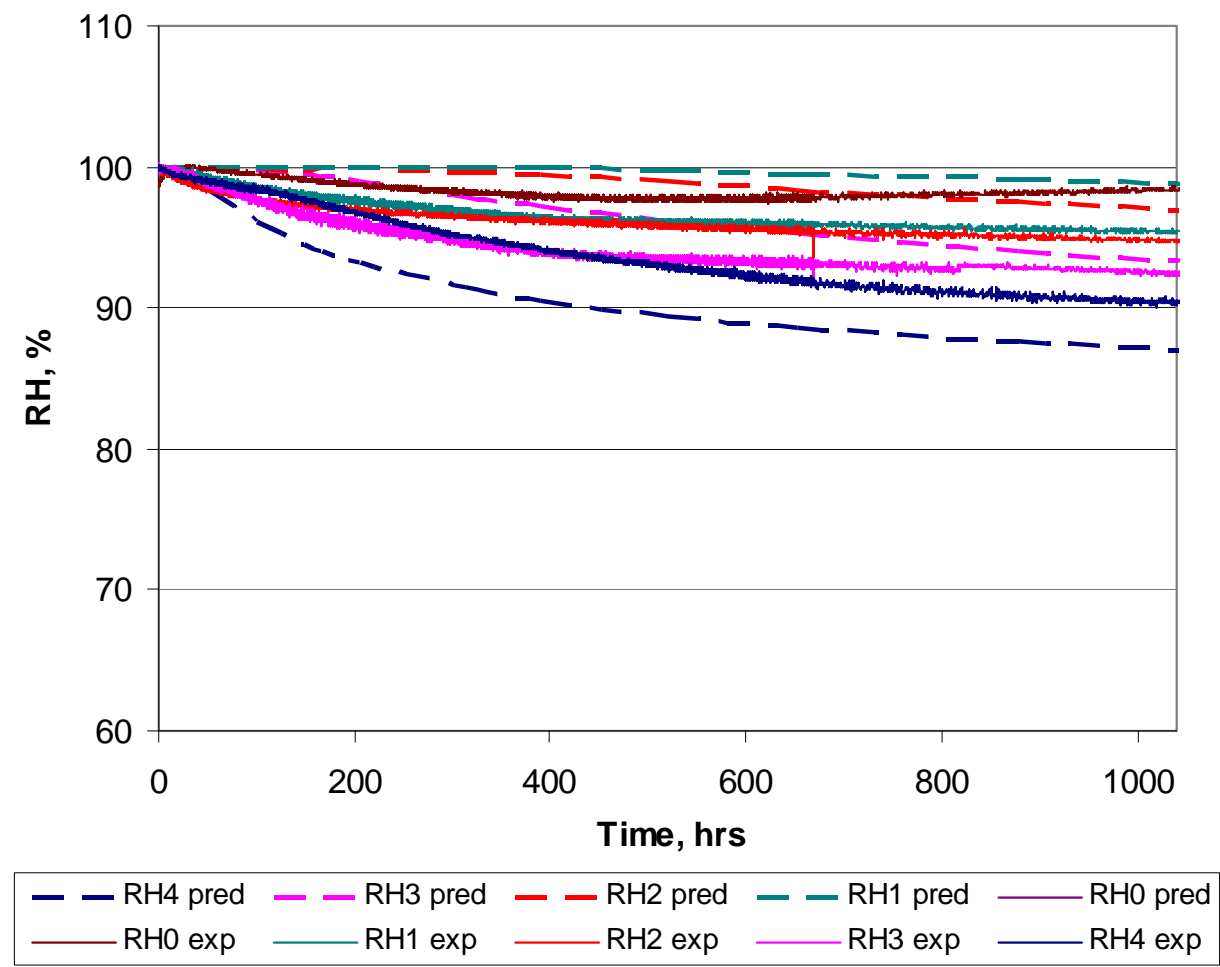

Figure 3-14 Experimental vs. Predicted Relative Humidity Values (by CEB-FIB Model) in Slab Specimen at $\mathbf{8 0} \%$ Ambient RH

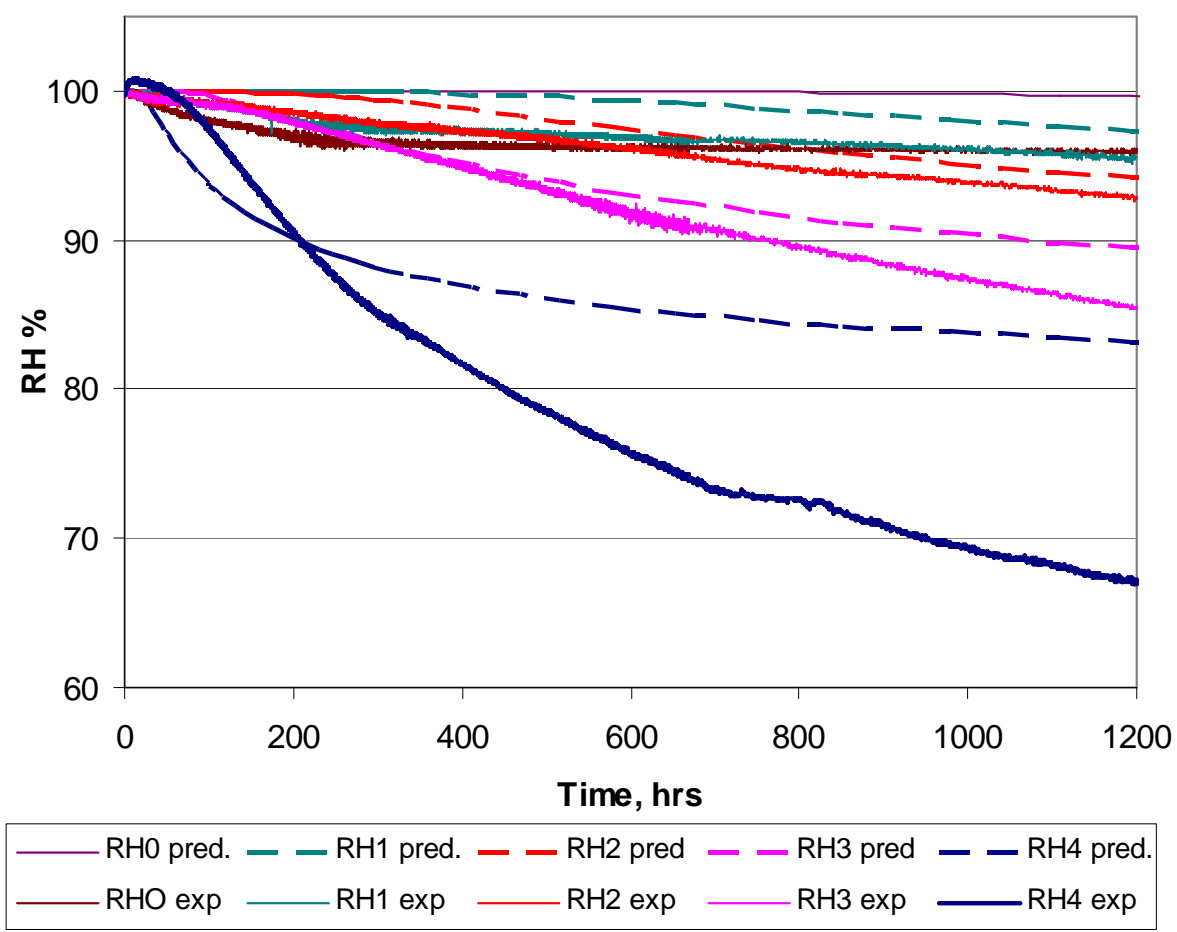

Figure 3-15 Experimental vs. Predicted Relative Humidity Values (by CEB-FIB Model) in Slab Specimen at $\mathbf{4 0 \%}$ Ambient RH 


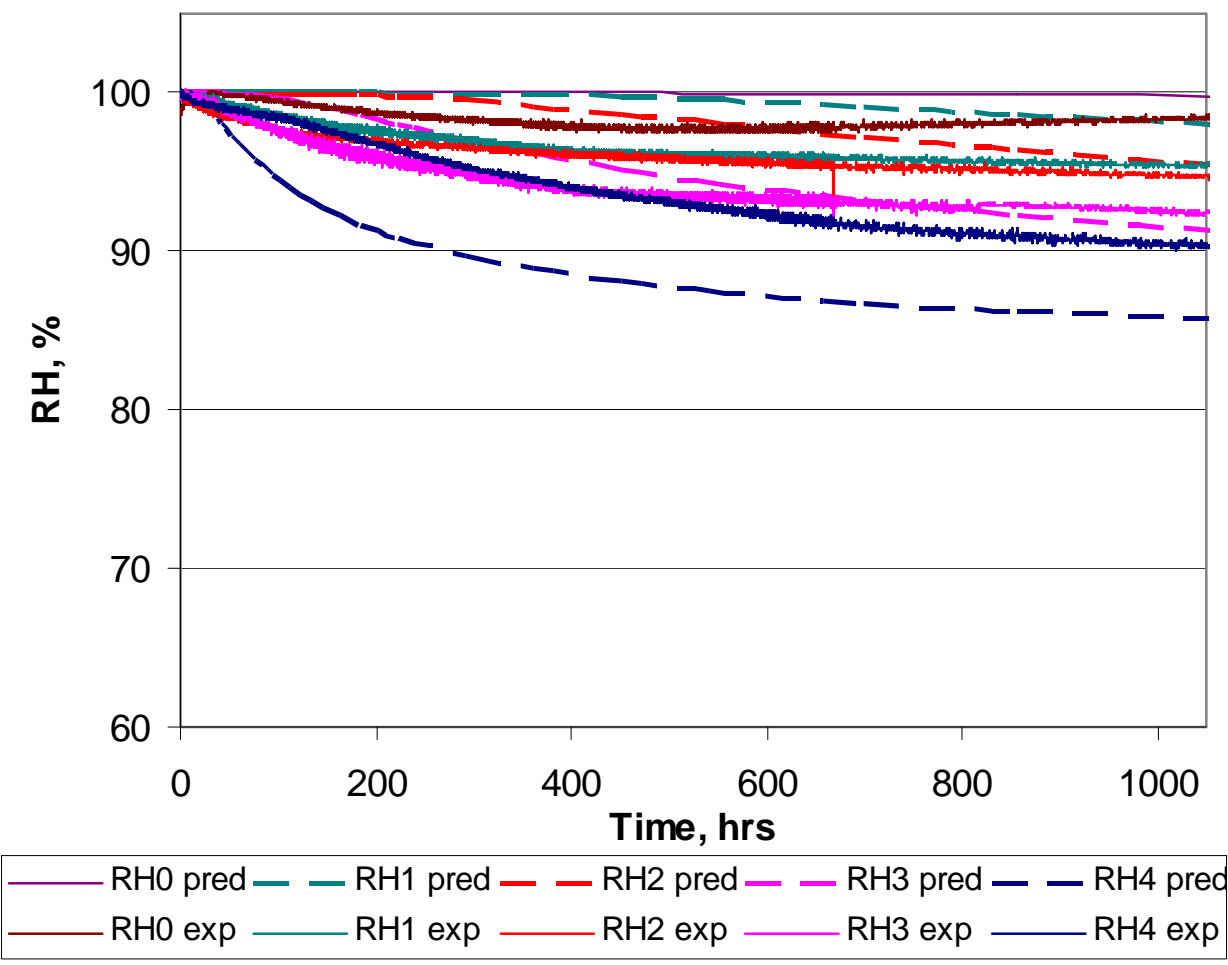

Figure 3-16 Experimental vs. Predicted Relative Humidity Values (this work) in Slab Specimen at $80 \%$ Ambient RH

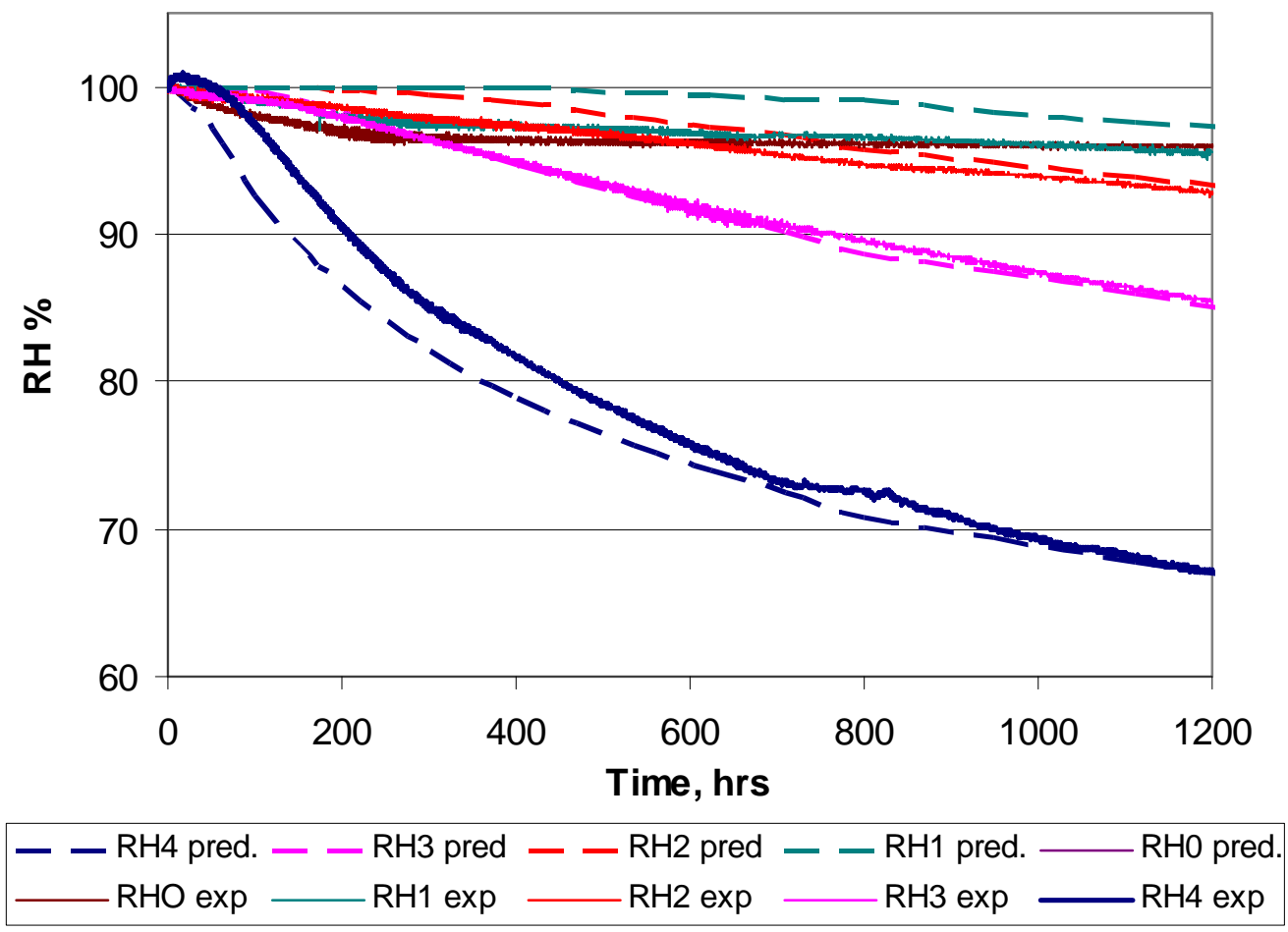

Figure 3-17 Experimental vs. Predicted Relative Humidity Values in Slab Specimen (This Work) at $40 \%$ Ambient RH 


\subsubsection{Concrete Mechanical Properties}

The elastic properties of a concrete mixture may be determined directly by tests, or by composite theory if such tests are not available. For the Cap Concrete, only the 28 day mean compressive strength (3450 psi per W. Mhyre [12]) was measured. Further, the variation of these properties with age, which is important for determination of the shrinkage and creep strains, is unknown. Young's modulus was not measured but was estimated for material cured for 28 days and for fully cured material. For this, code type calculation or age theory may be used.

Elastic properties are difficult to predict due to the dependence on factors such as waterto-cement ratio, aggregate elasticity, and relative volumes of cement paste and aggregate. These properties can be calculated using the general multi-scale micro-mechanics approach of Bernard, et al [13] and Ulm, et al [14] where the properties of individual cement particles such as clinkers, C-S-H particles, fine and coarse aggregates are combined at different levels using composite theory. First, cement paste is considered at a low level. The next higher level is where fine aggregates are added to the cement paste to make mortar, and the highest level is where coarse aggregates are added to make concrete. However, Eguchi and Teranishi [15] measured Young's modulus for mortar and concrete mixes of different $\mathrm{w} / \mathrm{c}$ ratios and volumetric ratios of fine and coarse aggregates. For $\mathrm{w} / \mathrm{c}=0.60$ and fine aggregate volumetric ratio of 0.44 , the measured value of Young's modulus for the mortar mix was $\mathrm{E}=25 \mathrm{GPa}$, and for a coarse aggregate volumetric ratio of 0.38 , the measured value for the concrete mix was $32 \mathrm{GPa}$. Ulm et al [14] calculated the Poisson ratio for both mortar and concrete mixes to be $v=0.25$. Thus, the drained bulk modulus, $K_{d}=E / 3(1-2 v)$ is $18.9 \mathrm{GPa}$ for the concrete mix. These values also are close to the values calculated by Ulm for w/c $=0.5$. The corresponding Biot's coefficient is $b=0.55$ for the mortar mix and $b=0.417$ for the concrete mix. The Biot's coefficient comes about due to the different moduli of elasticity of the solid skeleton (aggregates) and the porous matrix.

Young's modulus of elasticity required in Eq. (6) may be obtained from ACI 209.2R [16],

$$
E_{c}=4740 \sqrt{f_{c}}
$$

where: $E_{c}$ - short term modulus of elasticity (MPa)

$f_{c}$ - compressive strength (MPa)

For the Cap Concrete, the 28 day compressive strength was measured at 3450 psi or 23.4 MPa (per W. Mhyre). This gives $E_{c}=22.4 \mathrm{GPa}$ according to Eq. (6).

The variation of the modulus of elasticity with age is assumed in ACI 209R-82 [17] to be given by

$$
E_{c}=E_{c u} \frac{t}{t+7}
$$

where $\mathrm{E}_{\mathrm{cu}}$ is the ultimate modulus of elasticity (MPa) and $t$ is in days. Using the measured 28 day strength for the Cap Concrete in the above equation leads to a value of $28 \mathrm{GPa}$ for the ultimate compressive strength, which is a little bit lower than measured by Equchi and Teranishi [15] of 33 GPa for a concrete with similar conditions as the Cap Concrete. 
Alternatively, the concept of age or degree of hydration may be used. It has been shown that there is a strong correlation between compressive strength and degree of hydration. For the Cap Concrete, the heat of hydration has been measured using an adiabatic calorimeter at two starting temperatures, $23^{\circ} \mathrm{C}$ and $40^{\circ} \mathrm{C}$. Using the Arrhenius function [18], the heat of hydration as a function of time may be converted into a function of degree of hydration, as shown in Appendix A. Thus, while the measured heat of hydration in an adiabatic calorimeter is over a range of temperatures, the equivalent heat of hydration variation with time at a constant temperature of $23^{\circ} \mathrm{C}$ can be calculated knowing the Arrhenius parameters. Figure 3-18 shows the variation of the heat of hydration with age at two adiabatic calorimeter starting temperatures, and at a constant temperature of $23^{\circ} \mathrm{C}$. The curve for constant $23^{\circ} \mathrm{C}$ temperature may be transformed to a curve with respect to time (Appendix A) which gives a duration of 1200 hrs or 50 days to complete hydration. This time function of the heat of hydration is used in Figure 3-19 as the time function for the development of the modulus of elasticity,

$$
E=E_{u} \frac{t}{(t+1.375)}
$$

The ultimate modulus of elasticity for the capping concrete, $E_{u}$, was calculated using Equation (8) and the $E_{c}=23 \mathrm{GPa}$ at $\mathrm{t}=28$ days. See Figure 3-19.

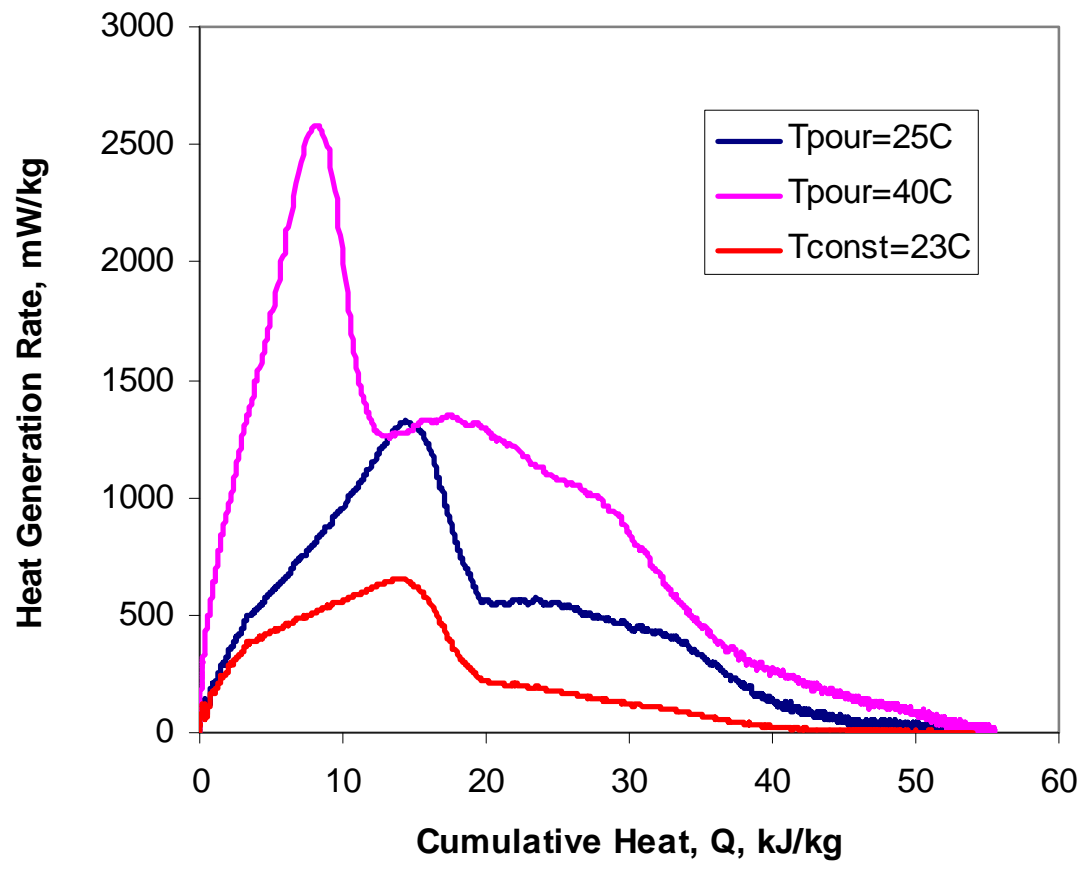

Figure 3-18 Heat of Hydration for the Cap Concrete vs. Cumulative Heat 


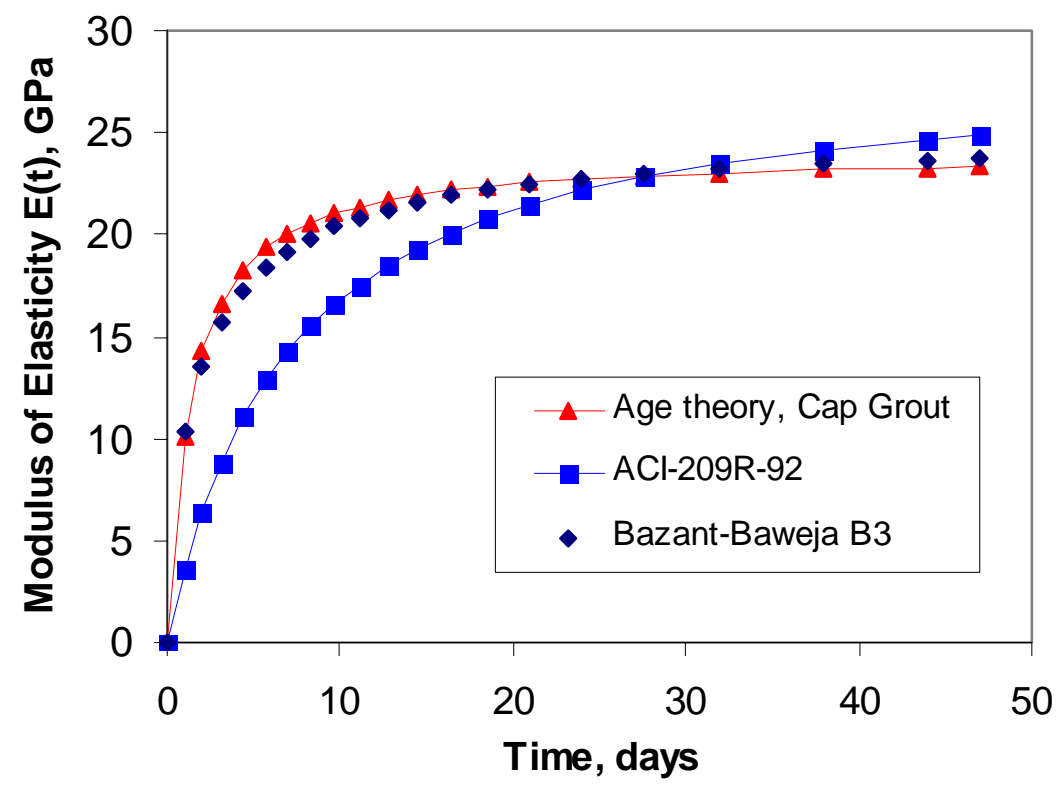

\section{Figure 3-19 Calculated Development of Capping Concrete Modulus of Elasticity with Age}

\subsubsection{Strain Calculations}

Various computational methods based on engineering correlations of existing data have been proposed. ACI 209.2R [16] gives details on the: 1) ACI 209R-92 model, 2) BazantBaweja B3 model, and others. These empirical models are intended to predict the time dependent behavior of the mean stress in an unreinforced concrete member and not under external load. The effect of reinforcements is given by Reference [17] and the effect of external load on creep must be analyzed, using the relations provided for the compliance function. For the analysis of detailed differential drying shrinkage in a geometry other than that used in experiments, an accurate physics-based theoretical model is more useful. This report will compare results of the code-type calculations with physics-based calculations, where available.

The approach in this report is to first develop a 2-dimensional finite element model of the slab specimen without restraint (rebar) consisting of the basic grout mixture without the expansion agent Conex. Then the effect of the expansive agent is added, and finally the effect of the restraining rod is included.

\subsubsection{Estimation of Time Varying Free Shrinkage Strain}

a) Code Calculation

ACI 209R-82 [18] gives the amount of unrestrained shrinkage, $\varepsilon_{s h}(t)$, as a function of time after the end of wet curing as:

$$
\varepsilon_{s h}(t)=\frac{t}{t+35} \varepsilon_{s h u}
$$

where $t=$ elapsed time after end of wet curing days 


$$
\varepsilon_{\text {shu }}=\text { ultimate shrinkage strain. }
$$

An estimate of the ultimate unrestrained drying shrinkage strain under standard conditions is given by ACI 209R-82 [17] to be:

$$
\varepsilon_{\mathrm{shu}}=780 \gamma_{\mathrm{sh}} \mathrm{x} 10^{-6}
$$

where $\gamma_{\text {sh }}$ is a product of correction factors to account for initial moist curing duration, relative humidity, volume to surface ratio of the concrete member, slump, fine aggregate fraction, cement content and air content. Appendix B gives the value of $\varepsilon_{\text {shu }}$ for the Cap Concrete which was determined in this study as $262 \mu \varepsilon$. This low value is mainly due to the large volume to surface ratio effect, owing to top surface drying only. The Bazant-Baweja B3 model [16] (Appendix B) gives a value of 841 $\mu \varepsilon$. The volume to surface ratio effect is embodied in the time function. Applying the Bazant-Baweja time function to the ultimate free shrinkage strain, the time varying free shrinkage strain is given by,

$$
\varepsilon_{s h}=841 \times 10^{-6} \tanh \left[\left(t-t_{c}\right) / \tau_{s h}\right]
$$

where $t_{c}$ is the curing period and $\tau_{s h}$ is the shrinkage half-time, calculated in Appendix B to be 255 days. This equation is plotted in Figure 3-20, together with the predicted shrinkage strain by the Capillary Stress model (Sec. 3.2.3.1b) at a location, $22.8 \mathrm{~mm}$ below the top surface of the Cap concrete specimen, where the lowest humidity was measured. The point to make is that the code-type calculation is for average conditions for a concrete member, while the Capillary Stress model is based on the local humidity at a point, which is predicted or measured. The Capillary Stress model is discussed next.

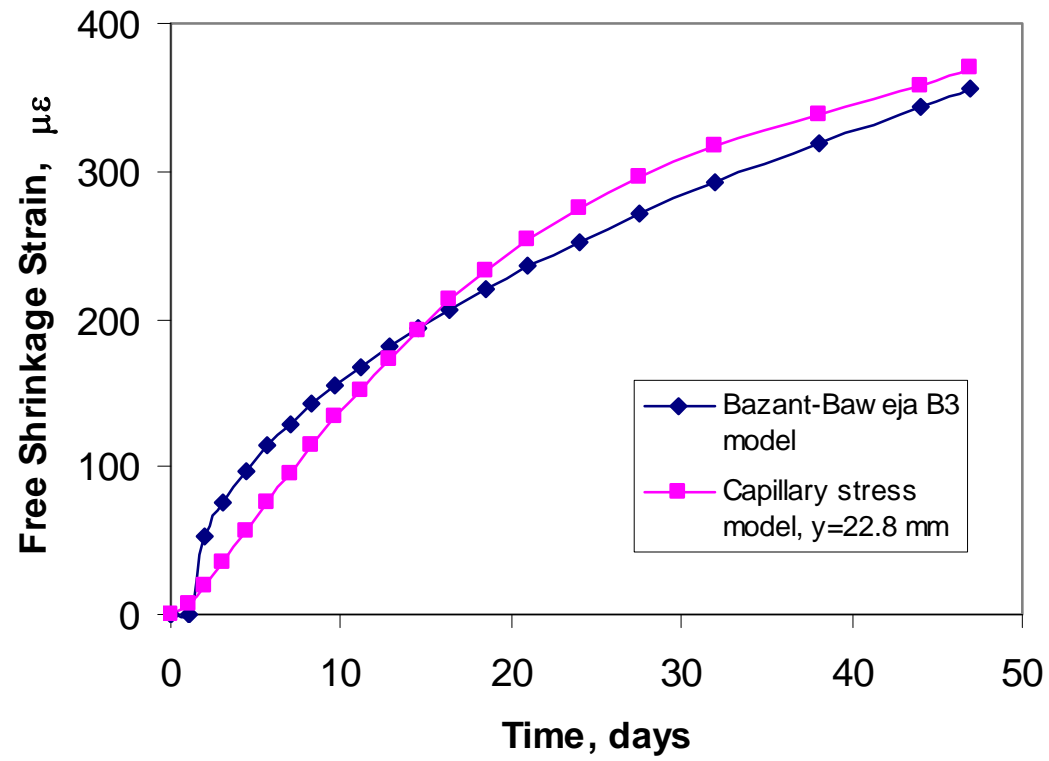

Figure 3-20 Calculation of Time Varying Shrinkage Strain by Capillary Stress Model vs. Bazant-Baweja B3 Model for the cap concrete 
b) Physics based Model for Hydro-mechanical Conditions and Shrinkage Strain Considering concrete as a poro-elastic medium, the change in strain as a result of a change in capillary pressure is given in Equation 12 [19],

$$
d \varepsilon=\frac{b S_{w} d p_{c}}{3 K_{d}}
$$

where $\varepsilon$ is the volumetric strain, $b$ is the Biot's coefficient, $S_{w}$ is the saturation ratio of the pores, $p_{c}$ is the capillary pressure, and $K_{d b m}$ is the drained bulk modulus. The capillary pressure can be obtained from the humidity measurements inserted into Eq. (1). We assume no air in the pores and thus the saturation ratio, $S_{w}$, is equal to 1 . The drained bulk modulus is given by

$$
K_{d b m}=\frac{E}{3(1-2 v)}
$$

Using the following values in Equation (11), $K_{d b m}=28 / 3(1-2(0.218))=16.5 \mathrm{GPa}$ [15], $\mathrm{R}=8.314 \mathrm{~J} / \mathrm{K}-\mathrm{mol}, \mathrm{T}=298 \mathrm{~K}, v_{\mathrm{m}}=1.8 \times 10^{-5} \mathrm{~m}^{3} / \mathrm{mol}$, and assuming a relative humidity of $60 \%$, the calculated vs. measured values of ultimate shrinkage for conditions similar to the Cap Concrete $(\mathrm{w} / \mathrm{c}=0.65, \mathrm{Vs}=0.44, \mathrm{Vg}=0.38)$ are:

$\begin{array}{lll}\text { Concrete mix } & \frac{\text { Calculated } \varepsilon_{\text {shu }}}{592 \mu \varepsilon} & \frac{\text { Test [15] }}{600 \mu \varepsilon}\end{array}$

Interestingly, the data of Egushi and Teranishi [15] for a water-to-cement ratio $\mathrm{w} / \mathrm{c}=0.60$, ambient conditions of $20^{\circ} \mathrm{C}$, relative humidity of $60 \%$, fine aggregate in the mortar mix with a volume fraction $\mathrm{V}_{\mathrm{s}}=0.444$, coarse aggregate with a volume fraction $\mathrm{V}_{\mathrm{g}}=0.38$ in the concrete mix , the concrete ultimate drying strain is $600 \mathrm{x}$ $10^{-6} \mathrm{in} / \mathrm{in}$. These conditions are closely similar to those for the Cap Concrete $(\mathrm{w} / \mathrm{c}=0.65)$. These predicted strains are fairly constant for a drying period from 28 days to 182 days.

Inserting the relation for capillary pressure as a function of humidity (1) into the equation for hydro-mechanical strain (12), combined with the equation for drained bulk modulus (13), the time varying free shrinkage strain for the Capillary Stress model is given by,

$$
\varepsilon_{s h}=994 \ln (h)[t /(t+1.38)](\mu \varepsilon)
$$

where the term in the brackets is the time function ( $t$ in days) to account for the approach to the ultimate strength of the concrete (28 GPa). As can be seen from Figure 3-20, the Capillary Stress model and the Bazant-Baweja B3 model gives very similar results in the first 50 days. This is not surprising since the Bazant-Baweja B3 model is based on empirical data from small test specimens where the relative humidity is relatively uniform throughout the specimen. For large concrete structures, a large relative humidity gradient can develop from the surface to the interior. The question is what average humidity value to assign to this structure in order to use the Bazant-Baweja model. The physics based Capillary Stress model however allows point wise calculation of the relative humidity and shrinkage strain for use in detailed stress calculations. 


\subsubsection{Creep Calculation}

Due to differential shrinkage, the top layers are restrained by the lower layers, resulting in a stress gradient and possible creep if elastic strains are exceeded. This section provides a means to calculate creep. Concrete differs from traditional viscoelastic materials due to the time dependent nature of its deformation. For a unit stress $d \sigma$ applied at time, $t_{o}$, to a material with age $t$, the increase in strain is given by $[3,20]$,

$$
d \varepsilon=J\left(t, t_{o}\right) d \sigma
$$

where the compliance function, $J\left(t, t_{0}\right)$, is empirically determined. Experiments have shown that the increase in strain is independent of all past load increments [3], [20, p. 9]. This suggests applicability of the superposition principle, (see equation (16), [20, p. 103]),

$$
\varepsilon=\int_{0}^{t} J\left(t, t_{o}\right) d \sigma
$$

The Bazant-Baweja B3 model $[16,20]$ is used in this analysis to determine the compliance function since it is simpler and better theoretically justified than other models. It is based on the idea in solidification theory that the aging properties of concrete is due to the growth of solidified matter whose properties vary with age. In this theory, the compliance function is composed of 3 factors.

$$
J\left(t, t_{o}\right)=q_{1}+C_{0}\left(t, t_{o}\right)+C_{d}\left(t, t_{0}, t^{\prime}\right)
$$

where, $q_{1}$ is the instantaneous elastic strain per unit stress, $C_{0}\left(t, t_{0}\right)$ is the basic creep composed of an aging viscoelastic term, non-aging viscoelastic term, and an aging flow term, $C_{d}\left(t, t_{o}, t^{\prime}\right)$ is the drying term, $t$ is the age drying began.

When the instantaneous elastic strain is excluded, the basic creep compliance term $Q\left(t, t_{o}\right)$ is defined as

$$
Q\left(t, t_{o}\right)=C_{0}\left(t, t_{o}\right)+C_{d}\left(t, t_{0}, t^{\prime}\right)
$$

Details of the calculations for the compliance function are given in Appendix B.

What Eq. (16) means is that a unit stress $d \sigma$ applied at time $t_{o}$ leads to a unit strain, $d \varepsilon$, which grows quasi-elastically, except for the plastic flow term, with time to an asymptotic value. When the applied stress is varying with time, these unit strains emanating from different $t_{o}$ 's must be summed up to time $t$, as illustrated in Figure 321. Figure 3-22 gives typical curves of $Q\left(t, t_{o}\right)$ for various initial loading times $t_{o}$. Calculation of the instantaneous creep at one point in the concrete block thus requires storing many stress-strain histories. Determination of the time varying stress-strain distribution in the block is therefore not an easy task. We simplify the calculation 
procedure by noting that except at very early times, the curves can be approximated by step functions with heights equal to the initial values or knee parts of the curves. The initial values are used instead of the higher later ones for conservatism since lower creep values would be calculated. This procedure means that the compliance function can be collapsed into a single curve, as shown in Figure 3-22 as $Q\left(t_{o}\right)$ such that it is assumed the creep deformation occurs immediately. The creep at any time $t$ is the sum of all increments in stress from $t=0$, multiplied by the compliance function at the instant of load application and the instantaneous elastic modulus. The quasielastic interpretation of Eq (15) means that stress decreases lead to negative strain or strain recovery, which is not exactly correct but this is assumed for simplicity.

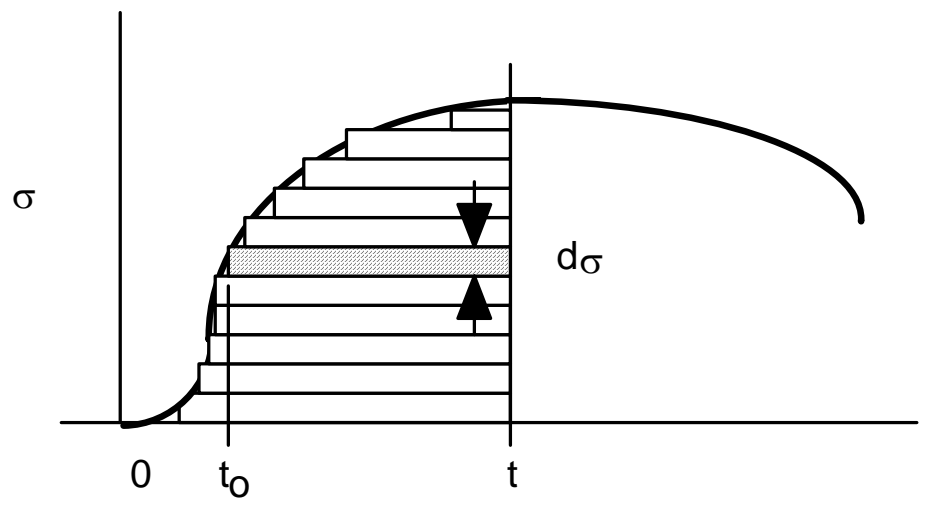

Figure 3-21 Illustration of Creep Integration for Time Varying Stress [20, p. 103] 


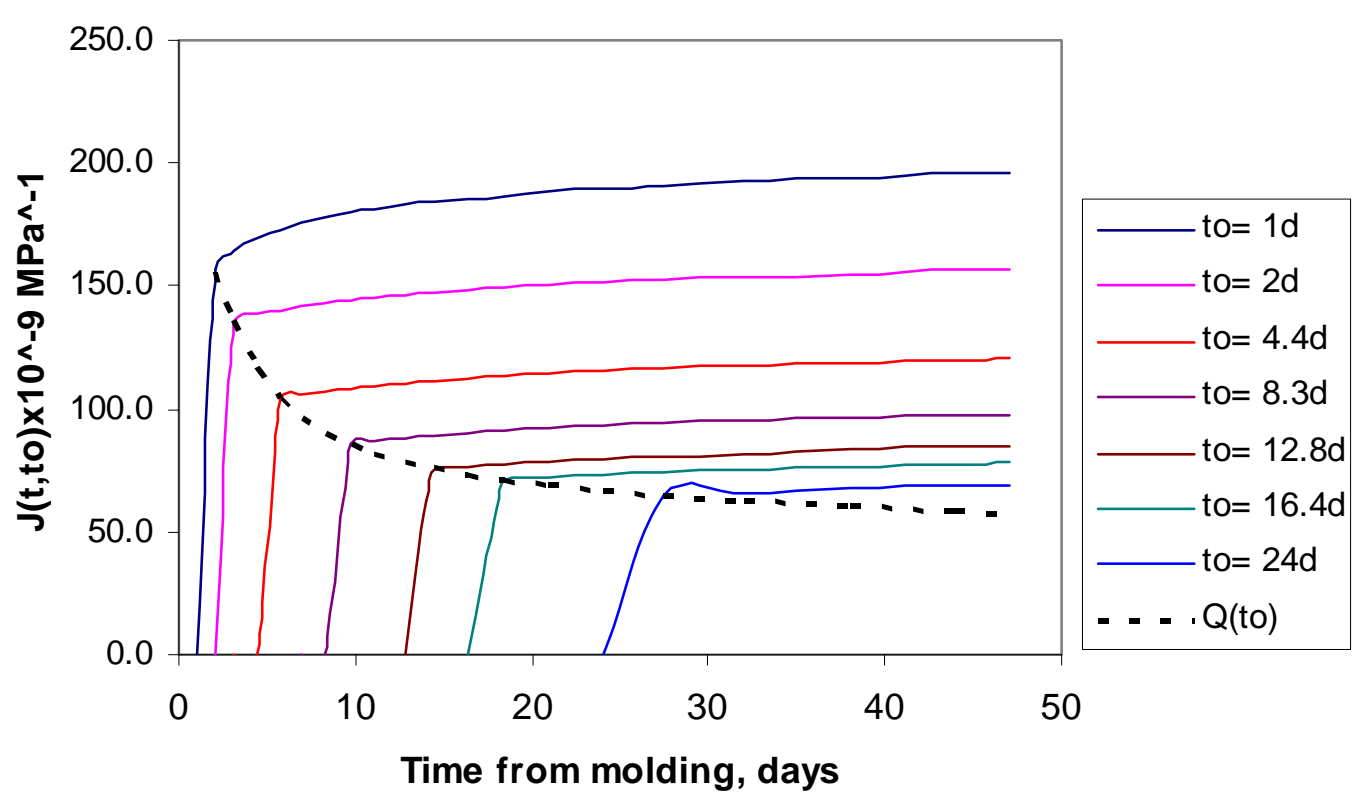

\section{Figure 3-22 Creep Compliance Curves for Various Loading Times, Calculated from [16]}

Expansion strains can be due to admixtures or from thermal stress. The total strain is made up of the shrinkage, creep, elastic, and expansion strains, as given by Eq. (17).

$$
\varepsilon_{t}=\varepsilon_{s h}+\varepsilon_{c r}+\varepsilon_{e l}+\varepsilon_{\exp }
$$

Although the slab specimen in the analysis described above was externally unrestrained, there was internal restraint due to the differential shrinkage of the layers of concrete. The potential stress [4] giving rise to creep was that due to the total strain without creep.

$$
\sigma_{p o t}=\left(\varepsilon_{t}-e_{s h}-\varepsilon_{\exp }\right) E
$$

This potential stress is in turn relaxed by creep. Inserting this term into the creep Equation (15), the final equation for creep strain is,

$$
d \varepsilon_{c r}=\frac{Q^{\prime}\left(t, t_{o}\right)}{1+Q^{\prime}\left(t, t_{o}\right) E(t)} d \sigma_{p o t}
$$

\subsubsection{Analysis of Restrained Shrinkage Strains in Slab Specimens}

A stress analysis of a representative concrete block is necessary to analyze the development of shrinkage and creep strains during the drying of the test slab specimens or the full scale Cap Concrete emplacement. The differential equations of stress and strain in two dimensions are solved as given below, 


$$
\frac{\partial}{\partial x}\left(\frac{E}{1-\mu^{2}}\left[\frac{\partial u}{\partial x}+\mu \frac{\partial v}{\partial y}\right]-\varepsilon_{s h}-\varepsilon_{c r}-\varepsilon_{\exp }\right)+\frac{\partial}{\partial y}\left(\frac{E}{2(1+\mu)}\left[\frac{\partial v}{\partial x}+\frac{\partial u}{\partial y}\right]\right)+F_{x}=0
$$

$$
\frac{\partial}{\partial x}\left(\frac{E}{2(1+\mu)}\left[\frac{\partial v}{\partial x}+\frac{\partial u}{\partial y}\right]\right)+\frac{\partial}{\partial y}\left(\frac{E}{\left(1-\mu^{2}\right)}\left[\frac{\partial v}{\partial y}+\mu \frac{\partial u}{\partial x}\right]-\varepsilon_{s h}-\varepsilon_{c r}-\varepsilon_{\exp }\right)+F_{y}=0
$$

where $\varepsilon_{x}=\partial u / \partial x$ and $\varepsilon_{y}=\partial v / \partial y, E$ is Young's modulus and $F_{x}$ and $F_{y}$ are body forces (assumed zero). Equations (20) and (21) were programmed into a twodimensional general purpose finite element program. All boundaries were set free. The unrestrained shrinkage strain was expressed as a function of humidity Eq.14, which in turn was a function of position. The expression for humidity was obtained from the analysis of moisture diffusion (Sec. 3.1.1). The creep term was obtained from Eq. 15. In this expression, the potential stress, $\sigma_{\text {pot, }}$ was obtained by first performing a stress analysis without creep and obtaining the axial stress distribution. The creep term was then included using the previously obtained stress distribution multiplied by the compliance term, $Q^{\prime}(t o) /\left(1+Q^{\prime}(t o) E\right)$. It is to be noted that for full restraint, the equivalent potential creep strain represents $41 \%$ of the shrinkage strain.

The results of the analysis are as follows:

Figure 3-23 shows the deformed grid for the slab specimen for shrinkage strains calculated for $\mathrm{t}=1200 \mathrm{hrs}$, showing clearly the shrinkage effects on the boundaries near the top. Figure 3-24 is a contour plot of the strains, showing that for this short test specimen, there are some end effects. However the strains at the center plane are representative of strains in the middle of a large slab by noting that increasing the length of the slab model did not change the strains. Figure 3-25 gives a plot of the strain along the vertical centerline of the slab.

Figure 3-26 plots a history of the calculated axial strain at the $22.8 \mathrm{~mm}$ position, compared to the experimental data for the same position for Cap Concrete Slab Specimen 4. For this location, the hydration of the $\mathrm{CaO}$ component of the Conex admixture is expected to be non-existent or significantly delayed (if it progresses at all) due to the low humidity of $65 \%$. The calculated and experimental strains agree to within a ratio of 0.86. This deviation may be due to experimental uncertainty, uncertainty in material properties, and the simplified calculation of creep. Predicted histories for other strain gage positions at 52.8, 82.8, $114.3 \mathrm{~mm}$ are also shown. These agree with the trend of negative strains shown in the data of Kim and Lee [2]. The corresponding experimental data are not shown since deeper into the slab, the increasing positive strain effect of the expansive agent Conex started to appear at $t=500$ hrs. A stress contour map of the slab specimen is given in Figure 3-25, showing tensile stresses close to the top surface. 
Cap Grout Slab under Shrinkage and Creep $x+200 * u, y+200 * v$

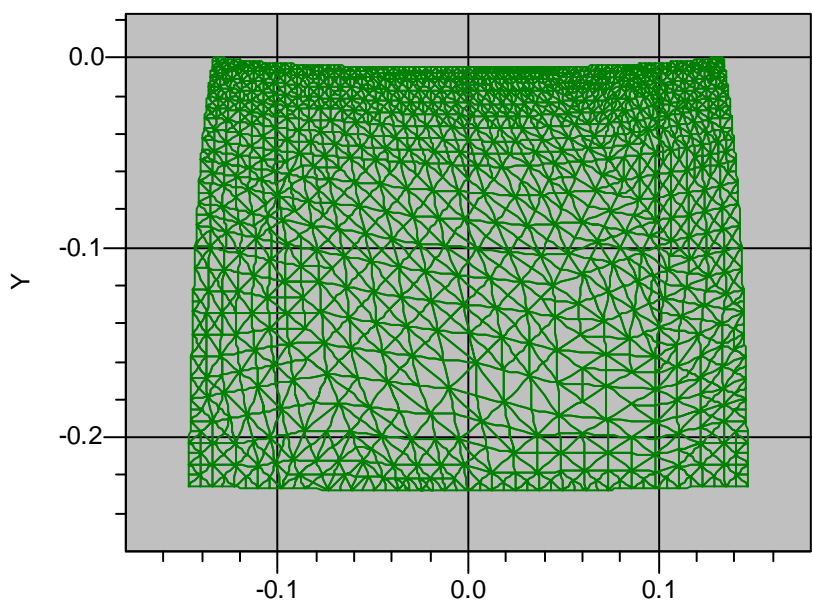

$-0.146<=X<=0.146$ $-0.228<=Y<=0$

PdzOPIt01Grid: Gr=9 err=9.054E-6

Figure 3-23 Deformed Grid of Cap Concrete Slab Specimen Model Under Combined Shrinkage and Creep

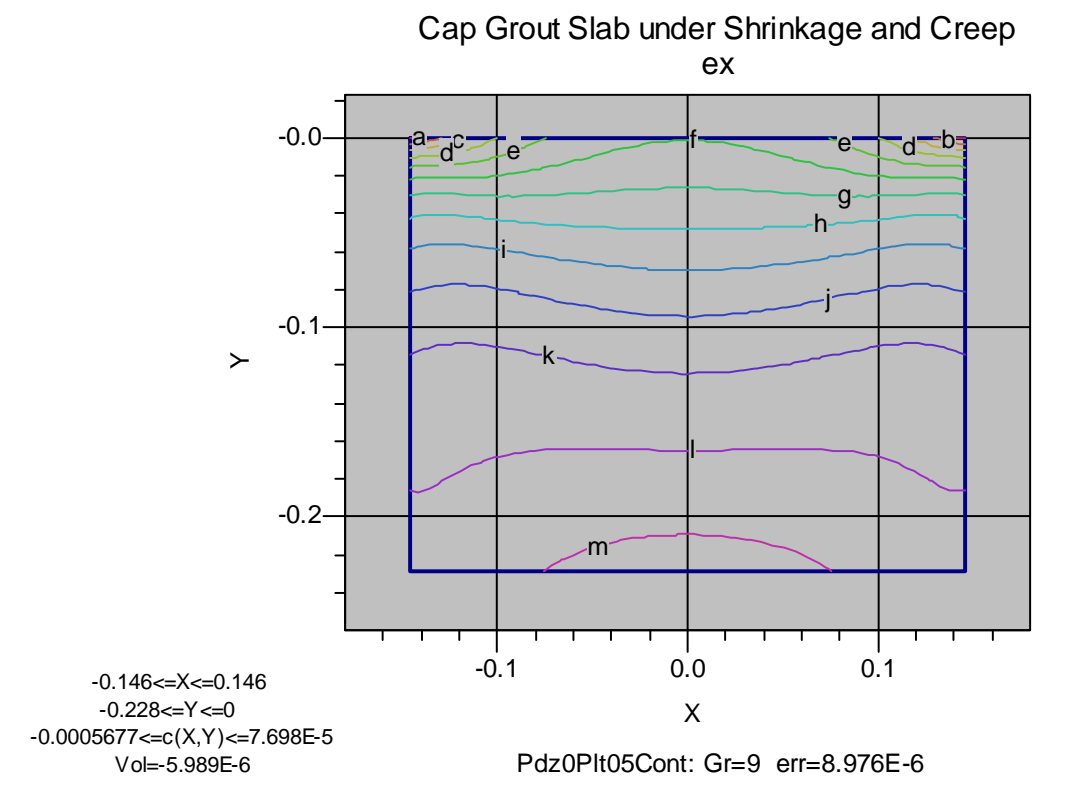

Contours:

min: -0.0005677

a: -0.00055

b: -0.0005

c: -0.00045

d: -0.0004

e: -0.00035

f: -0.0003

g: -0.00025

h: -0.0002

i: -0.00015

j: -0.0001

k: $-5 \mathrm{E}-5$

l: 0

m: $5 \mathrm{E}-5$

$\max : 7.698 \mathrm{E}-5$

Figure 3-24 Axial Strain Contour Map for Cap Concrete

Slab Specimen Model at 1200 hrs 
SRNL-STI-2010-00771

Revision 0

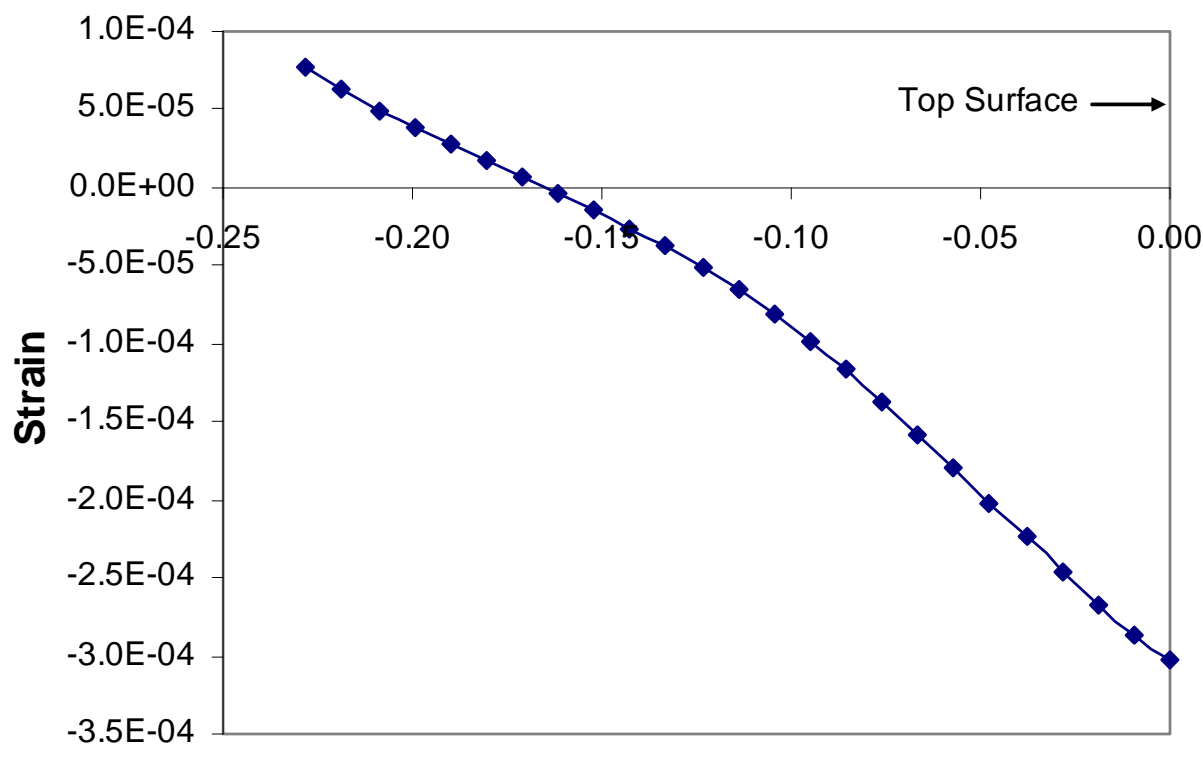

Distance from top surface, $m$

Figure 3-25 Predicted Axial Strain Distribution at Cap Concrete Slab Specimen Center Plane at 1200 hrs

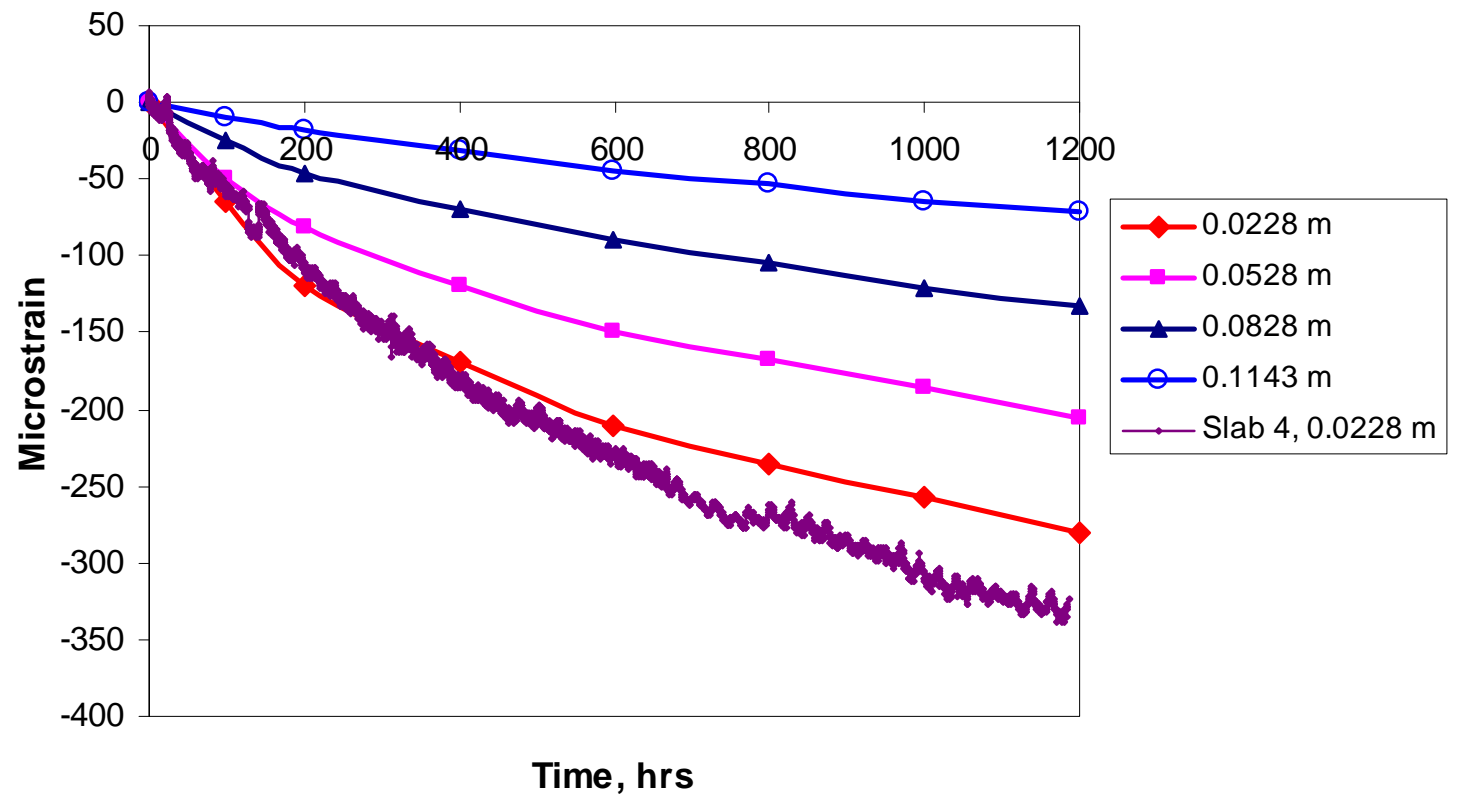

Figure 3-26 Predicted vs. Experimental Strain Time History for Cap Concrete Slab Specimens 3 and 4 
Figure 3-27 is a stress contour map and Figure 3-28 gives the stresses at the center plane and shows that tensile stresses at the top and bottom surfaces are balanced by compressive stresses in the middle of the slab. The predicted maximum tensile stress is $6 \times 10^{6} \mathrm{~Pa}$ (870 psi). This value is beyond an estimated value of the tensile strength of the concrete, given by [21],

$$
f r=0.59 \sqrt{f_{c i}}=0.59 \sqrt{23.4}=2.85 M P a
$$

This suggests that micro-cracking occurred in the outer region of the sample during the testing. Figures 3-7 and 3-8 show evidence of micro-cracking, where the data takes step increases in strain early in the strength development of the concrete.

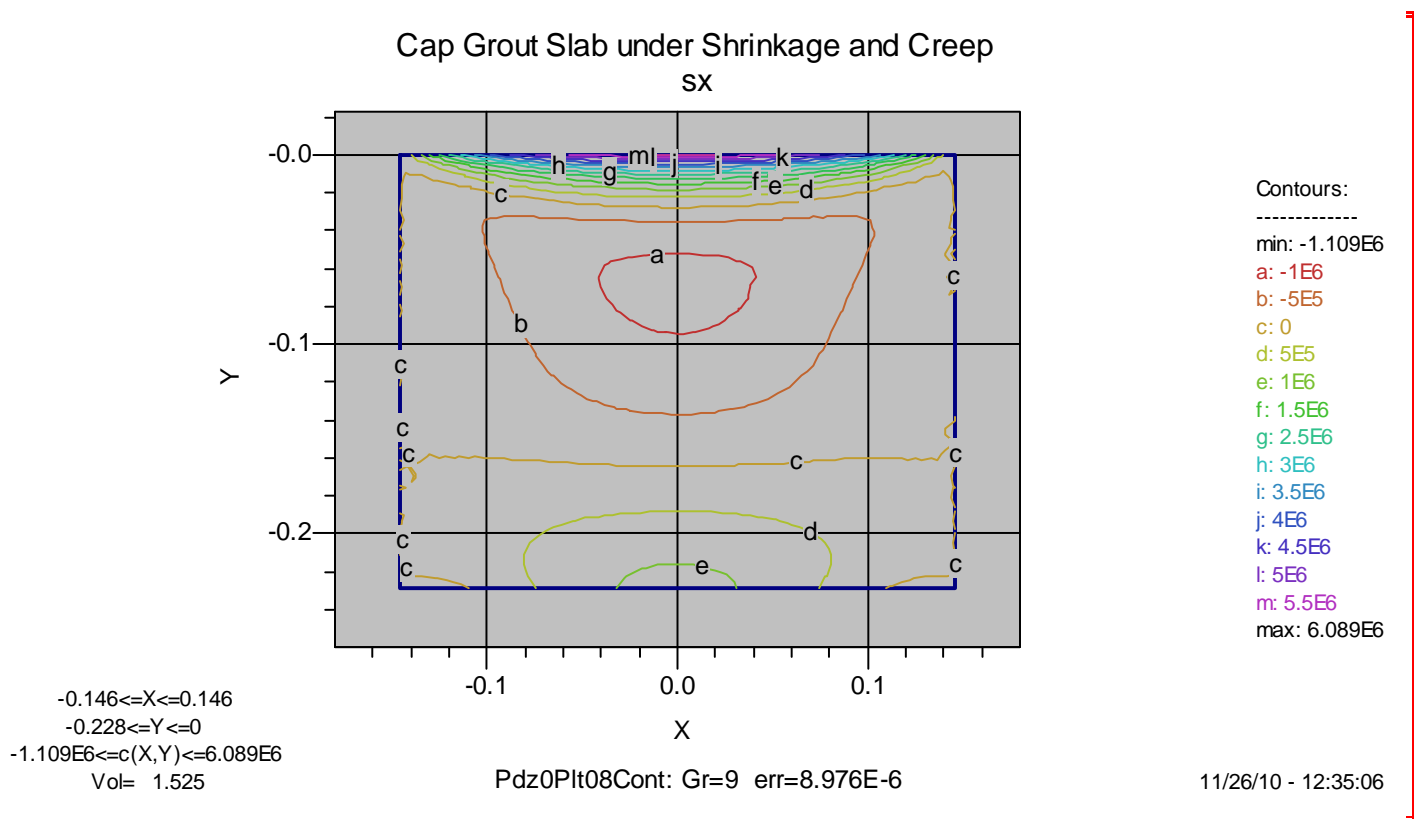

Figure 3-27 Stress Contour Map for Cap Concrete Slab Specimen Model at 1200 hrs. 


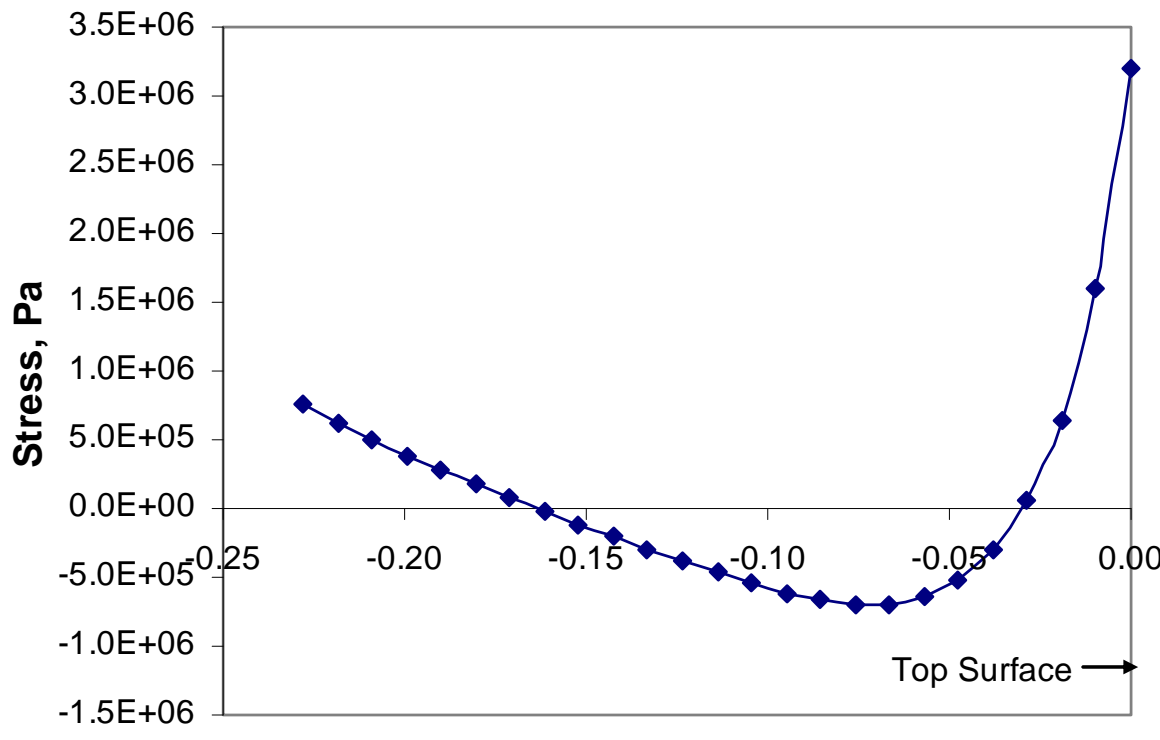

Distance from Slab Specimen Top Surface, m

Figure 3-28 Calculated Axial Stresses at Center Plane for Cap Concrete Slab Specimen Model at 1200 hrs 


\subsubsection{Effect of Reinforcing Rod}

The effect of the $11.1 \mathrm{~mm}$ diameter reinforcing rod (rebar) in the middle of Cap Concrete Slab Specimen 4 on the potential for cracking of the Cap Concrete may be investigated using the same model as in Sec. 3.2.3.3. In this case, a small strip with a thickness of $11.1 \mathrm{~mm}$ in the center of the slab is included in the model. The effective modulus of elasticity of this strip is made equal to the modulus of the concrete times a factor, $\mathrm{fr}=1+(\mathrm{Ar} / \mathrm{Ac})(\mathrm{Er} / \mathrm{Ec})$, where $\mathrm{Ar}$ and Ac are the areas of rebar and concrete, Er and Ec are the elastic moduli for rebar and concrete, respectively. Figure 3-29 shows the grid for the model.

Figure 3-30 indicates that there is virtually no difference in the stresses for the cases of no rebar and with rebar, except for a small dip at the $0.114 \mathrm{~m}$ position due to the rebar. As reported in Reference [16], concrete reinforcement does not decrease shrinkage strains, but it results in smaller cracks at more locations. The size and number of potential cracks for the slab specimen will not be analyzed since in the actual installation, the use of shrinkage compensating admixtures will result in positive strains at the surface.

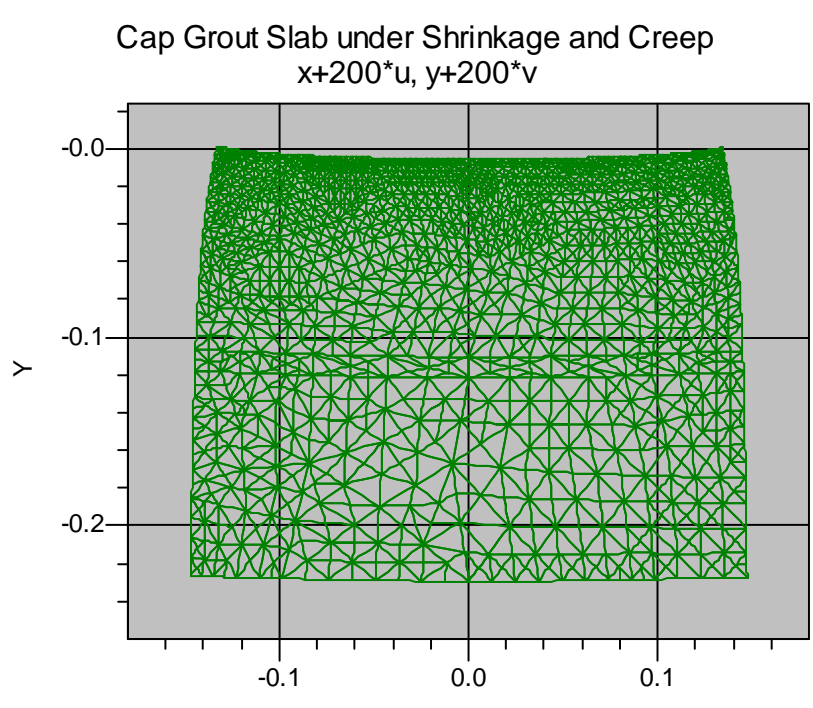

$-0.146<=X<=0.146$

$-0.228<=Y<=0$

Pdz0PIt01Grid: $\mathrm{Gr}=9$ err=8.3E-6

$11 / 18 / 10-07: 56: 31$

Figure 3-29 Deformed Grid for Cap Concrete Slab Specimen Model with Rebar 


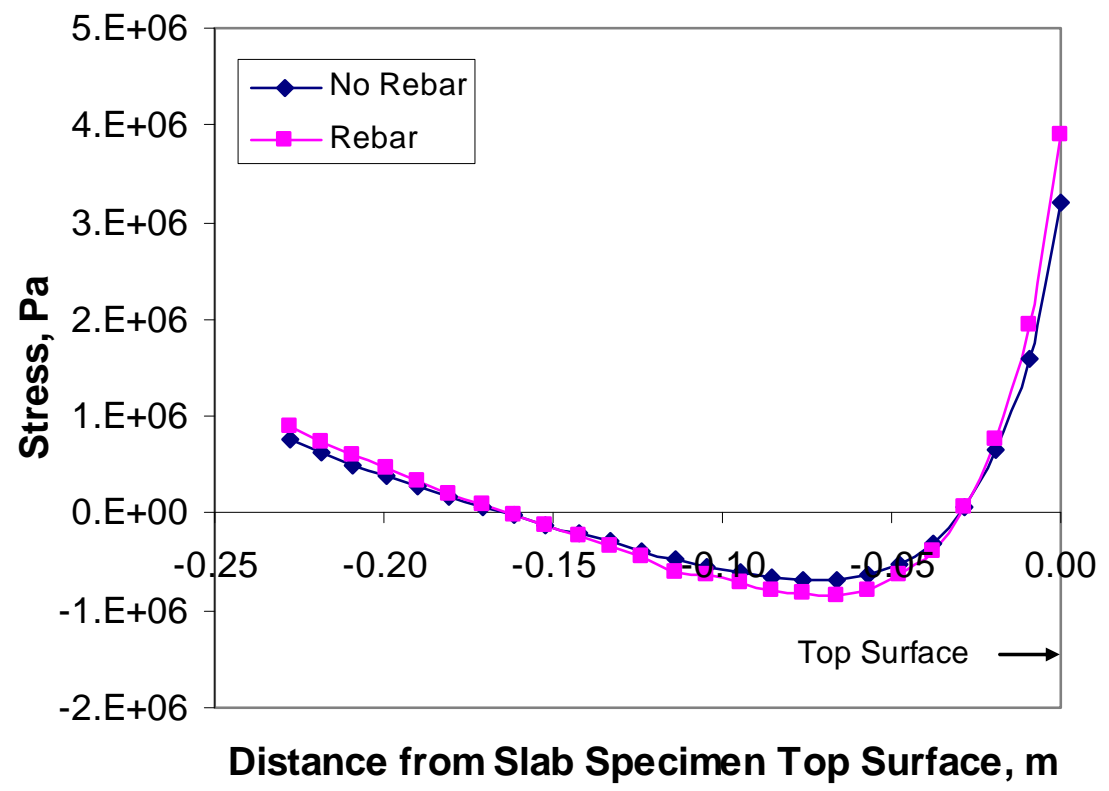
Figure 3-30 Calculated Axial Stresses in Cap Concrete Slab Specimen 3 without Rebar and
Slab Specimen 4 with Rebar

\subsubsection{Effect of Expansive Agent in Full Scale Cap Concrete Emplacement}

The effect of shrinkage compensating admixture and shrinkage reducing admixture in a hypothetical full-scale Cap Concrete emplacement over the P or R Reactor was modeled as follows:

- The height of the slab was made full-scale at $2438 \mathrm{~mm}(8 \mathrm{ft})$. The model length was made double this for convenience.

- The results at the center would be typical for any vertical cross-section of the slab except near the sides, as evidenced from changing the length of the slab specimen model.

- The bottom surface and sides were fixed.

- The shrinkage effect was modeled similarly as for the previous model, except for expected field relative humidity condition of $65 \%$.

- The full expansion effect of $1000 \mu \varepsilon$ was added to the shrinkage strain.

- Creep was calculated by a similar process as in the previous model.

Figure 3-31 gives the predicted time histories of the relative humidity at various elevations close to the top surface up to $1280 \mathrm{hrs}$. At deeper elevations, the relative humidity is close to 1.0. Figure 3-32 shows the model deformed grid where the expansion of the concrete is shown to extend upwards. An axial strain contour map over the entire slab is given in Figure 3-33 and the detailed distribution over the center plane is shown in Figure 3-34. The axial strain is shown to be positive in the top layers of the slab and compressive in the bottom ones. The corresponding stress contour map is given by Figure 3-35. The detailed stress distribution over the center plane shows that the stress is compressive throughout the interior of the slab, from $2.8 \times 10^{6} \mathrm{~Pa}$ to $-1.14 \times 10^{6} \mathrm{~Pa}$. The effect of creep is to reduce the maximum compressive stress by $37 \%$ from $17 \times 10^{6} \mathrm{~Pa}$ (not shown). Consequently, the net effect 
of adding the shrinkage compensating admixture, Conex, at the given dosage, was to impose compressive stress at the top surface, where it would have been a tensile stress without it, given the drying shrinkage effect shown in early period of the slab specimens' testing. This insures no cracking during and after curing of the Cap Concrete emplacement. 


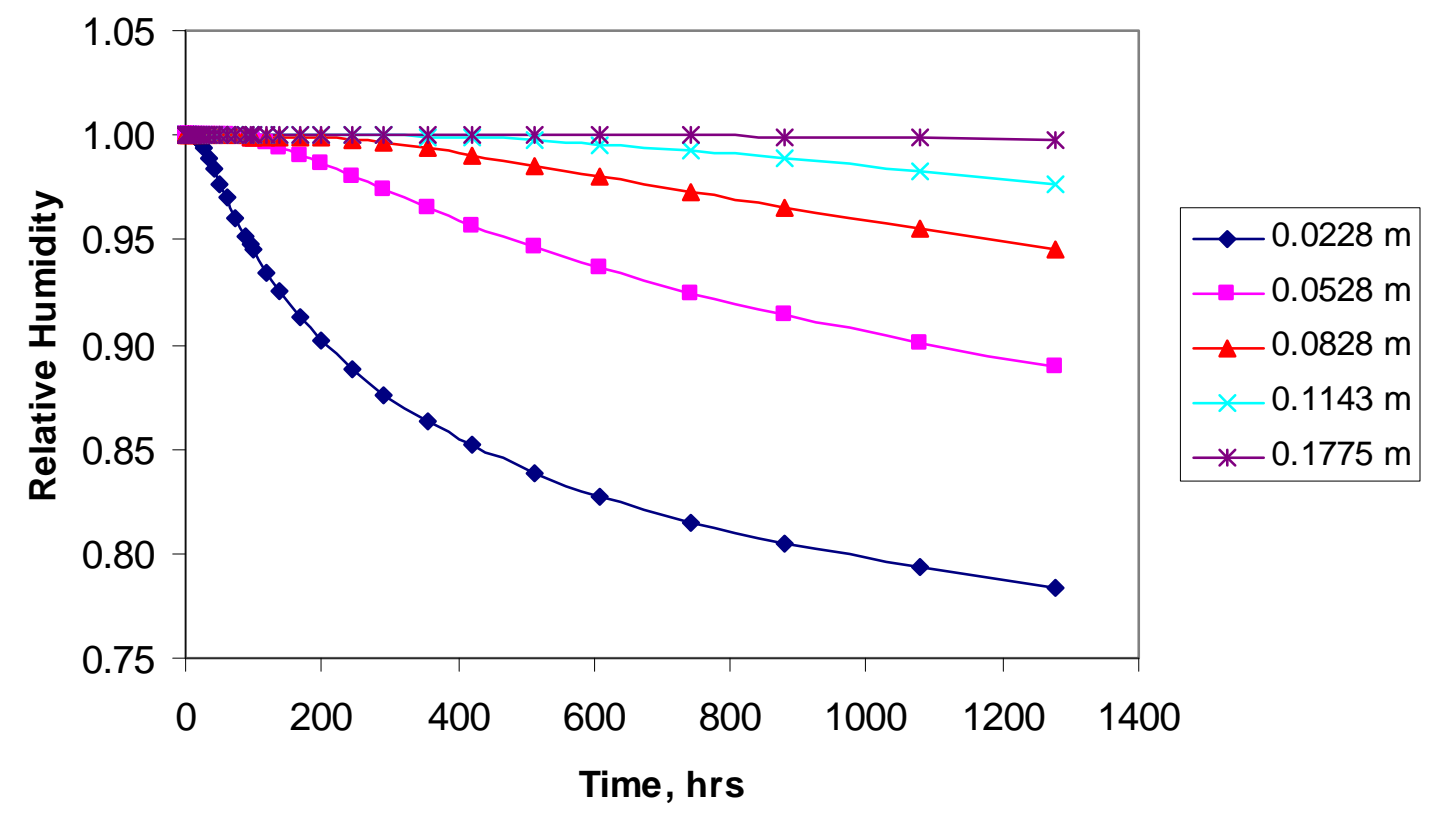

Figure 3-31 Predicted Relative Humidity Time Histories for Full-Scale Cap Concrete Slab

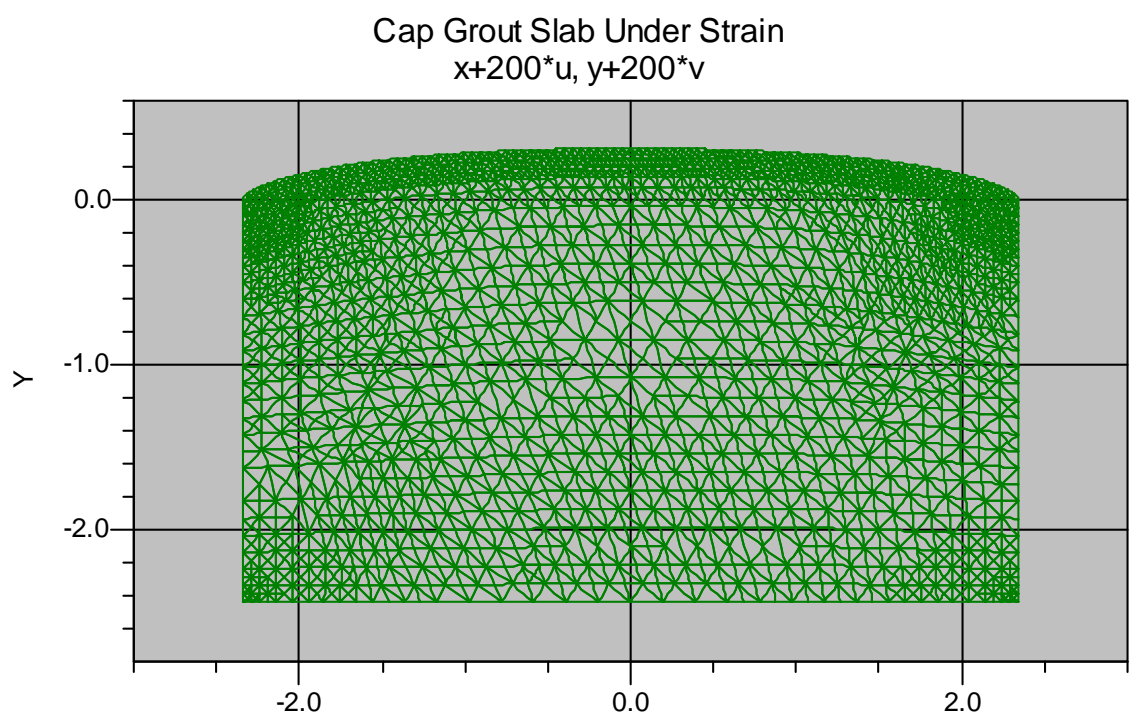

$-2.339<=X<=2.339$

Figure 3-32 Deformed Grid for Full-Scale Model with Shrinkage Compensating Admixture 
Cap Concrete Slab Under Strain

ex

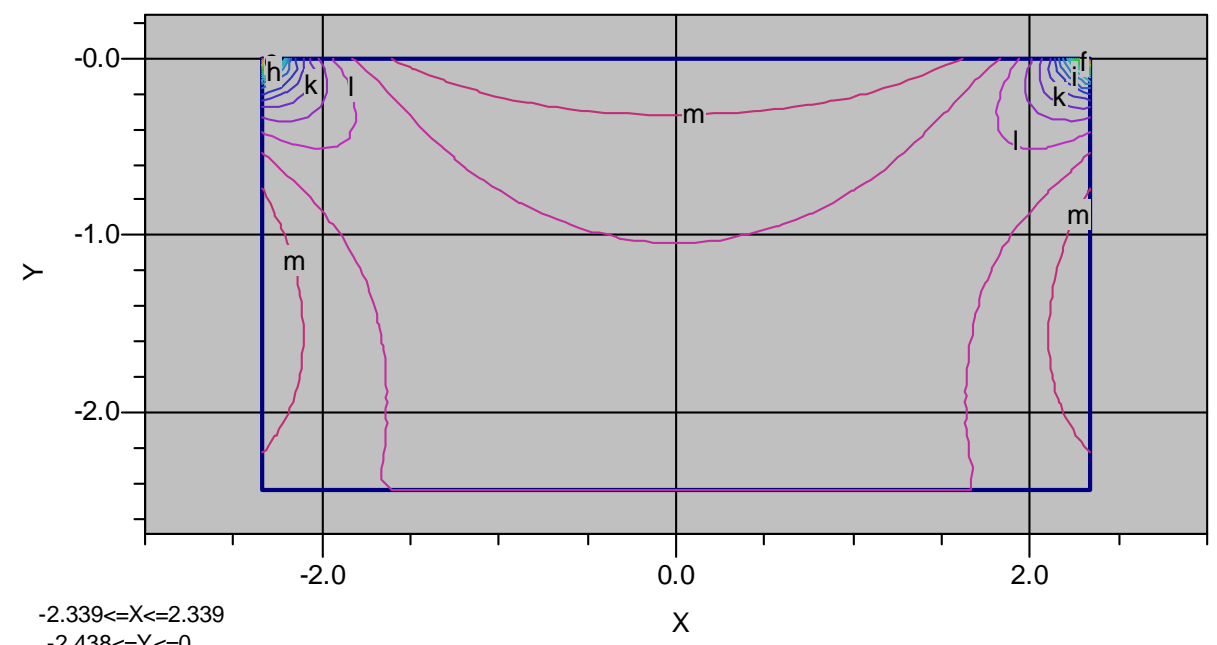

Contours:

$\min :-0.00203$

a: -0.002

b: -0.0019

c: -0.0017

d: -0.0015

e: -0.0013

f: -0.0012

g: -0.001

h: -0.0008

i: -0.0006

j: -0.0005

k: -0.0003

l: -0.0001

m: 0.0001

$\max : 0.0001907$

$-0.00203<=c(X, Y)<=0.0001907$

$\mathrm{Vol}=4.365 \mathrm{E}-8$

Pdz0PIt05Cont: $\mathrm{Gr}=10$ err=4.46E-5

08/22/11 - 08:21:21

Figure 3-33 Contour Map of Axial Strains for Full-Scale Cap Slab Model with Shrinkage Compensating Admixture

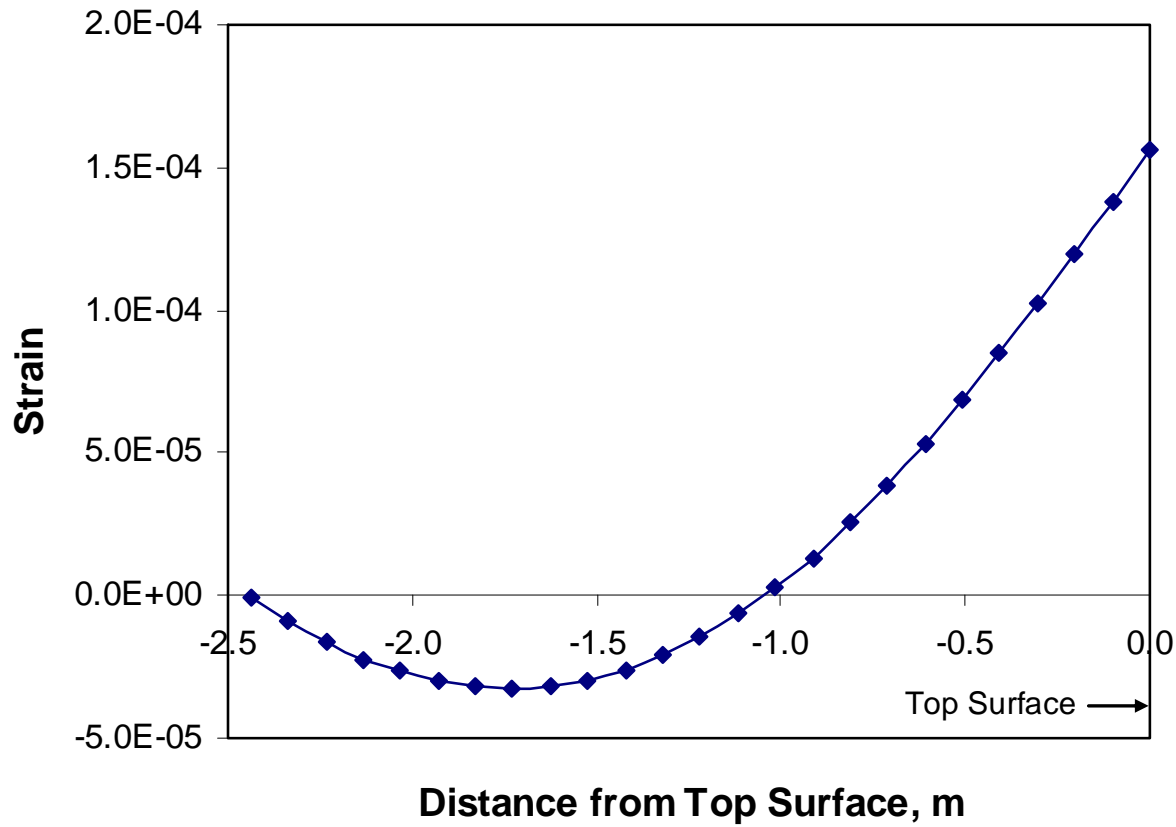

Figure 3-34 Axial Strains in the Center Plane of Full-Scale Cap Concrete Slab Model with Shrinkage Compensating Admixture 


\section{Cap Concrete Slab Under Strain}

sx

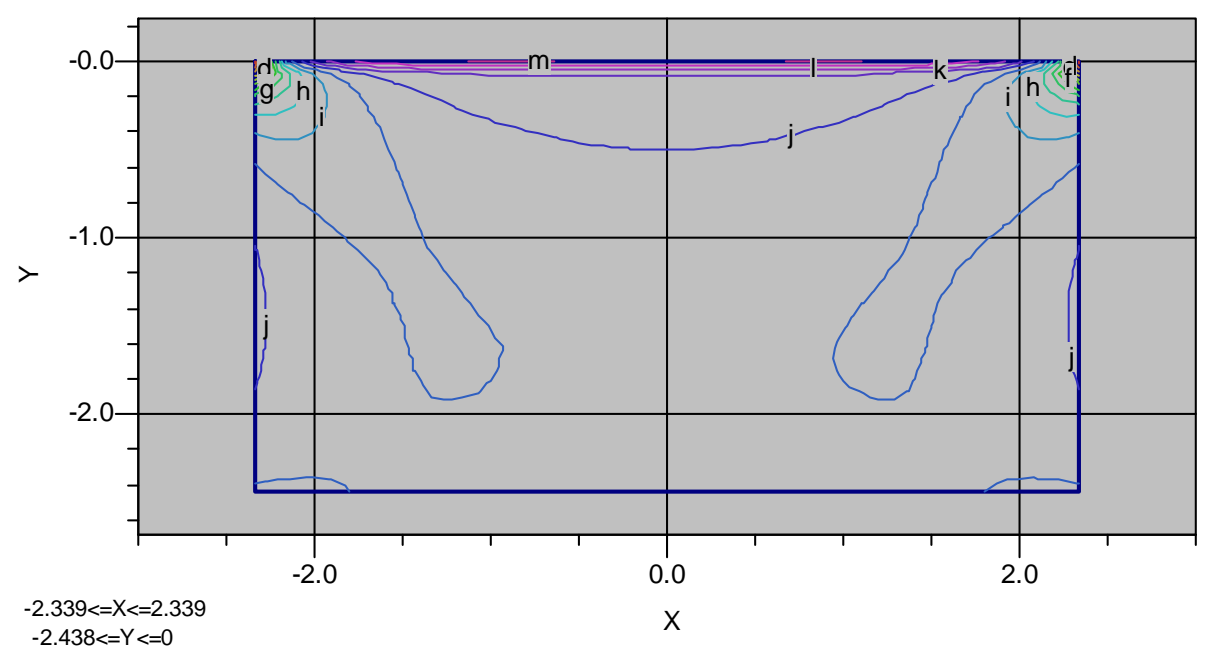

Contours:

min: -1.83E

a: $-1.8 \boxminus$

b: $-1.7 \mathrm{E}$

c: $-1.6 \mathrm{E}$

d: $-1.4 \mathrm{E}$

e: $-1.3 \mathrm{E}$

f: $-1.2 \mathrm{E}$

g: $-1.1 \mathrm{~g}$

h: $-9 E 6$

i: $-8 \mathrm{E} 6$

j: $-6 \mathrm{E} 6$

k: $-5 E 6$

I: $-4 \mathrm{E} 6$

m: $-2 E 6$

max: $-1.974 E 6$

$\begin{aligned} &-2.438<=Y<=0 \\ & .83 E<=c(X, Y)<=-1.974 E 6\end{aligned}$

Vol=-7.657E

PdzOPIt08Cont: $\mathrm{Gr}=10$ err=4.46E-5

08/22/11 - 08:21:21

Figure 3-35 Contour Map of Axial Stress for Full-Scale Cap Concrete Slab Model with Shrinkage Compensating Admixture

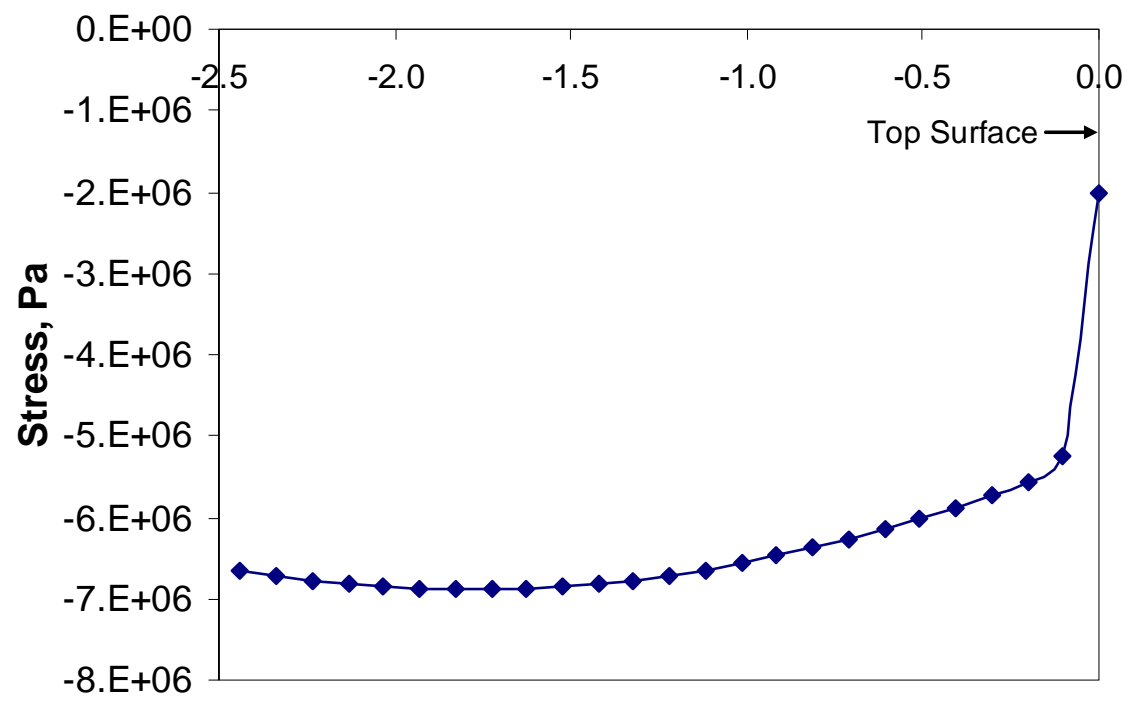

Full Scale Slab Elevation from Top Surface, m

Figure 3-36 Predicted Axial Stresses in Center Plane of Full-Scale Cap Concrete Slab Model with Shrinkage Compensating Admixture 


\section{3 $\underline{\text { Conclusions }}$}

Experimental and analytical studies were performed to evaluate the potential for cracking of protective concrete coverings for the P- and R-Reactor Vessels as part of their planned decommissioning. The experimental study showed that:

- Slab specimens cured and dried in air at $40 \% \mathrm{RH}$ showed negative strains indicative of pure shrinkage during the first $500 \mathrm{hrs}$ after molding. This behavior is similar to data previously reported by Kim and Lee. Beyond 500 hrs, positive rates of strain increase started to build up, with the highest rates occurring in the moist interior of the slabs and least in the dry regions closest to the surface. These positive rates of strain increase are attributed to the effect of shrinkage compensating admixture, Conex.

- Slab specimens cured and dried in air at $80 \%$ RH showed immediate increase in positive strains everywhere in the specimen, except for a short period of negative strain recorded by the strain gage closest to the surface. This suggests faster curing of the $\mathrm{CaO}$ content of Conex under high humidity conditions, as would happen with wet curing.

- Maximum positive strains reached were $715 \mu \varepsilon$ for the specimen initially kept at $40 \% \mathrm{RH}$ and $775 \mu \varepsilon$ for the specimen kept at $80 \% \mathrm{RH}$. These values are in line with data reported by Collepardi for a concrete mixture having similar w/c ratio and admixture concentration as the Cap Concrete.

- No significant difference was observed in strain development between slab specimens with and without rebar installed in each environmental chamber due to the small reinforcement ratio of reinforcing bar to concrete.

Results of the analytical study show that:

- Development of the moisture profile in the slab specimens with depth and time can be described closely by the differential equation of diffusion, where the diffusion constant is expressed by parameters obtained from experimental data specific to the concrete mixture.

- Prediction of early developing strains in concrete slab overlays can be made by including the effects of differential shrinkage, creep, and expansion due to shrinkage compensating admixture. Shrinkage strain can be determined from the development of capillary stress, drained bulk modulus of elasticity and saturation ratio of the concrete mixture. The capillary stress in turn is based on the Kevin-Laplace equation, which requires knowledge of the moisture content. The drained bulk modulus was based on a measurement of the 28 day compressive strength, the known relation between bulk modulus and compressive strength. The time dependence of the bulk modulus was based on the observed correspondence between hydration age of the concrete and strength. Creep was calculated by the BazantBaweja B3 model and expansive strains were based on vendor data.

- Validation of this theoretical approach was obtained using data from the slab specimen dried at $40 \% \mathrm{RH}$, where the shrinkage effect was preponderant during the first $1200 \mathrm{hrs}$ after molding and at the surface where expansive strains due to the admixture had not developed. Total strains were predicted to within $15 \%$ of the data.

- The effect of fully developed expansive strains of $1000 \mu \varepsilon$ due to the shrinkage compensating admixture, with shrinkage and creep under full restraint, is to impose compressive stresses of $-2.8 \times 10^{6} \mathrm{~Pa}$ at the surface and maximum stresses up to $-11.4 \times 10^{6} \mathrm{~Pa}$ in the interior of the full scale Cap Concrete emplacement. The effect of creep is to reduce the maximum stress by $37 \%$. This validates the use of Conex admixture to eliminate the possibility of cracking during curing of the full scale Cap Concrete emplacement. 


\subsection{Recommendations, Path Forward or Future Work}

Predictive methods for shrinkage and creep strains are well developed and our modeling results agree well with the data. However, predicting the development of expansive strains due to shrinkage compensating admixture in conjunction with curing conditions is not as well developed. Our test results differ from results of other tests in the literature, probably due to different curing conditions. Large expansive strains are needed to compensate for shrinkage and eliminate high tensile stresses at the concrete surface that may result in cracking. Thus, additional work is recommended to provide a strong data base for the development of the expansive strains as a function of reaction time, admixture concentration, and local humidity conditions. Of particular concern is the apparent diminishing of the expansive effect of the admixture with time. This should be verified and if necessary shrinkage reducing admixture may need to be added to the shrinkage compensating admixture to maintain expansion strains, as observed by Collepardi. (See Sec. 3.1.2.2 and Figure 3-12.) 


\subsection{References}

1. Yuan, Y., and Wan, Z., "Prediction of cracking within early-age concrete due to thermal, drying and creep behavior”, Cement and Concrete Research, vol. 32, 2002, pp. 1053-1059.

2. Guerrero, H., "Thermo-physical Characterization of Portland Cement Grout/ Concrete for P and R Rector In-Situ Decommissioning”, Technical Task and Quality Assurance Plan (TTQAP) SRNL-RP-2009-01184, January 13, 2009.

3. Kim, J. K., and Lee, C. S., "Prediction of Differential Drying Shrinkage in Concrete", Cement and Concrete Research, Vol. 28, No. 7, pp. 85-994, 1998.

4. Grasley, Z., and Lange, D., "Modeling Drying Shrinkage and Stress Gradients in Concrete”, Journal of Testing and Evaluation, Sept. 2002,

5. ASTM C 878C-878M-09, "Standard Method for Restrained Expansion of ShrinkageCompensating Concrete”, July, 2009.

6. Greenspan, L., "Humidity Fixed Points of Binary Saturated Aqueous Solutions”, Journal of Research of the National Bureau of Standards-A, Vol. 81A, January - February, 1977, 90-96.

7. Personal communication, H. Guerrero with J. Abbuhl and J. Langham of Euclid, October 11, 2010.

8. Collepardi, M. A. Borshoi, S. Collepardi, J. Olagot, R. Troli, "Effects of Shrinkage Reducing Admixture in ShrinkageCompensating Concrete", Cement and Concrete Composites, V. 26, No. 6, July, 2005, 704-708.

9. Ramachandran, V., Sereda, P., Feldman, R., Nature, V. 201, 1964, 288-289.

10. Wang, H. and Gillott, J., "Mechanism of Alkali-Silica Reaction and the Significance of Calcium Hydroxide”, Cement and Concrete Research, vol. 21, 647-654, 1991.

11. Xi, Y., Bazant, Z., Molina, L., and Jennings, H., "Moisture Diffusion in Cementitious Materials”, Advanced Cement Materials, 1994, Vol. 1, 254-266.

12. Personal communication, H. Guerrero with W. Mhyre.

13. Bernard, O., Ulm, F., Lemerchand, "A multiscale micromechanics-hydration model for the early-age properties of cement based materials”, Cement and Concrete Research, 33 (2003) 1293-1309.

14. Ulm, F-J., Constantinides, G., Heukamp, f., "Is concrete a poromechanics material? - A mulitscale investigation of poroelastic properties”, Materials and Structures, Vol. 37, January-February 2007, 2004, 43-58.

15. Eguchi, K. Teranshi, K., "Prediction equation of drying shrinkage of concrete based on composite model”, Cement and Concrete Research, 35 (2005) 483-493.

16. ACI-209.2R, Manual of Concrete Practice, American Concrete Institute.

17. Carino, N., Clifton, J., "Prediction of Cracking in Reinforced Concrete Structures", NISTIR 5634.

18. Suzuki, Y., T. Yukikazu, K.Maekawa, and H. Okamura, "Quantification of Hydration-Heat Generation Process of Cement in Concrete”, Concrete Library of JSCE, No. 16, December, 1990.

19. Gawin, D., Pesavento, F., Schreffer, B., "Modeling creep and shrinkage of concrete by effective stress", Materials and Structures, 2007, 40:579-591.

20. Bazant, Z., Mathematical Modeling of Creep and Shrinkage of Concrete, 1988, John Wiley.

21. Zain, M., Mahmud, H., Ilham, A., Faizal, M., "Prediction of splitting tensile strength of high performance concrete”, Cement and Concrete Research, 32 (2002) 1251-1258. 
SRNL-STI-2010-00771

Revision 0

Appendix A Calculation of Cap Concrete Compressive Strength Development with Age 
The strong dependence of Young's modulus of elasticity of concrete with age is well known. (Age, $r$, is synonymous with degree of hydration or ratio of accumulated heat generated by heat of hydration at a given time to the total heat, $Q(t) / Q_{t o t}$.) For example, Pane and Hansen [ ] showed an almost linear relationship between Young's modulus and age for different concrete mixes. For our purpose, we would like to find a relation for Young's modulus of the Cap Concrete as a function of time at a constant temperature of $23^{\circ} \mathrm{C}$, the same condition as during the environmental chamber testing. Thus, we need to determine the age as a function of time for constant temperature conditions, taking advantage of the close relationship between age and Young's modulus.

We measured the heat of hydration of the Cap Concrete by adiabatic calorimetry. Here, the temperature rise of the concrete as a function of time was measured, in which the heat of hydration was isolated from the outside by a glycol bath kept at the same temperature as the concrete. Thus, the concrete temperature was not constant. The effect of temperature on the rate of heat generation per unit weight, $H$, at any age can be determined by the relation [18],

$$
\begin{aligned}
& H=H_{\infty}(Q) \exp \left\{-\frac{E(Q)}{R T}\right\} \\
& Q=\int H d t
\end{aligned}
$$

where $H_{\infty}$ - heat generation rate at infinite temperature, w/Kg

$R$ - universal gas constant, $8.314 \mathrm{~J} / \mathrm{mol}-{ }^{\circ} \mathrm{K}$

$T$ - absolute temperature, ${ }^{\circ} \mathrm{K}$

The unrealistic quantity, $H_{\infty}$, can be eliminated by using a reference temperature, Ts, yielding,

$$
H(T, Q)=H\left(T_{s}, Q\right) \exp \left[\frac{E(Q)}{R}\left(\frac{1}{T}-\frac{1}{T_{s}}\right)\right]
$$

The procedure for obtaining (A-2) from the experimental data is as follows: First, the concrete temperature at two pouring temperatures were obtained, as shown in Figure A-1, 
SRNL-STI-2010-00771

Revision 0

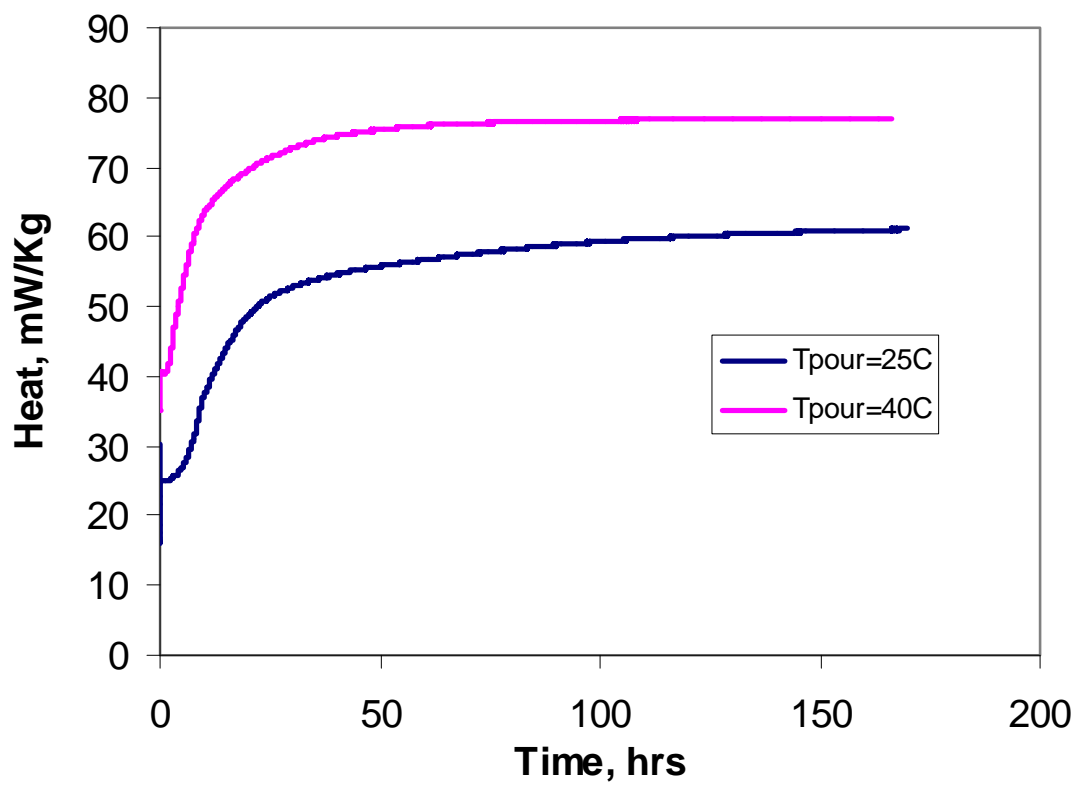

Figure A- 1 Cap Concrete Temperature Rise during Hydration at Two Pouring Temperatures

The instantaneous heat generation rate is then obtained by differentiating the curves with time and multiplying by the specific heat and density. The resulting heat generation curves are given in Figure A-2.

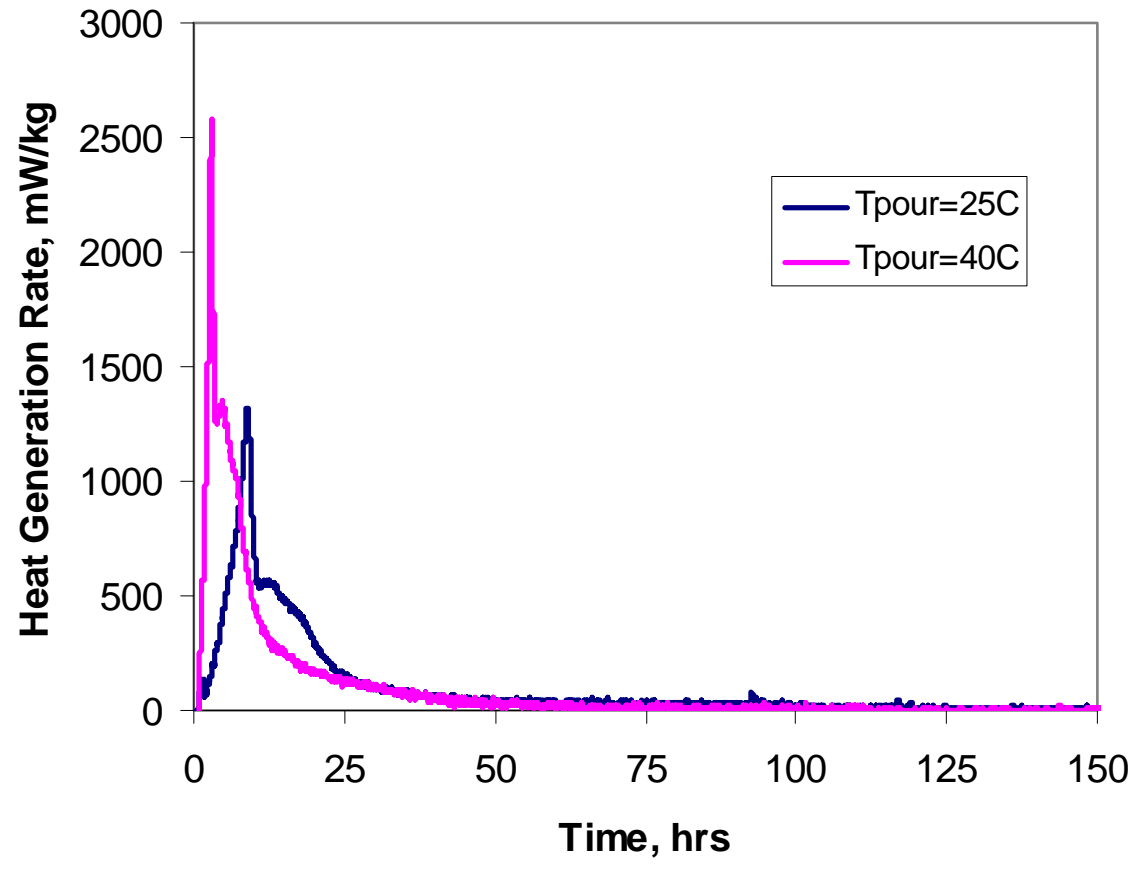

Figure A- 2 Heat Generation Rates at Two Pouring Temperatures by Adiabatic Calorimetry 
SRNL-STI-2010-00771

Revision 0

The hydration heat generation rates were then re-plotted as functions of integrated heat in Figure A-3.

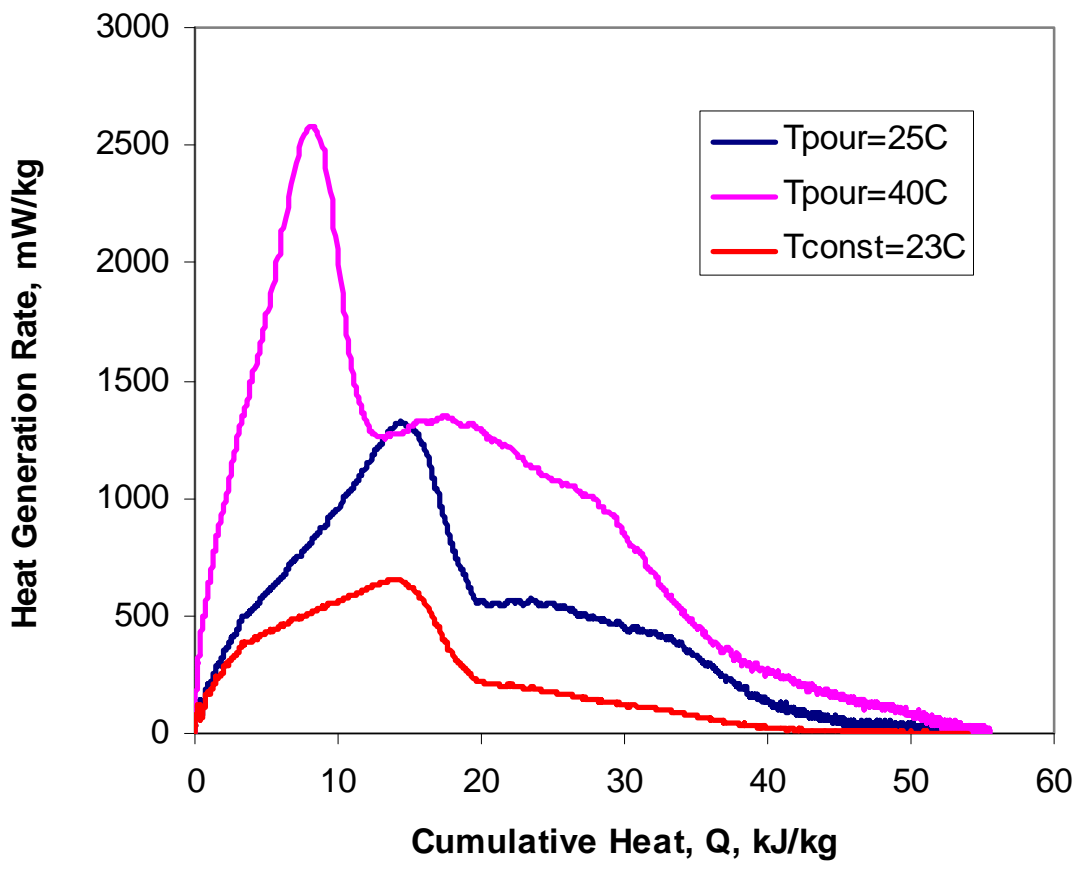

Figure A- 3 Heat Generation Rates vs. Cumulative Heat at Two Pouring Temperatures and at a Constant Temperature of $25^{\circ} \mathrm{C}$

At a number of cumulative heats $(\mathrm{Q}=10,20,30 \mathrm{~kJ} / \mathrm{kg}$, etc), the heat generation rate $\mathrm{H}$ for the two pouring temperatures were plotted against the reciprocal absolute temperature in Figure A-4. The average slope was found to be $5651{ }^{\circ} \mathrm{K}^{-1}$. The calculated activation energy $\mathrm{E}(\mathrm{Q})$ was found to be $47 \mathrm{~kJ} / \mathrm{mol}$. The heat generation rate at constant temperature and as a function of cumulative heat was obtained from Equation (A-3), and also plotted in Figure A-3. This heat generation rate at constant $23^{\circ} \mathrm{C}$ was then converted to a heat generation rate as a function of time by differentiating Equation A-2. This curve is plotted in Figure A-5 and fitted to a curve,

$$
Q=Q_{t o t} \frac{t}{t+33}
$$

where $t$ is in days.

Young's modulus can then be written as,

$$
E=E_{u} \frac{t}{t+33}
$$

where $E_{u}$ is the ultimate value of Young's modulus. 
SRNL-STI-2010-00771

Revision 0

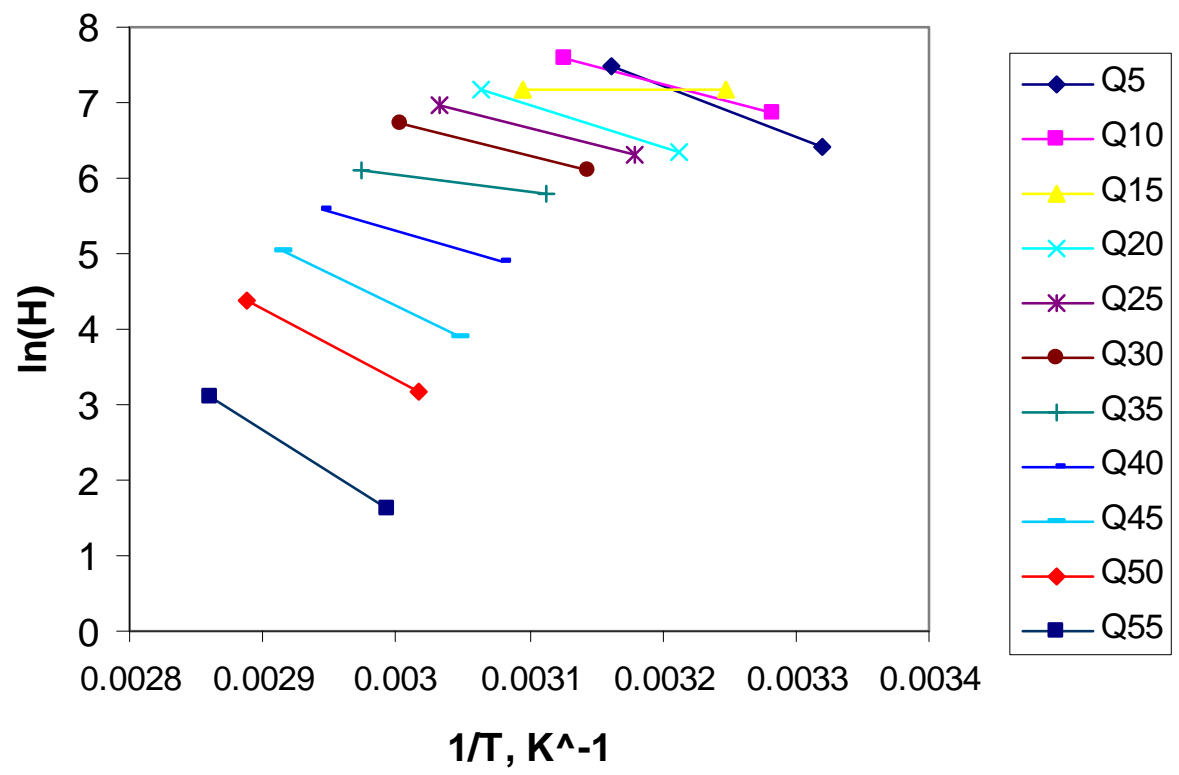

Figure A- 4 Determination of $E(Q) / R$

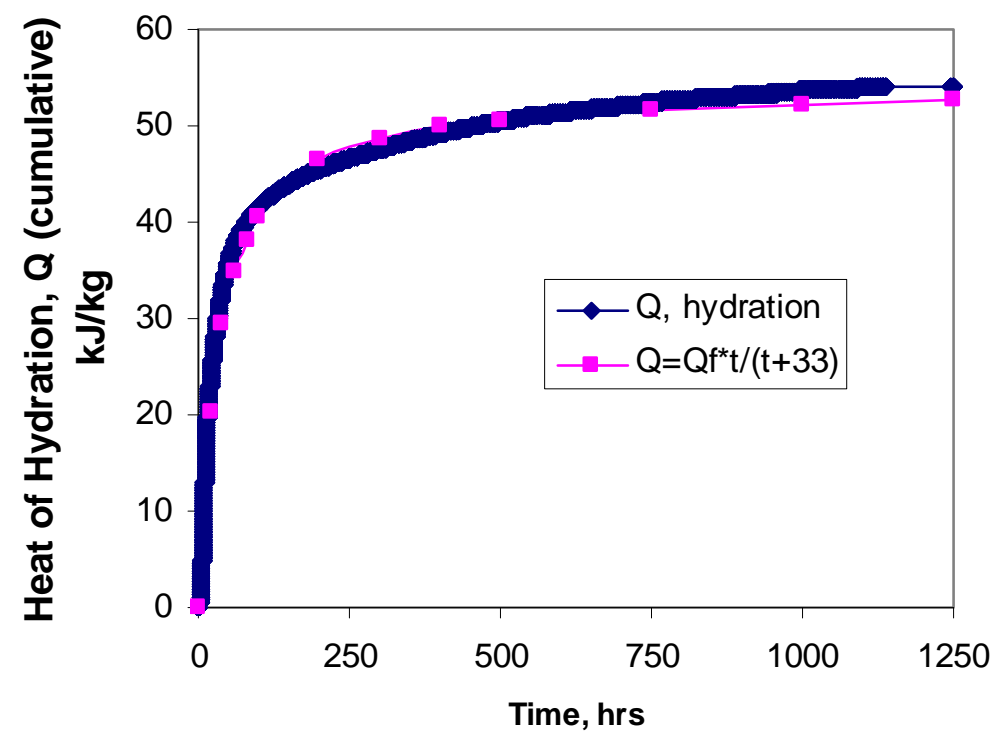

Figure A- 5 Cap Concrete Age vs. Time at Constant $25^{\circ} \mathrm{C}$ 
Appendix B

Calculation of Creep Strain for Slab Specimens 
Bazant-Bajewa B3 Model Solution for Slab Specimen

The Bazant-Bajewa B3 Model is considered the most accurate among the code type calculational methods for determining creep/shrinkage effects on stress. It is based on solidifcation theory where the volume fraction of the solidified (hydrated) matter at a given time determines the load bearing characteristics of the material. The material properties are age independent. It includes a viscoelastic strain, a viscous flow term and drying shrinkage term.

a) The following are estimated concrete properties for the Cap Concrete

\begin{tabular}{|l|l|l|}
\hline Mean 28 day strength & $\mathrm{f}_{\mathrm{cm} 28}(\mathrm{~W}$. Myhre $)$ & $23.4 \mathrm{Mpa}$ \\
\hline Mean 28 day elastic modulus & $\mathrm{E}_{\mathrm{cm} 28}=4734 *\left(\mathrm{f}_{\mathrm{cm} 28}\right)^{\wedge} 0.5$ & $22.9 \mathrm{GPa}$ \\
\hline Cement content & $\mathrm{c}$ & $278 \mathrm{~kg} / \mathrm{m}^{3}$ \\
\hline Water content & $\mathrm{W}$ & $181 \mathrm{~kg} / \mathrm{m}^{3}$ \\
\hline Water-cement ratio & $\mathrm{w} / \mathrm{c}$ & 0.65 \\
\hline Aggregate-cement ratio & $\mathrm{a} / \mathrm{c}$ & 3.94 \\
\hline Fine aggregate percentage & $\psi$ & $32 \%$ \\
\hline Unit weight of concrete & $\gamma_{\mathrm{c}}$ & $2369 \mathrm{~kg} / \mathrm{m}^{3}$ \\
\hline Volume to surface ratio & $\mathrm{V} / \mathrm{S}$ & $228 \mathrm{~mm}$ \\
\hline
\end{tabular}

b) Calculation of the shrinkage strain as a function of time is as follows:

\begin{tabular}{|l|l|l|}
\hline Ambient relative humidity factor & $\mathrm{k}_{\mathrm{h}}=1-\mathrm{h}^{3}$ & \\
\hline Cement type factor & $\alpha_{1}$ & 1 \\
\hline Curing condition factor & $\alpha_{2}$ (sealed for a day) & 1.2 \\
\hline Nominal ultimate shrinkage & $e_{s \infty}=-\alpha_{1} \alpha_{2}\left[0.019 w^{2.1} f_{c m 28}{ }^{-0.28}+270\right] x 10^{-6}$ & $845 \times 10^{-6}$ \\
\hline Member shape factor & $\mathrm{k}_{\mathrm{s}}$ & 1 \\
\hline Volume/surface ratio & $\mathrm{V} / \mathrm{S}$ & $228 \mathrm{~mm}$ \\
\hline Shrinkage half time & $\tau_{s h}=0.085 t_{c} f_{c m 28}^{0.25}\left[2 k_{s}(V / S)\right]^{2}$ & 8077 days \\
\hline Time dependence factor & $\frac{E_{c m 607}}{E_{c m(t c+t s h)}}=\left(\frac{1.0805}{\left(t_{c}+\tau_{s h}\right) /\left(4+0.85\left(t_{c}+\tau_{s h}\right)\right.}\right)^{0.5}$ & 0.996 \\
\hline Ultimate shrinkage strain & $\varepsilon_{s h \infty}=-\varepsilon_{s \infty} E_{c m 607} / E_{c m(t c+t s h)}$ & $841 \times 10^{-6}$ \\
\hline Shrinkage time function & $S\left(t-t_{c}\right)=\tanh \left[\left(t-t_{c}\right) / \tau_{c}\right]^{0.5}$ & \\
\hline Shrinkage strains & $\varepsilon_{s h}\left(t, t_{c}\right)=-\varepsilon_{s h \infty} \tanh \left[\left(t-t_{c}\right) / \tau_{c}\right]^{0.5}$ & \\
\hline
\end{tabular}


SRNL-STI-2010-00771

Revision 0

\begin{tabular}{|l|l|l|}
\hline $\mathrm{t}$, days & $\mathrm{S}\left(\mathrm{t}-\mathrm{t}_{\mathrm{c}}\right)$ & $\varepsilon_{\mathrm{sh}}\left(\mathrm{t}, \mathrm{t}_{\mathrm{c}}\right) \times 10^{-6}$ \\
\hline 1 & 0 & 0 \\
\hline 14 & 0.04 & 33.6 \\
\hline 28 & 0.0578 & 48.6 \\
\hline 50 & 0.0779 & 65.5 \\
\hline 85 & 0.1019 & 85.6 \\
\hline
\end{tabular}

c) The shrinkage strain according to the ACI 209R-92 Model is as follows:

\begin{tabular}{|l|l|l|}
\hline Nominal ultimate shrinkage strain & $\varepsilon_{\text {shu }}$ & $780 \mathrm{x}^{10-6}$ \\
\hline Moist curing factor & $\gamma_{\mathrm{sh}, \mathrm{cc}}=1.202-0.2337 \log (\mathrm{tc})$ & 1.2 \\
\hline Ambient relative humidity factor & $\gamma_{\mathrm{shRH}}=1.40-1.02 \mathrm{~h}$ & 0.992 \\
\hline Volume to surface ratio factor & $\gamma_{\mathrm{shvs}}=1.2 \exp [-0.00472(\mathrm{~V} / \mathrm{S})]$ & 0.409 \\
\hline Slump of fresh concrete & $\gamma_{\mathrm{sh}, \mathrm{s}}$ & 1 \\
\hline Fine aggregate factor & $\gamma_{\mathrm{sh}, \mathrm{psi}}=0.30+0.014 \mathrm{psi}$ & 0.75 \\
\hline Cement content factor & $\gamma_{\mathrm{sh}, \mathrm{c}}=0.75+0.00061 \mathrm{c}$ & 0.91958 \\
\hline Air content factor & $\gamma_{\mathrm{sh}, \alpha}$ & 1 \\
\hline Cumulative correction factor & $\gamma_{\mathrm{sh}}=\gamma_{\mathrm{sh}, \mathrm{tc}} \gamma_{\mathrm{shRH}} \gamma_{\mathrm{shVs}} \gamma_{\mathrm{sh}, \mathrm{s}} \gamma_{\mathrm{sh}, \mathrm{psi}} \gamma_{\mathrm{sh}, \mathrm{c}} \gamma_{\mathrm{sh}, \alpha}$ & 0.336 \\
\hline Ultimate shrinkage strain & $\varepsilon_{\mathrm{shu}}=0.336^{*} 780 \mathrm{x} 10^{-6}$ & $262 \mathrm{x} 10^{-6}$ \\
\hline Shrinkage time function & $\mathrm{f}\left(\mathrm{t}, \mathrm{t}_{\mathrm{c}}\right)=\left[\left(\mathrm{t}-\mathrm{t}_{\mathrm{c}}\right)^{\alpha} /\left(\mathrm{f}+\left(\left(\mathrm{t}-\mathrm{t}_{\mathrm{c}}\right)^{\alpha}\right)\right]\right.$ & \\
\hline Vol.to surface ratio time factor & $\mathrm{f}=26 \exp \left\{1.42 \times 10^{-2}(\mathrm{~V} / \mathrm{S})\right\}$ & 677 days \\
\hline Shrinkage strains & $\varepsilon(\mathrm{t}, \mathrm{tc})==\left[\left(\mathrm{t}-\mathrm{t}_{\mathrm{c}}\right)^{\alpha} /\left(\mathrm{f}+\left(\left(\mathrm{t}-\mathrm{t}_{\mathrm{c}}\right)^{\alpha}\right)\right] \varepsilon_{\mathrm{shu}}\right.$ & \\
\hline
\end{tabular}

\begin{tabular}{|l|c|c|c|c|}
\hline & \multicolumn{2}{|c|}{$\mathrm{f}=677$} & \multicolumn{2}{c|}{$\mathrm{f}=55$} \\
\hline $\mathrm{t}$, days & $\mathrm{f}(\mathrm{t}-\mathrm{tc})$ & $\mathrm{e}_{\mathrm{sh}}(\mathrm{t}, \mathrm{tc}) \times 10^{-6}$ & $\mathrm{f}(\mathrm{t}-\mathrm{tc})$ & $\mathrm{e}_{\mathrm{sh}}(\mathrm{t}, \mathrm{tc}) \times 10^{-6}$ \\
\hline 1 & 0 & 0 & 0 & 0 \\
\hline 14 & 0.019 & 4.9 & 0.271 & 71.0 \\
\hline 28 & 0.038 & 10.0 & 0.435 & 114.1 \\
\hline 50 & 0.067 & 17.7 & 0.583 & 152.8 \\
\hline 85 & 0.110 & 28.9 & 0.706 & 184.9 \\
\hline
\end{tabular}


d) The Bazant-Baweja B3 Model for calculating creep is provided below:

\begin{tabular}{|c|c|}
\hline Compliance & $\mathrm{J}\left(\mathrm{t}, \mathrm{t}_{\mathrm{o}}\right)=\mathrm{q}_{\mathrm{I}}+\mathrm{C}_{\mathrm{o}}\left(\mathrm{t}, \mathrm{t}_{\mathrm{o}}\right)+\mathrm{C}_{\mathrm{d}}\left(\mathrm{t}, \mathrm{t}_{\mathrm{o}}\right)$ \\
\hline \multirow[t]{2}{*}{ Instantaneous compliance } & $\mathrm{q}_{\mathrm{I}}=1 / \mathrm{E}_{\mathrm{o}}=0.6 / \mathrm{E}_{\mathrm{cm} 28}$ \\
\hline & $\mathrm{q}_{\mathrm{I}}=0.6 / 22.9 \mathrm{GPa}^{-1}=26.2 \mathrm{MPa}^{-1}$ \\
\hline Basic creep compliance function & $\mathrm{C}_{0}\left(\mathrm{t}, \mathrm{t}_{\mathrm{o}}\right)=\mathrm{q}_{2} \mathrm{Q}\left(\mathrm{t}, \mathrm{t}_{\mathrm{o}}\right)+\mathrm{q}_{3} \ln \left[1+\left(\mathrm{t}-\mathrm{t}_{\mathrm{o}}\right)^{\mathrm{n}}\right]+\mathrm{q}_{4} \ln \left(\mathrm{t} / \mathrm{t}_{\mathrm{o}}\right)$ \\
\hline $\mathrm{q}_{2}=185.4 \times 10^{-6} \mathrm{c}^{0.5} \mathrm{f}_{\mathrm{cm} 28}{ }^{-0.9}$ & $\mathrm{q}_{2}=181 \times 10^{-6} \mathrm{MPa}^{-1}$ \\
\hline \multicolumn{2}{|l|}{$\mathrm{Q}_{\mathrm{f}}\left(\mathrm{t}_{\mathrm{o}}\right)=\left[0.086\left(\mathrm{t}_{\mathrm{o}}\right)^{2 / 9}+1.21\left(\mathrm{t}_{\mathrm{o}}\right)^{4 / 9}\right]^{-1}$} \\
\hline $\mathrm{m}$ & 0.5 \\
\hline $\mathrm{n}$ & 0.1 \\
\hline $\mathrm{r}\left(\mathrm{t}_{\mathrm{o}}\right)$ & $1.7\left(\mathrm{t}_{0}\right)^{0.12}+8$ \\
\hline \multicolumn{2}{|l|}{ Aging viscoelastic term } \\
\hline \multicolumn{2}{|c|}{$\mathrm{Z}\left(\mathrm{t}, \mathrm{t}_{\mathrm{o}}\right)=\left(\mathrm{t}_{0}\right)^{-\mathrm{m}} \ln \left[1+\left(\mathrm{t}-\mathrm{t}_{0}\right)^{\mathrm{n}}\right]$} \\
\hline \multicolumn{2}{|c|}{$\mathrm{Q}\left(\mathrm{t}, \mathrm{t}_{0}\right)=\mathrm{Q}_{\mathrm{f}}\left(\mathrm{t}_{0}\right)\left[1+\left\{\mathrm{Q}_{\mathrm{f}}\left(\mathrm{t}_{0}\right) / \mathrm{Z}\left(\mathrm{t}, \mathrm{t}_{0}\right)\right\}^{\mathrm{r}\left(\mathrm{to}_{0}\right)}\right]^{-1 / r(\mathrm{to})}$} \\
\hline \multicolumn{2}{|l|}{ Nonaging viscoelastic term } \\
\hline \multicolumn{2}{|l|}{$\mathrm{q}_{3} \ln \left[1+(\mathrm{t}-\mathrm{to})^{\mathrm{n}}\right]$} \\
\hline $\mathrm{q}_{3}=0.29(\mathrm{w} / \mathrm{c})^{4} \mathrm{q}_{2}$ & $3.23 \times 10^{-6} \mathrm{MPa}^{-1}$ \\
\hline Aging flow term & $\mathrm{q}_{4} \ln (\mathrm{t} / \mathrm{to})$ \\
\hline $\mathrm{q}_{4}=20.3 \times 10^{-6}(\mathrm{a} / \mathrm{c})^{-0.7}$ & $=7.77 \times 10^{-6} \mathrm{MPa}-1$ \\
\hline
\end{tabular}

e) Typical Compliance Functions for Various Start of Loading Days $t_{o}$

\begin{tabular}{|c|c|c|c|c|c|}
\hline \multicolumn{6}{|c|}{ to=1 day } \\
\hline $\mathrm{t}$, days & $\mathrm{q} 1$ & $\mathrm{q} 2 \mathrm{Q}(\mathrm{t}, \mathrm{to})$ & $\begin{array}{c}\mathrm{q} 3 \ln (1+\mathrm{t}- \\
\text { to)n] }\end{array}$ & $\mathrm{q} 4 \ln \{\mathrm{t} / \mathrm{to})$ & $\mathrm{J}(\mathrm{t}, \mathrm{to})$ \\
\hline 0 & & & & & \\
\hline 1 & 0 & 0.0 & 0.0 & 0.0 & 0.0 \\
\hline 2 & 26.2 & 121.6 & 3.1 & 5.4 & 156.3 \\
\hline 3.1 & 26.2 & 126.1 & 3.1 & 8.8 & 164.2 \\
\hline 4.4 & 26.2 & 128.7 & 3.1 & 11.5 & 169.5 \\
\hline 5.7 & 26.2 & 130.2 & 3.1 & 13.5 & 173.0 \\
\hline 7 & 26.2 & 131.2 & 3.1 & 15.1 & 175.7 \\
\hline 8.3 & 26.2 & 132.0 & 3.1 & 16.4 & 177.8 \\
\hline 9.7 & 26.2 & 132.7 & 3.1 & 17.7 & 179.6 \\
\hline 11.1 & 26.2 & 133.2 & 3.1 & 18.7 & 181.2 \\
\hline 12.8 & 26.2 & 133.7 & 3.1 & 19.8 & 182.8 \\
\hline 14.5 & 26.2 & 134.1 & 3.1 & 20.8 & 184.2 \\
\hline 16.4 & 26.2 & 134.5 & 3.1 & 21.7 & 185.5 \\
\hline 18.5 & 26.2 & 134.8 & 3.1 & 22.7 & 186.8 \\
\hline 21 & 26.2 & 135.2 & 3.1 & 23.7 & 188.1 \\
\hline 24 & 26.2 & 135.5 & 3.1 & 24.7 & 189.5 \\
\hline 27.5 & 26.2 & 135.8 & 3.1 & 25.8 & 190.9 \\
\hline 32 & 26.2 & 136.1 & 3.1 & 26.9 & 192.4 \\
\hline 38 & 26.2 & 136.5 & 3.1 & 28.3 & 194.1 \\
\hline 44 & 26.2 & 136.7 & 3.1 & 29.4 & 195.5 \\
\hline 47 & 26.2 & 136.8 & 3.1 & 29.9 & 196.1 \\
\hline
\end{tabular}


SRNL-STI-2010-00771

Revision 0

\begin{tabular}{|c|c|c|c|c|c|}
\hline \multicolumn{6}{|c|}{ to=8.3 days } \\
\hline t, days & $\mathrm{q} 1$ & $\mathrm{q} 2 \mathrm{Q}(\mathrm{t}, \mathrm{to})$ & $\begin{array}{c}\mathrm{q} \ln (1+\mathrm{t}- \\
\text { to)n] }\end{array}$ & $\mathrm{q} 4 \ln \{\mathrm{t} / \mathrm{to})$ & $\mathrm{J}(\mathrm{t}, \mathrm{to})$ \\
\hline 8.3 & 0 & 0 & 0 & 0 & 0 \\
\hline 9.7 & 26.2 & 55.9 & 2.3 & 1.2 & 85.6 \\
\hline 11.1 & 26.2 & 55.8 & 2.4 & 2.3 & 86.7 \\
\hline 12.8 & 26.2 & 55.8 & 2.5 & 3.4 & 87.9 \\
\hline 14.5 & 26.2 & 55.8 & 2.5 & 4.3 & 88.9 \\
\hline 16.4 & 26.2 & 55.7 & 2.6 & 5.3 & 89.8 \\
\hline 18.5 & 26.2 & 55.7 & 2.6 & 6.2 & 90.8 \\
\hline 21 & 26.2 & 55.7 & 2.7 & 7.2 & 91.8 \\
\hline 24 & 26.2 & 55.6 & 2.7 & 8.3 & 92.8 \\
\hline 27.5 & 26.2 & 55.6 & 2.8 & 9.3 & 93.9 \\
\hline 32 & 26.2 & 55.6 & 2.8 & 10.5 & 95.0 \\
\hline 38 & 26.2 & 55.5 & 2.8 & 11.8 & 96.3 \\
\hline 44 & 26.2 & 55.4 & 2.9 & 13.0 & 97.5 \\
\hline 47 & 26.2 & 55.4 & 2.9 & 13.5 & 98.0 \\
\hline
\end{tabular}

\begin{tabular}{|c|c|c|c|c|c|}
\hline \multicolumn{6}{|c|}{ to=24 days } \\
\hline $\mathrm{t}$, days & $\mathrm{q} 1$ & $\mathrm{q} 2 \mathrm{Q}$ & $\begin{array}{c}\mathrm{q} 3 \ln (1+\mathrm{t}- \\
\text { to)n] }\end{array}$ & $\mathrm{q} 4 \ln \{\mathrm{t} / \mathrm{to})$ & $\mathrm{J}(\mathrm{t}, \mathrm{to})$ \\
\hline 24 & 0 & 0 & 0 & 0 & 0 \\
\hline 27.5 & 26.2 & 35.1 & 2.4 & 1.1 & 64.8 \\
\hline 32 & 26.2 & 35.0 & 2.6 & 2.2 & 66.0 \\
\hline 38 & 26.2 & 34.9 & 2.7 & 3.6 & 67.4 \\
\hline 44 & 26.2 & 34.8 & 2.8 & 4.7 & 68.5 \\
\hline 47 & 26.2 & 34.8 & 2.8 & 5.2 & 69.0 \\
\hline
\end{tabular}

e) Calculation of Creep Due to Full Restraint of Free Shrinkage at Position $22.8 \mathrm{~mm}$ from Top Surface

\begin{tabular}{|c|c|c|c|c|c|c|c|}
\hline $\mathrm{t}$ & $\mathrm{Q}^{\prime}$ & $\mathrm{E}$ & $\mathrm{Q}^{\prime} \mathrm{E}^{*} /\left(1+\mathrm{Q}^{\prime} \mathrm{E}\right)$ & $\varepsilon \mathrm{sh}$ & $\mathrm{d} \varepsilon \mathrm{cr}$ & $\Sigma \varepsilon \mathrm{cr}$ & $\varepsilon \mathrm{cr} / \varepsilon \mathrm{sh}$ \\
\hline 0 & 0.0 & 0.0 & 0 & 0 & & & \\
\hline 1 & 0.0 & 10.1 & 0 & 22.3 & & & \\
\hline 2 & 129.3 & 14.2 & 0.648 & 43.2 & 13.6 & 13.6 & 0.314 \\
\hline 3.1 & 109.3 & 16.6 & 0.645 & 65.6 & 14.4 & 28.0 & 0.427 \\
\hline 4.4 & 90.7 & 18.3 & 0.624 & 91.0 & 15.9 & 43.8 & 0.482 \\
\hline 5.7 & 78.0 & 19.4 & 0.601 & 115.3 & 14.6 & 58.5 & 0.507 \\
\hline 7 & 69.7 & 20.1 & 0.583 & 138.6 & 13.6 & 72.1 & 0.505 \\
\hline 8.3 & 63.8 & 20.6 & 0.568 & 160.8 & 12.6 & 84.6 & 0.503 \\
\hline 9.7 & 59.4 & 21.0 & 0.556 & 183.4 & 12.6 & 97.2 & 0.499 \\
\hline 11.1 & 55.6 & 21.4 & 0.543 & 204.8 & 11.6 & 108.8 & 0.496 \\
\hline 12.8 & 52.7 & 21.7 & 0.533 & 229.0 & 12.9 & 121.7 & 0.492 \\
\hline 14.5 & 49.6 & 21.9 & 0.521 & 251.4 & 11.6 & 133.4 & 0.488 \\
\hline 16.4 & 47.1 & 22.2 & 0.511 & 274.2 & 11.7 & 145.0 & 0.484 \\
\hline 18.5 & 44.8 & 22.4 & 0.500 & 296.8 & 11.3 & 156.4 & 0.479 \\
\hline 21 & 42.7 & 22.5 & 0.490 & 320.4 & 11.6 & 167.9 & 0.475 \\
\hline 24 & 40.6 & 22.7 & 0.480 & 344.4 & 11.5 & 179.4 & 0.471 \\
\hline 27.5 & 38.5 & 22.9 & 0.468 & 367.0 & 10.6 & 190.0 & 0.466 \\
\hline
\end{tabular}


SRNL-STI-2010-00771

Revision 0

\begin{tabular}{|l|l|l|l|l|l|l|l|}
32 & 36.5 & 23.0 & 0.392 & 389.6 & 10.3 & 200.3 & 0.462 \\
\hline 38 & 34.5 & 23.2 & 0.381 & 412.7 & 10.3 & 210.6 & 0.458 \\
\hline 44 & 32.1 & 23.3 & 0.367 & 434.6 & 9.4 & 220.0 & 0.453 \\
\hline 47 & 29.7 & 23.3 & 0.354 & 447.6 & 5.3 & 225.3 & 0.450 \\
\hline
\end{tabular}




\section{Distribution:}
A. B. Barnes, 999-W
D. A. Crowley, 773-43A
S. D. Fink, 773-A
B. J. Giddings, 786-5A
C. C. Herman, 999-W
S. L. Marra, 773-A
A. M. Murray, 773-A
F. M. Pennebaker, 773-42A
J. H. Scogin, 773-A
W. R. Wilmarth, 773-A

J. K. Blankenship

C. A. Langton

D. B. Stefanko 